

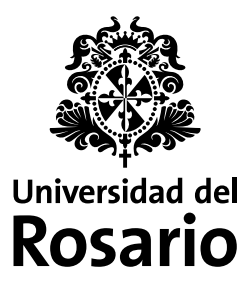




\title{
Evolución del balance financiero de los hogares bogotanos
}

\section{Resumen}

Este libro presenta nueva evidencia del efecto redistributivo de la política fiscal que afecta el balance financiero de los hogares en Bogotá, municipios de la Sabana y el departamento de Cundinamarca. Se presenta una cuidadosa identificación de aquellos subsidios, contribuciones e impuestos que reciben o pagan los miembros de un hogar y de este modo, utilizando la metodología de análisis de incidencia, logra medir el efecto redistributivo en términos de ingreso tanto en Bogotá como en los municipios que conforman la región de influencia de la capital del país.

En esta obra los autores van más allá de calcular el efecto redistributivo y enfocan sus resultados a reconocer la capacidad redistributiva que tienen las grandes urbes para mejorar la distribución del ingreso de sus habitantes. El texto logra explicar y mostrar que ciudades como Bogotá cuentan con diversos instrumentos que mejoran sustancialmente el bienestar de sus residentes y reducen los niveles de desigualdad. Este libro es un aporte sustancial en la generación de evidencia empírica sobre el papel que pueden jugar las ciudades para mejorar el bienestar social de sus residentes.

Palabras clave: distribución del ingreso, justicia social, renta, hogares, aspectos económicos, Bogotá, Colombia.

\section{The Evolution of Household Finances in Bogotá}

\begin{abstract}
This work provides new evidence for the redistributive effect of tax policy on the financial condition of households in Bogotá, in the municipios (similar to U.S. counties) of the Savanah of Bogotá, and the department of Cundinamarca. There is a careful identification of the subsidies, taxes, and other levies that members of households pay or receive, and their combined impact is analyzed to measure the redistributive effect on household income in Bogotá and in the municipios that make up its area of influence.

The authors do more than just calculate the redistributive effect, however. They consider the redistributive capacity of large cities and their ability to improve the distribution of income among their inhabitants. The text demonstrates and examines how cities like Bogotá have multiple instruments with which they substantially improve the well-being of their residents, decreasing the level of inequality. This work makes a substantial contribution to generating empirical evidence on the role that cities can play to improve the well-being of their residents.
\end{abstract}

Keywords: Income distribution, social justice, income, households, economic factors, Bogotá, Colombia.

Citación sugerida

Gallego Acevedo, J. M.; González Borrero, J. I. y Sepúlveda Rico, C. E. (2017). Evolución del balance financiero de los hogares bogotanos. Bogotá: Editorial Universidad del Rosario - Secretaría Distrital de Planeación.

DOI: doi.org/10.12804/te9789587389425 
Evolución del balance financiero de los hogares bogotanos 
Secretaría Distrital de Planeación

Alcalde Mayor de Bogotá

Enrique Peñalosa Londoño

Secretario Distrital de Planeación

Andrés Ortiz Gómez

Subsecretario de Información y Estudios Estratégicos

Antonio José Avendaño Arosemena

Director de Estratificación

Ariel Eliécer Carrero Montañéz

Dirección de Estratificación

Adriana Alejandra García Sierra

María Esperanza Corredor Collazos

Julieta Rodríguez González

Mario Humberto Ruiz Sarmiento

Edward Martin Salamanca Morales

Victor Julio Guerrero Rodriguez 


\section{Evolución del balance financiero de los hogares bogotanos}

Juan Miguel Gallego Acevedo

Jorge Iván González Borrero

Carlos Eduardo Sepúlveda Rico 
Evolución del balance financiero de los hogares bogotanos / Juan Miguel Gallego Acevedo, Jorge Iván González Borrero, Carlos Eduardo Sepúlveda Rico. - Bogotá: Editorial Universidad del Rosario; Secretaría Distrital de Planeación, 2017.

xv, 121 páginas. - (Colección Textos de Economía)

Incluye referencias bibliográficas.

Distribución del ingreso - Bogotá (Colombia) / Justicia social - Bogotá (Colombia) / Renta - Bogotá (Colombia) / Hogares - Aspectos económicos - Bogotá (Colombia) / Bogotá (Colombia) - Política económica / I. Gallego Acevedo, Juan Miguel / II. Sepúlveda, Carlos / III. González, Jorge Iván / IV. Universidad del Rosario / V. Bogotá. Alcaldía Mayor. Secretaría Distrital de Planeación / VI. Título. / VII. Serie.

$336.185 \quad$ SCDD 20

Catalogación en la fuente - Universidad del Rosario. CRAI

JDA

Agosto 28 de 2017

Hecho el depósito legal que marca el Decreto 460 de 1995

Colección Textos de Economía

(C) Editorial Universidad del Rosario

(C) Universidad del Rosario

(C) Alcaldía Mayor de Bogotá, Secretaría de Planeación

(C) Juan Miguel Gallego Acevedo, Jorge Iván González Barrero, Carlos Eduardo Sepúlveda Rico

(C) Ariel Eliécer Carrero Montañez, Antonio José Avendaño Arosemena, por el Prólogo

(C) Andrés Ortiz Gómez, por la Presentación

Editorial Universidad del Rosario

Carrera 7 № 12B-41, oficina 501・ Teléfono 2970200

editorial.urosario.edu.co
Primera edición: Bogotá D.C., septiembre de 2017

ISBN: 978-958-738-941-8 (impreso)

ISBN: 978-958-738-942-5 (ePub)

ISBN: 978-958-738-943-2 (pdf)

DOI: doi.org/10.12804/te9789587389425

Coordinación editorial: Editorial Universidad del Rosario Corrección de estilo: Carolina Méndez Téllez Montaje de portada: Miguel Ramírez, Kilka, DG Diagramación: Precolombi EU-David Reyes

Impresión: Panamericana Formas e Impresos S. A.

Impreso y hecho en Colombia

Printed and made in Colombia

Los conceptos y opiniones de esta obra son de exclusiva responsabilidad de sus autores y no comprometen a la universidad ni sus políticas institucionales.

El contenido de este libro fue sometido al proceso de evaluacion de pares, para garantizar los altos estandares academicos. Para conocer las politicas completas, visitar: editorial.urosario.edu.co

Todos los derechos reservados. Esta obra no puede ser reproducida sin el permiso previo por escrito de las instituciones editoras. 


\section{Contenido}

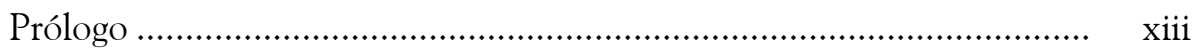

Ariel Eliécer Carrero Montañez

Antonio José Avendaño Arosemena

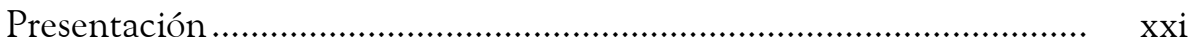

Andrés Ortiz Gómez

Capítulo 1. Balance financiero de los hogares. Fundamentos

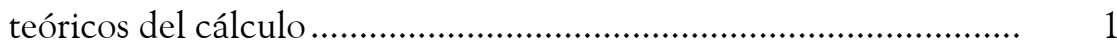

Marco conceptual de análisis......................................................... 3

Revisión de la literatura sobre análisis de incidencia....................... 5

Metodología para la identificación de subsidios

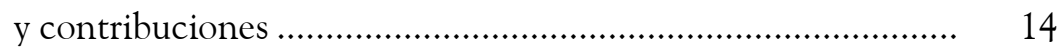

Resumen de los principales resultados............................................ 15

Organización y estructura del libro................................................... 21

Capítulo 2. La política social y tributaria: descripción de los

principales componentes ........................................................... 23

Gasto público social con un propósito ............................................. 24

Evolución de las condiciones de vida en Bogotá ...................... 24

Política social en Bogotá y su impacto en la pobreza

y la desigualdad ........................................................ 28

Política social y tributaria en los municipios aledaños .............. 29

Descripción de la política social y tributaria en Bogotá ................... 36

Formación de capital humano ................................................. 36

Capítulo 3. Ingreso disponible. Metodología de cálculo .......................... 47

El ingreso disponible de los hogares.................................................. 47 
Componentes del ingreso disponible ............................................... 48

Cálculo del ingreso y gasto corriente ........................................ 49

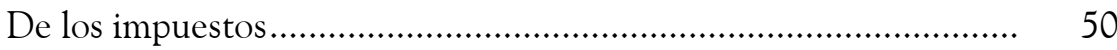

Subsidios y contribuciones del hogar ............................................ 52

Subsidios enfocados a la formación de capital humano........... 52

Mejorar infraestructura física del hogar......................................... 57

Capítulo 4. Resultados y análisis de la estimación del balance

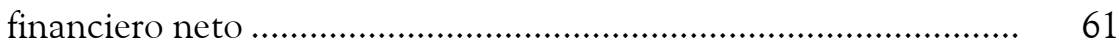

Cálculo del balance financiero neto de los hogares ........................ 62

Estimación de la capacidad de pago de los hogares ......................... 66

Patrones de gasto en Bogotá .......................................................... 67

Valor de los subsidios y contribuciones directas percibido por los hogares.................................................................... 70

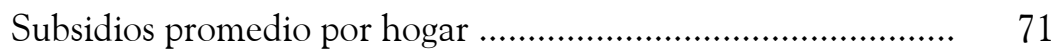

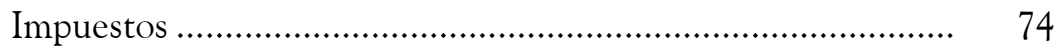

Evolución del ingreso disponible de los hogares entre 2011 y 2014 en Bogotá .......................................................... 75

Capítulo 5. Efecto redistributivo de la política fiscal ............................... 79

Efectos de la política fiscal sobre la distribución del ingreso........... $\quad 80$

Efectos de los subsidios sobre desigualdad en el ingreso ................. $\quad 84$

Impacto de los impuestos sobre el ingreso y la desigualdad ............. 91

Capítulo 6. Análisis espacial del balance financiero

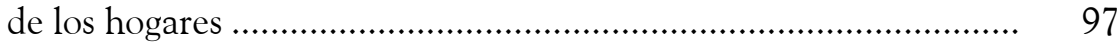

Auto-correlación espacial en el ingreso disponible ....................... 100

Modelo econométrico de correlación espacial................................ 110

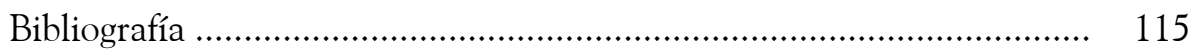

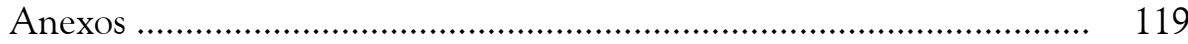

Anexo 1. Capítulos de la EM2014 _................................................. 119

Anexo 2. Lista de siglas y acrónimos ............................................. 121 


\section{Índice de gráficas y mapas}

Gráfica 1.1. Curva de Lorenz del ingreso por tipo de instrumento de política fiscal

Gráfica 2.1. Evolución de la pobreza monetaria en cinco ciudades de Colombia, 2002-2014

Gráfica 2.2. Porcentaje de los ingresos tributarios y predial sobre ingresos totales (31 municipios, sin Bogotá) ................................. $\quad 30$

Gráfica 2.3. Puntaje Sisbén promedio por municipio (2014) .................. 33

Gráfica 2.4. Porcentaje de ingresos tributarios sobre el total de ingresos y la pobreza monetaria .................................................... 34

Gráfica 3.1. Metodología para calcular los subsidios en SPD ................... 58

Gráfica 3.2. Metodología para calcular los subsidios en SPD considerando mínimo vital

Gráfica 4.1. Ingreso corriente, ingreso disponible y gasto promedio mensual por hogar Bogotá + Región 67

Gráfica 5.1. Curva de Lorenz de ingresos imputados .............................. 89

Gráfica 5.2. Progresividad de los subsidios netos al capital humano...... 89

Gráfica 5.3. Progresividad subsidios netos en SPD .................................. 90

Gráfica 5.4. Progresividad de subsidios en transporte y vivienda............ 91

Gráfica 5.5. Curva de concentración de impuestos en Bogotá

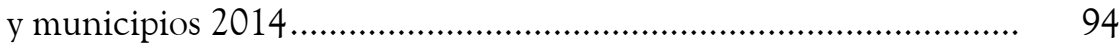

Gráfica 6.1. Matriz de vecindades tipo Queen....................................... 99

Mapa 1. Distribución espacial del ingreso disponible y sus componentes en la ciudad de Bogotá

Mapa 2. Distribución espacial del ingreso disponible y sus componentes para Bogotá-Región 


\section{Índice de tablas}

Tabla 1.1. Impuestos, subsidios e ingresos. Valor mensual total expandido para Bogotá .................................................................. 16

Tabla 1.2. Subsidios netos mensuales. Total Bogotá ............................... 17

Tabla 1.3. Impuestos mensuales totales pagados en Bogotá..................... 20

Tabla 2.1. Opinión del jefe o del cónyuge respecto a si se considera pobre en Bogotá.................................................................... 25

Tabla 2.2. Opinión del jefe o del cónyuge sobre los ingresos

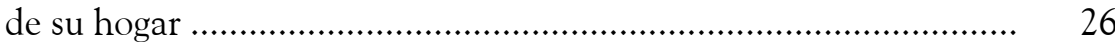

Tabla 2.3. Participación de los ingresos tributarios en los ingresos totales del municipio ................................................................. 31

Tabla 2.4. Beneficiarios de programas sociales del gobierno

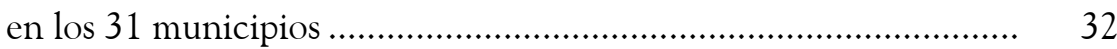

Tabla 2.5. Indicadores sociales por municipio........................................ 34

Tabla 2.6. Tarifas de subsidios en educación por grado y tipologia

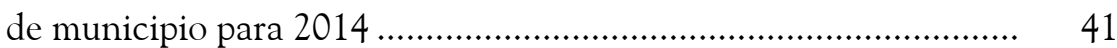

Tabla 3.1. Valores de la UPC para 2014 para el régimen subsidiado y contributivo ............................................................................. 54

Tabla 3.2. Valor del costo de la canasta educativa anual colegio públicos y en concesión ............................................................ 55

Tabla 3.3. Subsidios condicionados a la asistencia escolar....................... 56

Tabla 4.1. Ingreso corriente y disponible total mensual para Bogotá

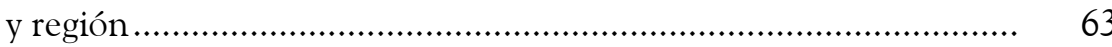

Tabla 4.2. Total de ingreso corriente y disponible por estrato para todos los municipios de la EM2014 ............................................... 65

Tabla 4.3. Total de ingreso corriente y disponible por quintil de gasto corriente para todos los municipios de la EM2014 
Tabla 4.4. Gasto total y gasto promedio mensual para todos los municipios de la EM2014

Tabla 4.5. Patrón de gasto del hogar por estrato según grandes rubros de gasto en la ciudad de Bogotá...................................................... 68

Tabla 4.6. Evolución-distribución del gasto de los hogares para la ciudad de Bogotá

Tabla 4.7. Subsidios y contribuciones promedio mensual del hogar para la ciudad de Bogotá

Tabla 4.8. Impuestos promedio mensual por hogar para la ciudad de Bogotá

Tabla 4.9. Comparación ingreso disponible a precios corrientes y constantes

Tabla 4.10. Comparación ingreso disponible a precios constantes según estrato 76

Tabla 4.11. Comparación ingreso disponible según quintil..................... 77

Tabla 5.1. Efecto redistributivo de la política fiscal ................................ 81

Tabla 5.2. Efecto de la política fiscal sobre la desigualdad por estrato y quintiles de gasto para Bogotá

Tabla 5.3. Efecto de la política fiscal sobre la desigualdad por estrato y quintiles de gasto para municipios de la Región

Tabla 5.4. Efectos de los subsidios netos sobre desigualdad 86

Tabla 5.5. Descomposición del Gini de ingresos imputados por estrato y quintiles de gasto

Tabla 5.6. Efectos de los subsidios netos sobre desigualdad .................... 92

Tabla 6.1. Índice de Moran del ingreso disponible y sus componentes .. 109

Tabla 6.2. Estimación del modelo econométrico simple para ingreso disponible por $\mathrm{MCO}$

Tabla 6.3. Pruebas de multiplicador de lenguaje para comparar tipos de modelo de correlación espacial

Tabla 6.4. Comparación de los modelos de MCO y SEM para el caso del nivel Bogotá-Región

Tabla 6.5. Comparación de los modelos por MCO y SAR solo Bogotá...... 112 
Este libro contó con la colaboración académica de Javier Acosta, Alexis Maluendas, Denis López, Humberto Mayorga y Ana Jaimes. 


\title{
Prólogo
}

\author{
Ariel Eliécer Carrero Montañez \\ Director de Estratificación de la Secretaría Distrital de Planeación \\ Antonio José Avendaño Arosemena \\ Subsecretario de Información y Estudios Estratégicos \\ de la Secretaría Distrital de Planeación
}

Diferentes estudios señalan que los programas sociales tienen dificultad para lograr una mayor efectividad en sus objetivos redistributivos debido a que existen circunstancias que no permiten que lleguen de forma exclusiva a las personas de bajos ingresos. Por ejemplo, en el Proyecto de Ley 186 de 2016 el Gobierno Nacional Central sostiene que los subsidios no son progresivos ${ }^{1}$ porque no están bien focalizados; asimismo, las investigaciones técnicas de la Secretaría Distrital de Planeación sobre subsidios a los servicios públicos domiciliarios en Bogotá D. C. indican que existen errores de inclusión y exclusión de beneficiarios, esto es, que hay hogares que reciben subsidios sin que tengan derecho a ellos, y hogares que cumpliendo los requisitos para acceder no los reciben; y, además, el Departamento Nacional Planeación (DNP) en la revisión a la base de datos del Sisbén encontró que algunas personas se beneficiaron de los subsidios sin tener derecho a ello.

Y por el lado del pago de contribuciones y de tributos se presentan problemas similares. En los servicios públicos domiciliarios la norma permite

\footnotetext{
1 Proyecto de Ley 186 de 2016 Senado, Gaceta del Congreso 1007, Bogotá, 17 de noviembre de 2016, pp. 23 y ss.
} 
que los usuarios de ingresos altos eviten el pago de las contribuciones con su decisión de ubicación residencial. Como el estrato socioeconómico no es una medida del ingreso, entonces, un hogar de ingreso alto que decida residir en un estrato inferior para reducir costos de localización necesariamente elude la contribución y, posiblemente, recibirá subsidios sin que ello se tipifique en un acto indebido, es simplemente un problema de la norma que al definir los criterios básicos permite la elusión. En materia impositiva según los estudios de la Dirección de Impuestos y Aduanas Nacionales (DIAN) la evasión en el país alcanza un 30\%, lo que implica un volumen significativo de menores recursos al gobierno para costear y ampliar el gasto social.

Al haber hogares o personas que se benefician de los programas sociales sin calificar, queda en evidencia que los filtros de selección no funcionan correctamente. Esto conduce de inmediato a la cuestión de la información que permite la selección de los beneficiarios, así como al seguimiento y a la evaluación de los programas. En materia de información al menos se deben considerar dos aspectos. El primero de ellos corresponde a la asimetría de información que se presenta entre las entidades públicas y quienes solicitan ser incorporados a los programas. En el punto de admisión, por principio, el Estado tiene que partir de la buena fe del ciudadano que hace la solicitud, lo cual no es impedimento para que la administración pública diseñe y ponga en funcionamiento una serie de controles que permitan verificar la veracidad de los datos entregados por el candidato, y esto conduce al segundo aspecto, los sistemas de información disponibles para ejercer supervisión.

El concepto de sistema implica que los elementos que lo integran tienen una relación orgánica, esto es, están ordenados y coordinados para poder cumplir su función inherente. Y la información que se requiere para realizar el control de programas sociales redistributivos son datos sobre la capacidad de pago del ciudadano. Por consiguiente, para evitar la inclusión y exclusión de beneficiarios y la evasión de quienes contribuyen se necesita un sistema de información que integre una serie de bases de datos que se encuentran en los registros administrativos y las encuestas que llevan o que hacen, respectivamente, las entidades públicas y las privadas que desempeñan funciones públicas - por ejemplo, las Entidades Promotoras de Salud (EPS). Esa integración implica procesos exactos, normas que regulen los procedimientos y una base tecnológica común que permita la interacción entre los diferentes programas sociales, las entidades y los niveles de 
gobierno (nacional, departamental y municipal), sin violar los principios de privacidad y reserva estadística.

Un sistema de información de beneficiarios también es esencial para el seguimiento y la evaluación de los programas y de la política social en general. Para darle alcance a esa importancia considérese el caso en que no existe un sistema. En esta situación normalmente el seguimiento de cada programa se limita a registrar la ejecución financiera y presupuestal, mantener actualizados algunos datos básicos de los beneficiarios, realizar visitas domiciliarias esporádicas y aleatorias a los hogares y registrar algunas variables de ejecución física. Este tipo de proceder imposibilita los cruces estadísticos con otras entidades o programas y profundiza la asimetría de información que favorece a los colados e incrementa los problemas de focalización. Al mismo tiempo se crea una descoordinación entre programas que limitan la identificación de puntos y procesos críticos, y la reformulación de objetivos, coberturas y asignación de los recursos fiscales, e incluso la consistencia y pertinencia de los programas existentes. Todo ello le resta eficiencia y eficacia a la gestión de la política social.

La carencia de un buen sistema de información para realizar el seguimiento y las evaluaciones a lo largo del ciclo del programa (evaluación ex ante, en ejecución y ex post) conduce a una inercia en la ejecución que le da vida a una visión estática pues implícitamente se considera que los hogares inscritos en los programas mantienen en el tiempo sus niveles de capacidad de pago, lo que hace que tiendan a permanecer como beneficiarios durante horizontes largos, como si las circunstancias económicas y sociales de los hogares se congelaran.

La necesidad de información confiable es una cuestión permanente, más aún si se desea emitir un concepto sobre el logro de los objetivos que los programas se proponen y con base en evaluaciones formular nuevos programas o articular acciones entre entidades ejecutoras o entre políticas o programas. De forma acertada el Gobierno Nacional Central entendió este problema y, en el Proyecto de Ley 186, propone un sistema de información. En efecto, el proyecto dedica el Capítulo IV a la creación del Sistema Interoperable de Registros de Consulta Pública "con el objetivo de optimizar los procesos de intercambio de información entre las entidades públicas y particulares que ejerzan funciones públicas... El sistema permitirá cruzar todos los registros en materia de subsidio e identificar a todos los beneficiarios de 
los mismos, señalando todos los subsidios que estos reciben", lo cual llevaría a deducir que en el sistema quedarían integrados los demás niveles de gobierno, pero, no hay que olvidar que en el parágrafo del capítulo primero se sostiene que la ley "aplica a la destinación de recursos públicos para financiar subsidios que sean parte de políticas y programas del orden nacional y a aquellos en los que concurran para su financiación recursos públicos del orden nacional", es decir, el mismo proyecto de norma circunscribe su ámbito de aplicabilidad.

Por lo anterior, en nuestra opinión, el proyecto se queda corto porque desconoce que muchas de las variables que se utilizan para la asignación de subsidios requieren la participación de los gobiernos locales en el levantamiento y provisión de la información estadística y que, a su vez, esos niveles de gobierno necesitan de la información nacional para implantar controles y realizar buenos seguimientos y evaluaciones. En otras palabras, se necesita un proceso y procedimiento de información sistémico, que integre a las fuentes de información sobre subsidios nacionales las correspondientes a los subsidios departamentales y municipales más las bases de datos que permitan determinar la capacidad de pago de los beneficiados como las tributarias de los tres niveles de gobierno, los registros de las cámaras de comercio, etc., con el propósito de no incurrir en los errores de diseño del presente y que llevan a los problemas anteriormente señalados.

Como lo muestra la experiencia internacional, un sistema de información que permita crear filtros para el control y hacer un seguimiento y una evaluación de programas sociales necesita de bases de datos administrativos, de censos y de encuestas pues ese conjunto de información hace posible un proceso para depurar a los aspirantes a los subsidios y aumenta la precisión de los resultados cuantitativos del seguimiento y la evaluación de programas.

En todo el mundo las encuestas tienen problemas de respuestas deficientes para algunas de las preguntas que buscan medir variables socioeconómicas importantes. Una de las causas de este inconveniente está en que el informante considera que no debe entregar información crítica o estratégica para él; otra, porque los formularios tienen grupos de preguntas que los individuos se niegan a contestar; y, porque algunos grupos sociales incurren en costos altos en contestar encuestas y prefieren no colaborar, especialmente los hogares de mayores ingresos, lo que induce a subestimaciones. Estos y otros hechos de la recolección de los datos exigen un esfuerzo 
de investigación estadística para corregir y reducir los problemas derivados de la imprecisión o de la no respuesta, desde los métodos de imputación para el tratamiento de datos atípicos hasta los de ponderación para suplir el dato faltante (Biffignandi et al., 2016).

Los censos, que en su totalidad son puntuales y distanciados en el tiempo, pese a que sufren de los mismos problemas de las encuestas periódicas ayudan a complementar la información, siempre y cuando exista compatibilidad entre las preguntas de los formularios y las variables que se desean medir los censos y las encuestas.

Otra fuente que permite corregir y ampliar la información de las encuestas son los registros administrativos. Su uso como complemento de aquellas exige metodologías para realizar los emparejamientos, la agregación de variables, la conciliación de las discrepancias frente a los datos de las encuestas, la compatibilización entre diferentes fuentes administrativas que miden las mismas variables y la conexión entre ellas. En ausencia de esas metodologías se limitan los resultados de los estudios, se pierde información, se tienen emparejamientos deficientes, entre otros aspectos (Abraham y Kopczuk, 2016; Dearden, 2010; y Molfino et al., 2017). Igualmente, se necesita una labor previa en la construcción de protocolos de acceso a los datos administrativos donde se plasmen reglas claras de gobernanza, de privacidad, de la asignación de responsabilidades en los temas de la recolección de información, custodia y preservación de las bases de datos y, en general, de las buenas prácticas estadísticas.

Los registros administrativos tienen la ventaja de reducir los problemas de imputación, se gana en precisión y se puede construir la tendencia de las variables en estudio, siempre y cuando se tengan registros precisos, confiables y amplios. Pero su uso con el propósito de aumentar la calidad de la información implica la creación de metodologías que compatibilicen las unidades de observación de los registros con las encuestas y los censos. Entre las desventajas se encuentra el reto de no violar los principios estadísticos claves de privacidad y confidencialidad. Si bien se podría argumentar que la dificultad se supera con la anonimización de las bases de datos, esta solución puede restringir la identificación exacta de los beneficiarios de los programas.

La relación entre encuestas y registros administrativos nos trae al tema de este libro: el cálculo del balance financiero neto que permite valorar ex post la política pública social en Bogotá D. C., veinte municipios de 
Cundinamarca y once cabeceras de provincia a la que concurren diferentes niveles de gobierno y programas. El punto técnico crucial es el cálculo del ingreso disponible ajustado para lo cual se utilizó la Encuesta Multipropósito de 2014 y datos de registros administrativos. Las limitaciones para la estimación del pago de impuestos locales, como bien lo manifiestan los autores, se pudo superar con la imputación a partir de las bases de datos de la Secretaría Hacienda Distrital, o cómputos indirectos con base en las normas que regulan algunas transferencias como los subsidios condicionados que se entregan para asistencia escolar o a los servicios de salud.

Sin embargo, por la ausencia en el país de un sistema de información que integre los diferentes niveles de gobierno y entidades encargadas de los programas en esta investigación, los autores tuvieron restricciones para calcular los impuestos que pagan los hogares en los municipios vecinos lo que limita la comparación espacial del balance financiero neto. Además, tampoco pudieron acceder a los registros de la DIAN para calcular bien los pagos del impuesto de renta de los hogares. El costo de esas restricciones es la imprecisión en el cálculo del ingreso disponible de los hogares y, desde luego, el ingreso disponible ajustado, lo que infortunadamente limita las conclusiones sobre este ingreso y la progresividad tributaria a las que llega el estudio para municipios y cabeceras de provincia de Cundinamarca. Pese a estas restricciones, es de resaltar que el estudio es el primer esfuerzo por calcular un balance financiero de estas zonas y es una herramienta útil para los gobiernos locales y para la planeación regional en su conjunto.

Las circunstancias objetivas de limitaciones de información que tuvo este estudio es un ejemplo entre muchos de la necesidad que tiene el país de crear un sistema integrado de información que apenas se empieza a superar con la propuesta del Proyecto de Ley 186 de crear un Sistema Interoperable de registros y Consulta Pública administrado por el DNP y cuyo propósito es permitir cruzar todos los registros de los programas de subsidios y hacer pública la información pues el beneficiario aceptara la publicación de su información pero sujeto al hábeas data. Si bien la intención va en la vía correcta, el Gobierno Nacional Central limita la información a los subsidios sin considerar los datos adicionales que se necesitan para llevar a cabo estudios integrales sobre los programas sociales redistributivos, información que va más allá de los subsidios. 
Para superar este vacío, la administración del Distrito Capital ha hecho esfuerzos en la creación de sistemas integrados de información que permitan mejorar la focalización y el uso de los recursos públicos. Entre ellos se encuentra la creación del Sistema Integrado de Información Poblacional (SIIP), contemplado en el artículo 126 del Plan de Desarrollo Bogotá Mejor Para Todos, el cual tiene por objeto consolidar la información de los beneficiarios que acceden a los servicios, beneficios y programas provistos por el Distrito Capital y promover su integración con los sistemas de información del orden nacional. Por otro lado, ha consolidado una propuesta técnica, en colaboración con la Empresa de Acueducto y Alcantarillado de Bogotá (EAAB), la Empresa de Energía de Bogotá (EEB) y ONU Hábitat para la construcción de una metodología de análisis multidimensional de las condiciones socioeconómicas de los ciudadanos del Distrito Capital a partir de un sistema interoperable de registros administrativos.

El DANE (2014) ya definió los lineamientos de la metodología para la operación estadística con registros administrativos, que complementa las correspondientes a los censos y encuestas por muestreo, ello dentro del marco del Sistema Estadístico Nacional. Empero, el país requiere más que una metodología para estar a la par de la tendencia internacional. Los pasos del proyecto de ley y del DANE todavía están lejos de la creación de un verdadero sistema de información que permita superar las restricciones que hoy tienen las investigaciones para obtener mediciones más precisas y tener mayor alcance en sus conclusiones, como lo ejemplifica el tema que se desarrolla en este libro.

Bogotá D. C., agosto de 2017

\section{Referencias}

Abraham, K. G. y Kopczuk, W. (2016). Comments and Discussion. Working Papers on Economic Activity, Spring, pp. 313-331.

Biffignandi, S., L. Nascia y Zeli, A. (2016). Combining survey and administrative data in Italian business surveys. Journal of Economic and Social Measurement, 41(1), pp. 67-83.

DANE. (2014). Lineamientos para documentar la metodología de operaciones estadísticas basadas en registros administrativos. Bogotá D. C.: DANE. 
Dearden, L. (2010). Administrative data and economic rolicy evaluation. The Economic Record, 86, Special Issue, September, pp. 18-21. Molfino, E., Korkmaz, G., Keller, S., Schroeder, A., Shipp, S. y Weinberg, D. (2017). Can administrative housing data replace survey data? Journal of Policy Development and Research, 19(1). 


\title{
Presentación
}

\author{
Andrés Ortiz Gómez \\ Secretario Distrital de Planeación
}

En Colombia los gobiernos de los niveles nacional, departamental y municipal ejecutan una gama de políticas públicas que tienen como objetivo reducir la desigualdad de ingresos y de oportunidades entre los hogares. Se entregan subsidios en especie o en dinero para que las personas o los hogares tengan acceso a los servicios públicos domiciliarios, salud, educación, alimentación, entre otros; se exceptúa del pago del impuesto de renta a los individuos que tienen menores ingresos laborales, se cobran contribuciones a los hogares que viven en inmuebles residenciales pertenecientes a los estratos altos de las ciudades y se asignan las tarifas impositivas más altas a los individuos que reciben mayores ingresos.

Algunos de los programas redistributivos tomaron tal importancia que se convirtieron en políticas de Estado, lo que les permite tener continuidad en el tiempo, es decir, se les proporcionó independencia frente al ciclo político de los gobiernos. Asimismo, en momentos en que las estadísticas señalan que se mantiene la concentración del ingreso y, en el mediano plazo, los índices de pobreza tienen una tendencia decreciente, los gobiernos refuerzan los programas de lucha contra la desigualdad con recursos nuevos, reasignaciones presupuestales y mejoras en los diferentes instrumentos para el cobro de tributos. Por ejemplo, con el fin de mejorar la equidad en el cobro del impuesto predial, la Administración Distrital realizó una reforma 
tributaria mediante el Acuerdo 648 de 2016 que asigna a los estratos bajos tarifas preferenciales para viviendas de interés social o prioritario.

Estas y otras acciones políticas y administrativas manifiestan la necesidad de un esfuerzo fiscal importante en el país, llevando a las autoridades a preguntar sobre la eficacia de las políticas públicas redistributivas y sobre los posibles factores que la determinan.

Para la Secretaría Distrital de Planeación, atendiendo los objetivos de consolidar una ciudad igualitaria e incluyente, expresados a través del primer eje del Plan Distrital de Desarrollo: Bogotá Mejor Para Todos, es primordial la generación de información para analizar la eficacia de la política redistributiva, pues su medición puede arrojar resultados conducentes a repensar y mejorar las políticas públicas.

En este volumen titulado Evolución del balance financiero de los hogares bogotanos se plantea una respuesta sobre el alcance de las políticas redistributivas en Bogotá D. C. y en la Región, esta última conformada por los 20 municipios vecinos del Distrito Capital y 11 cabeceras de provincia del Departamento de Cundinamarca. La estimación se realizó con la información disponible en las Encuestas Multipropósito de 2011 y 2014, con una mirada comparativa para el caso de Bogotá y un examen puntual para la Región, dado que para los municipios sólo se tiene la información disponible de la Encuesta Multipropósito 2014.

En el marco de las funciones de la Secretaría Distrital de Planeación, el análisis y los resultados presentados en las siguientes páginas contribuyen en la generación de documentos técnicos que aporten a mejorar la formulación, coordinación y orientación de la planeación social del territorio y el diseño e implementación de instrumentos de focalización para la asignación de servicios sociales básicos que respondan a las dinámicas y necesidades propias de los ciudadanos.

Si existe una variedad de políticas que afectan las condiciones de vida y de pobreza de los hogares bogotanos y de la región, como se muestra en el libro, entonces se espera un aumento de la capacidad de pago y una disminución del índice de desigualdad de ingreso. El aporte del estudio es precisamente brindar un orden de magnitud sobre la eficacia de las políticas redistributivas. Entre los hallazgos se destaca que los subsidios netos a los hogares bogotanos de los estratos 1, 2 y 3 crecieron entre 2011 y 2014. Los servicios públicos domiciliarios absorbieron el 38\% de los subsidios 
entregados, el $22 \%$ se destinaron a transporte y el $35 \%$ a los gastos en salud, educación, jardines infantiles y el componente de nutrición del programa de Familias en Acción. Los subsidios permitieron aumentar la capacidad de pago de los hogares de los estratos 1 y 2 ; y visto por quintiles de ingreso, el gasto público en subsidios benefició a los tres primeros.

Los recursos para financiar los subsidios salieron de los hogares de los estratos 5 y 6 , o del último quintil de ingreso. Esos estratos aportan vía la tributación y las contribuciones por el consumo de servicios públicos domiciliarios. Lo que habla bien de las políticas redistributivas, aunque es posible un mayor esfuerzo de equidad en materia impositiva.

Asimismo, el balance fiscal muestra un subsidio mensual recibido por los hogares beneficiados de \$126.252, de los cuales el gobierno de Bogotá aporta el 94,1\% vía el gasto en educación y subsidios a los servicios públicos domiciliarios. Los subsidios en servicios públicos domiciliarios no modifican la distribución del ingreso, en cambio los subsidios en salud afectan de manera significativa el coeficiente de Gini, y reducen la desigualdad en casi 6\%. En el tema impositivo el resultado es de regresividad, en especial el peso del IVA en los hogares de ingresos bajos. En términos generales, las políticas tuvieron efectos redistributivos pues el índice de Gini se redujo en un $8,6 \%$ en Bogotá y un 6\% en los municipios de Cundinamarca analizados.

No todo está bien. El estudio detecta problemas de focalización de los subsidios en los estratos 3, 5 y 6 . Las administraciones públicas encargadas de los programas sociales en el Distrito Capital y en la Región requieren de mejores mecanismos de selección, control y evaluación de beneficiarios, así como de mejores sistemas de información, con integración de las bases de datos de identificación de beneficiarios a diferentes niveles de gobierno. De esta manera, con recursos fiscales similares se puede llegar a más hogares necesitados, dejando de otorgar subsidios a aquellos que no lo requieren. Este es precisamente el objetivo del actual proyecto de ley sobre subsidios en trámite por el gobierno Nacional.

En general, las órdenes de magnitud del estudio indican que se va en la dirección correcta, no obstante, es imperativo implementar procesos y procedimientos que mejoren la selección y permanencia de beneficiarios. Incorporar estas acciones permitirá el diseño de una política social sostenible, que mitigue las actuales condiciones deficitarias de diferentes sistemas de subsidios cruzados, como por ejemplo el existente en los servicios públicos 
domiciliaros, que, en la actualidad, presenta un desbalance que pone en riesgo no sólo la asignación del subsidio, sino la sostenibilidad financiera de las empresas prestadoras.

En este sentido, los esfuerzos institucionales a nivel nacional, regional y de Bogotá por una adecuada asignación de los recursos fiscales limitados, contribuirán a reducir significativamente la desigualdad de ingresos, mantener la tendencia de reducción de la pobreza y mejorar sustancialmente el bienestar de los hogares, garantizando la sostenibilidad económica de la política social.

Bogotá D. C., septiembre de 2017 


\section{Capítulo 1 Balance financiero de los hogares. Fundamentos teóricos del cálculo}

Los gobiernos locales de las grandes urbes cuentan con un potencial de acciones para mejorar las condiciones de vida de los hogares y personas que habitan en ellas. Las estadísticas sobre pobreza y condiciones de vida, a través de diferentes indicadores, muestran un diferencial en favor de mejores condiciones para los hogares residentes en los espacios urbanos comparados con aquellos en zonas rurales. En particular, en el año 2016, la incidencia de pobreza multidimensional en el área urbana en Colombia fue de $12,1 \%$ comparado con un 37,6\% de incidencia en el sector rural (DANE, 2017). Una de las causas de estas diferencias amplias en favor de los hogares residentes en las ciudades, es la posibilidad de aprovechar las economías de aglomeración y las externalidades positivas generadas por ellas, en particular, a través del aumento de los salarios de sus habitantes. Pero de igual forma, la diferencia a favor de los habitantes urbanos se relaciona con la capacidad de los gobiernos de las ciudades para atender las necesidades sociales exigidas por las personas que convergen hacía dichas aglomeraciones urbanas.

Estas estadísticas alentadoras en términos de pobreza a nivel urbano no son homogéneas entre las grandes ciudades. Para el caso colombiano, las grandes ciudades presentan diferencias sustanciales con respecto a las intermedias y pequeñas, siendo Bogotá y Bucaramanga aquellas con mejores indicadores sociales. Los avances en la lucha contra la pobreza no han estado acompañados de logros similares en equidad. En general, en el país la desigualdad continúa siendo muy alta (DANE, 2017). 
En economía urbana existe un debate abierto sobre la relación entre el nivel de urbanización de un país, el desarrollo y las desigualdades en el ingreso. Empíricamente se ha documentado una relación creciente entre desigualdades regionales y desarrollos urbanos (o crecimientos de las ciudades). Dicha relación parece observarse en una etapa inicial del sistema de urbanización de un país. En general, se trata de una regularidad empírica documentada en economías desarrolladas, que cuentan con un sistema urbano bien establecido. Estas asimetrías regionales parecen estar explicadas, en parte, por diferencias en la compensación de las calificaciones en el mercado laboral. Las grandes ciudades, o aquellas con mayor crecimiento urbano, tienen una mayor diversidad de industrias que reconocen de una forma más adecuada las calificaciones de los trabajadores que las habitan, en comparación con ciudades pequeñas que tienen una economía menos diversificada. Esta relación positiva puede ser la causa de la agrupación de hogares en las dos colas de la distribución del ingreso: por un lado, los hogares más pobres pueden localizarse en ciudades más grandes porque tienen acceso a mejores provisiones de bienes y servicios públicos y, por otro, los hogares de altos ingresos buscan las ciudades grandes porque allí perciben mayores ingresos por sus calificaciones.

La dinámica de las ciudades requiere de altas inversiones en educación, salud, saneamiento e infraestructura vial, para estimular su expansión. Colombia tiene una población urbana relativamente balanceada, y la primacía de la ciudad principal (Bogotá) no es tan fuerte como en Argentina, Perú o Chile. Pero aun así, se observan altas diferencias regionales en términos de ingreso y de desarrollo social, lo cual podría señalar un proceso de urbanización en etapa aún de consolidación.

Una pregunta central en economía urbana parte de entender por qué las personas deciden aglomerarse en un territorio específico y cómo la política pública puede afectar dichas tendencias. Desde el punto de vista de la economía de las aglomeraciones, las políticas sociales buscan compensar los costos de la aglomeración, asociados principalmente con congestión, contaminación y desigualdades. Para el caso de Bogotá es importante dimensionar el impacto redistributivo de la acción del gobierno nacional y local, a través de la asignación de subsidios, impuestos y contribuciones (Gallego et al., 2015). Este enfoque es una alternativa válida para evaluar los potenciales efectos que tendría la provisión de servicios sociales, bienes 
públicos y facilidades urbanas, en la decisión de una ubicación específica. El análisis de los efectos de las políticas fiscales en el bienestar-medido como la capacidad de pago, los patrones de consumo, la pobreza, la desigualdad o la redistribución del ingreso- se hace más relevante cuando se realizan comparaciones entre Bogotá y otras poblaciones vecinas.

Con el fin de entender los efectos redistributivos de la política de fortalecimiento de la capacidad de pago de los hogares bogotanos y los municipios de la Sabana de Bogotá y Cundinamarca, se desarrolló una metodología de Análisis de Incidencia en el contexto de las economías de aglomeración. El objeto principal de este libro es presentar los avances en estos aspectos para Bogotá y analizar los efectos espaciales que tienen lugar entre Bogotá y 31 municipios y cabeceras de provincia incluidos en la Encuesta Multipropósito 2014 (EM2014).

La literatura en economía urbana ha desarrollado un esquema de análisis en el cual se pueden calcular los impactos que tienen las políticas sociales y fiscales implementadas por los gobiernos centrales y locales en el balance financiero de los hogares y en las desigualdades. Este enfoque nos permite establecer comparaciones entre Bogotá y los municipios cercanos, con el fin de determinar la incidencia de las políticas públicas en la equidad y el bienestar social. Además, al ser aplicada en otros estudios, la metodología permite analizar los cambios presentados entre 2011 y 2014.

\section{Marco conceptual de análisis}

La literatura existente para el caso de Bogotá sobre análisis de incidencia se basa principalmente en el estudio de autores como Gallego et al. (2015), quienes presentan un marco conceptual para examinar la política fiscal en el contexto de las economías de aglomeración.

El sistema de aglomeraciones urbanas de un país es el resultado de un proceso dentro del cual las políticas y las instituciones locales pueden jugar un papel fundamental en los cambios en la distribución del ingreso de los hogares residentes en una determinada ciudad. En este sentido, las diferencias observadas pueden ser explicadas por determinantes claves de la aglomeración como variables de equilibrio, en un espacio geográfico, el capital, el valor de la tierra, el balance neto (ingresos menos costos), y el factor trabajo. Interacciones de este tipo se observan en los estudios de Combes et al. (2005), Duranton $(2008,2016)$, los cuales parten de modelos 
basados en el espacio y en los flujos que tienen lugar entre los agentes económicos, en particular, en las conmutaciones laborales.

Es así como en una ciudad el crecimiento implica una relación entre los ingresos y los costos de vida según el tamaño del mercado laboral. Siguiendo el concepto de externalidades en grandes urbes, los ingresos son más altos porque se presentan rendimientos crecientes, que cualifican el capital humano y mejoran la productividad. En la ciudad también se presentan externalidades negativas, expresadas en mayores costos de vida, los cuales se asocian a fenómenos como la congestión, el crimen, la contaminación, entre otros. De esta forma, el ingreso neto se va ajustando, según los mercados, hasta un punto de equilibrio después del cual se vuelve ineficiente (cuando las ganancias en los ingresos son inferiores al crecimiento de los costos de vida).

Este enfoque conceptual permite entender cómo a través de políticas públicas se puede mejorar la calidad de vida de las personas, disminuyendo los costos de aglomeración, y aumentando la productividad de la ciudad. Para encontrar un balance favorable, las intervenciones públicas deben estimular la innovación de las empresas, aumentar la movilidad laboral, mejorar el acervo de las habilidades de los trabajadores, acelerar la conectividad física y virtual. Y por el lado de la disminución del costo de vida, se requiere contemplar políticas encaminadas a mejorar los mercados de la vivienda, a agilizar la prestación de servicios públicos y sociales, y a proveer bienes públicos locales.

Como se mencionó anteriormente, una forma idónea para comprender integralmente los efectos de las políticas sociales en urbes específicas, parte de una metodología de análisis de la incidencia de los subsidios y las contribuciones. Este estudio se nutre principalmente del trabajo metodológico diseñado en el libro Subsidios y contribuciones. Balance financiero de los hogares bogotanos (Gallego et al., 2015), el cual estudia el efecto de la política social y tributaria sobre los hogares bogotanos en el 2011.

Como cualquier metodología basada principalmente en la imputación de acciones de política pública, existen aspectos por mejorar. En particular, para el caso de este libro se lograron cálculos más precisos, gracias a una actualización de información, y a mayor disponibilidad de datos. También se hicieron avances en la metodología de imputación. Entre los cambios más importantes se destaca la imputación del subsidio de salud, la cual potencializa 
la capacidad que tiene la fuente principal de información (EM2014) para poder identificar la probabilidad de uso de servicios de salud, de acuerdo con el perfil epidemiológico de los miembros del hogar.

Por otro lado, la metodología de análisis también mejora porque una vez imputados los subsidios y contribuciones, se incluyen análisis derivados del enfoque de economías de aglomeración con una perspectiva espacial. Bajo determinadas condiciones, la diferencia entre entidades territoriales puede explicarse como el resultado del nivel de eficiencia de las políticas, o como una consecuencia del grado específico de desarrollo urbano. Aunque el libro de Gallego et al. (2015) planteó como marco de referencia el análisis de economías de aglomeración urbana y regional, la ausencia de información de otras entidades territoriales (o ciudades) dentro de una misma encuesta de análisis, no permitió aprovechar el enfoque espacial con el que ahora se cuenta para la EM2014.

\section{Revisión de la literatura sobre análisis de incidencia}

Con el objeto de presentar la importancia que ha tenido el Análisis de Incidencia como metodología de aproximación al efecto redistributivo de la política social y fiscal, se hace una revisión de esta literatura en Colombia y en América Latina.

El enfoque de Análisis de Incidencia ha sido ampliamente utilizado para aproximarse al efecto redistributivo de las políticas sociales y tributarias sobre el presupuesto de los hogares. En su estudio seminal Marshall y Selowsky (1980) explican cómo los gobiernos pueden mejorar la distribución del ingreso y erradicar la pobreza extrema cambiando la composición y dirección del gasto público. Y más allá de la capacidad del presupuesto fiscal de transferir ingresos, es su posibilidad de incidir en el consumo de bienes básicos como la vivienda, los servicios de agua y alcantarillado, la salud y educación, entre otros.

Bajo este direccionamiento del gasto público, los grupos más pobres de la población pueden disfrutar de niveles más altos de consumo en una etapa temprana de (su) desarrollo. Estos logros son superiores a aquellos posibles por la dinámica de las fuerzas (privadas) de la oferta y la demanda. Existen dos elementos importantes a considerar: en primer lugar, dada la alta desigualdad del ingreso y la extrema pobreza, hay espacio y obligación de la acción pública (gasto público social, en términos más modernos de 
nuestra legislación) para reducir esa pobreza y generar una sociedad más igualitaria. En segundo lugar, la acción pública permite a los hogares más pobres acceder al consumo de bienes esenciales para el desarrollo de sus capacidades, que de otra manera les sería muy difícil lograrlo.

Los hallazgos más importantes de Marshall y Selowsky (1980) resaltan la progresividad de los subsidios a la educación primaria, así como la alta regresividad de aquellos destinados a la educación superior. En lo que respecta a los servicios públicos domiciliarios de electricidad, agua y alcantarillado, los autores encontraron: primero, una alta concentración de los usuarios totales en las zonas urbanas y, segundo, una composición de un 25-30\% de los usuarios pertenecientes al $40 \%$ más pobre de los hogares, frente a un $50-55 \%$ de los usuarios pertenecientes al $40 \%$ más rico de la población. Estos resultados fueron muy influyentes en su momento y se convirtieron en un punto de referencia básico para posteriores desarrollos de metodologías de análisis de incidencia, sobre todo en los estudios impulsados por el Banco Mundial.

Existen trabajos posteriores al de Marshall y Selowsky (1980) en Colombia, de los cuales se destaca el de Vélez (1996), el cual se desarrolla en el marco del Estudio de pobreza e incidencia del gasto público social liderado por el Departamento Nacional de Planeación (DNP). Este trabajo analizó la incidencia del gasto público social (GPS) sobre la pobreza y la distribución del ingreso, encontrando una relación del GPS y el Producto Interno Bruto (PIB) entre un $1,7 \%$ en 1980 hasta un $3 \%$ en 1984, y fluctuaciones entre $1,75 \%$ y 2,6 \% en los años posteriores de 1985 a 1993. En general como lo resalta el autor, la política pública hacia lo social estuvo afectada fuertemente por el ciclo económico. No obstante, el crecimiento del GPS osciló alrededor de 4,7\% entre 1980 y 1992. El impacto del GPS sobre la distribución del ingreso se materializó en una reducción de 41 milésimas del coeficiente de Gini. Los subsidios a la educación tuvieron la mayor incidencia redistributiva explicando un $44 \%$ de la disminución del Gini. La política pública en salud impactó en segundo lugar la redistribución del ingreso con un $25 \%$. Los servicios públicos se situaron en tercer lugar con una incidencia del $23 \%$ en la reducción de la desigualdad.

En otro estudio, Sánchez y Núñez (2000) cuantificaron los impactos que tuvo la política pública dirigida a los servicios sociales y a los servicios públicos domiciliarios en el bienestar y en el ingreso de los hogares. 
Uno de sus principales aportes fue comparar los resultados de dos años diferentes: 1993 y 1997. La incidencia de la política pública en la distribución del ingreso vuelve a ser positiva e importante. Para esos dos años, los Gini antes y después de la acción pública fueron 0,4923 y 0,4909, mejorando ligeramente la distribución del ingreso. Las mayores contribuciones en la reducción de la desigualdad del ingreso vuelven a recaer en los subsidios a la educación, a la salud y, en menor medida, los orientados a los servicios públicos domiciliarios (SPD).

En esta misma línea de análisis, Lasso (2004) realizó un estudio en el marco de la Misión para el Diseño de una Estrategia para la Reducción de la Pobreza y la Desigualdad, conocida como MERPD, en el cual se analizó la incidencia del GPS sobre la distribución del ingreso y la reducción de la pobreza. Con base en estadísticas de la CEPAL el autor hace una representación del gasto social en Colombia de 6,8 \% del PIB para en el bienio 1990 1991, 15,3 \% en el bienio 1996-1997 y 13,6 \% en los dos primeros años del presente siglo, algo superiores a los estudios que le antecedieron. Similar a lo encontrado anteriormente, Lasso señala al sector educativo como el de mayor impacto del GPS, medido por los subsidios imputados. En sus resultados, para el año 2003, los subsidios educativos disminuyen el Gini en 27 milésimas repartido de la siguiente manera: 16 milésimas por los subsidios a la educación primaria, 10 milésimas a la educación secundaria, y sólo una milésima a la educación superior. En total, los subsidios a la educación explican un 54,3\% de la disminución del Gini. Los subsidios a la salud, los cuales incluyen los destinados al régimen subsidiado y los que contribuyen a financiar la oferta, impactaron en 15 milésimas el Gini, siendo la salud el segundo sector en importancia en la mejora en la distribución del ingreso nacional. Y, a diferencia de Vélez quien encontró un impacto del $23 \%$ de los subsidios a los SPD en la reducción de la desigualdad del ingreso, Lasso muestran impacto de 8,8 \% (evidenciando una reducción en el Gini de 4 milésimas).

En uno de los estudios más recientes para el caso de Colombia, Núñez (2009) indaga por la incidencia del GPS en la reducción de la pobreza y la distribución del ingreso para el periodo 2003 al 2008. Como lo enfatiza el autor, su aporte a la discusión del tema es el análisis de la incidencia del gasto público social sobre la reducción de la indigencia. En el estudio se destacan dos hallazgos: el primero evidencia una reducción significativa, 
de casi 8 puntos porcentuales de la pobreza entre los años de estudio; el segundo pese a lo anterior, muestra una variación casi nula de la indigencia, al mantenerse en un nivel cercano al 19\%. La tendencia a la baja de la pobreza también se observó usando como variables las insuficiencias del gasto y del ingreso de los hogares. El impacto del gasto público social fue positivo e importante. Núñez encontró un impacto del GPS en la pobreza de casi 11 puntos porcentuales para el 2003, y alrededor de 14 puntos porcentuales para el 2008. Al cuantificar la incidencia del GPS sobre la desigualdad del ingreso, los resultados fueron igualmente positivos. En el 2003, la política social redujo la desigualdad en casi 4.1 puntos, en tanto que en el 2008 la reducción alcanzó casi 6.3 puntos.

Recientemente la Universidad del Rosario y la Secretaría Distrital de Planeación realizaron un estudio sobre el efecto redistributivo de la política social y tributaria en los hogares de Bogotá para el año 2011 (Gallego et al., 2015). El trabajo compilado en el libro Subsidios y contribuciones: balance financiero de los hogares bogotanos se convirtió en el primer estudio de análisis de incidencia con un panorama completo entre subsidios, contribuciones e impuestos. Los resultados muestran una reducción significativa de la desigualdad gracias a la política social, especialmente en educación y salud. Sin embargo, dichas ganancias sociales pueden verse opacadas por una política tributaria altamente regresiva, en especial por el IVA, al afectar significativamente a los hogares de menores recursos. Adicionalmente los subsidios en servicios públicos domiciliarios no afectan la distribución del ingreso, y ello se explica por problemas e ineficiencias del instrumento de focalización (errores de inclusión y exclusión, e inflexibilidad para capturar la capacidad de pago de los hogares).

En el ámbito de la literatura internacional, el Análisis de Incidencia también ha adquirido relevancia para estudiar el impacto redistributivo de la política social. En un grupo de trabajos recientes para América Latina, diversos autores bajo la coordinación de Nora Lustig estudiaron el efecto redistributivo de la política social en América Latina de manera integral. Para la totalidad de los estudios se utilizaron como fuente principal de información la Encuesta Nacional de Hogares, donde se reporta, a nivel de hogar, información sobre impuestos, ingreso, consumo y acceso a los sistemas de salud y educación. Y para cada país de análisis se utilizan fuentes de información secundaria específicas a cada uno para complementar los datos. 
Los estudios de Análisis de Incidencia en Argentina, Bolivia, Brasil, México, Perú y Uruguay buscan estimar el efecto redistributivo de la política fiscal nacional sobre los niveles de pobreza y desigualdad. Para los casos latinoamericanos en general, los niveles de desigualdad registrados son altos frente al promedio mundial. En general, se estudia la incidencia de los impuestos (directos e indirectos), de las transferencias (directas o en especie) y de los subsidios en el ingreso final de los hogares. También se evalúa el grado de efectividad de las políticas implementadas, se determina si los programas e imputaciones son regresivos o progresivos, y se identifican los principales problemas de la política fiscal del país.

Como cualquier análisis de incidencia estándar, con la información recolectada se determina una línea de base a partir de los niveles de ingreso reportados en la encuesta nacional de hogares. Posteriormente se incluyen las transferencias e impuestos reportados o estimados y, de esta manera, se obtiene el monto de ingreso final del hogar. Una vez encontrado dicho valor se compara con el ingreso inicial del hogar, es decir, antes de aplicar la política fiscal nacional. Si el ingreso final es mayor, el hogar es beneficiario neto. Si es menor, el hogar es contribuyente neto.

Aunque existen particularidades para cada país, las metodologías comparten los mismos criterios básicos. De todas maneras, es importante resaltar algunas variaciones metodológicas. Para los casos de Argentina (Lustig y Pessino, 2014), Bolivia (Arauco, Gray, Yáñez y Jiménez, 2014), México (Scott, 2014), Perú (Jaramillo, 2014) y Uruguay (Bucheli, Lustig, Rossi y Amábile, 2014), los autores incluyen las pensiones del régimen contributivo en el ingreso del hogar, y en los análisis de sensibilidad consideran dichas pensiones como transferencias del Gobierno. Por otra parte, en el caso de Bolivia los autores excluyen del ingreso el impuesto a la renta, e incluyen las pensiones del sistema formal y la renta imputada (Arauco, Gray, Yáñez y Jiménez, 2014). De manera amplia, la totalidad de los estudios aportan análisis de incidencia basados en una metodología común, facilitando la comparación con otros países de Latinoamérica.

Para complementar el marco teórico, enseguida se presenta una síntesis de los principales elementos y avances metodológicos de los estudios sobre países latinoamericanos. 
- El aporte de Higgins y Pereira para Brasil radica en transitar de los modelos microsimulados a utilizar datos reales de contribuciones y transferencias. Este ejercicio permite obtener resultados más realistas al tener en cuenta fenómenos como evasión, exclusión y fugas bajo el supuesto de veracidad de la información reportada en la encuesta nacional de hogares.

- En el caso de Argentina, Lustig y Pessino estudian a profundidad el efecto marginal de la política fiscal introducida durante el periodo post-crisis y evalúan la sostenibilidad del aumento en gasto social generado en dicho país. Adicionalmente, el estudio del caso argentino brinda un marco innovador al analizar la medida denominada "efecto redistributivo". Por último, evalúa puntos distintos a los tenidos en cuenta en el marco común, como los efectos de las políticas sobre el nivel de calidad de la educación, la procedencia del incremento en el financiamiento del gasto social, y los desincentivos generados a partir de los subsidios.

- Para el caso de México, el aporte de Scott radica en llevar a cabo un análisis desagregado frente a la población urbana y la rural. Esta aproximación es de gran importancia dada las profundas diferencias en las condiciones de vida de ambas poblaciones. Así mismo, provee información actualizada sobre el sistema mexicano de transferencias e impuestos, que sufrió cambios en los últimos años principalmente de cara a los impuestos ad-valorem, los subsidios al consumo y las transferencias focalizadas.

Además de presentar un marco de análisis común se pueden destacar resultados similares: i) las transferencias en especie son efectivas en la reducción de la desigualdad, ii) las transferencias directas permiten reducir la pobreza (en especial la extrema), y iii) el efecto de los impuestos directos sobre la desigualdad es positivo, a excepción del caso de Bolivia donde dichos impuestos no se tienen en cuenta.

Al hacer un análisis particular de cada país podemos decir que en Perú las transferencias directas son efectivas para reducir la pobreza, en especial la extrema, pero su efecto es de corto plazo y mayor en áreas rurales que urbanas. Este hecho se explica por la concentración de las transferencias. Por otro lado, los subsidios en especie (dirigidos a salud y educación) son 
efectivos a la hora de reducir la desigualdad, en especial en el largo plazo, al tener un impacto directo en la formación de capital humano. Los impuestos directos contribuyen levemente a reducir la desigualdad, principalmente en áreas urbanas. Adicionalmente, su efecto sobre la pobreza es nulo. Los impuestos indirectos se muestran neutrales al nivel de desigualdad, una vez tenida en cuenta la informalidad. No obstante, elevan ligeramente el nivel de pobreza extrema y, en mayor medida, el de la pobreza total. Su impacto negativo es mayor en áreas urbanas.

En el caso de Uruguay las transferencias directas son efectivas por sí solas para reducir la pobreza. Las transferencias e impuestos indirectos disminuyen el nivel de desigualdad. El Gini baja 6\%. Las transferencias en especie tienen efectos positivos en el nivel de desigualdad. Los impuestos indirectos tienen una incidencia negativa en la pobreza. Los subsidios indirectos, el gasto en salud y el gasto en educación (a excepción de la educación terciaria) son progresivos en términos absolutos. El efecto de los impuestos directos sobre la desigualdad es positivo. Para 2009 el gasto social del Gobierno uruguayo constituía el 21,7 \% del PIB. Según los resultados arrojados por el estudio de Bucheli, Lustig, Rossu y Amábile, la política fiscal de Uruguay resulta ser efectiva a la hora de reducir los niveles de pobreza y desigualdad del país. Las variaciones encontradas entre el análisis de referencia y el de sensibilidad sugieren que las pensiones del Régimen Contributivo tienen un efecto significativo. Adicionalmente, se deben promover las transferencias directas ya que aparentemente son suficientes para sacar a los individuos de sus estados de pobreza moderada y extrema, aunque no logran erradicar la pobreza extrema.

En Bolivia las transferencias directas y los impuestos indirectos no afectan el nivel de desigualdad. El Gini permanece en 0,503. Las transferencias en especie en salud y educación reducen la desigualdad en 11,3\%. Los impuestos indirectos aumentan el nivel de pobreza total y extrema. Los impuestos en general son regresivos. Los subsidios a gas y gasolina tienen un efecto positivo sobre el nivel de desigualdad. Entre 2007 y 2009, el gasto social en Bolivia aumentó en $3 \%$ del PIB en principal medida gracias a la inserción de nuevos programas de transferencia directas y la expansión del régimen de pensiones no contributivo. No obstante, dicho aumento no tuvo mayor impacto redistributivo como consecuencia de los problemas de 
focalización de las transferencias (muchos recursos desviados a población por fuera del estado de pobreza) y su bajo monto per cápita.

En el caso de Brasil los impuestos directos disminuyen los niveles de desigualdad, y los impuestos indirectos no tienen efecto sobre el nivel de desigualdad. Las transferencias en especie son las más efectivas a la hora de reducir la desigualdad, después de las transferencias directas. Por otro lado, los impuestos directos disminuyen los niveles de pobreza y los impuestos indirectos aumentan la pobreza moderada y extrema. Brasil cuenta con buenos programas en contra de la pobreza, con amplia cobertura pero con transferencias per cápita bajas y mala focalización, ya que gran número de beneficiarios no hacen parte de la población en estado de pobreza. De igual forma, Higgings y Pereira concluyen que la reducción en pobreza y desigualdad lograda por la política fiscal del país es baja relativa al nivel de gasto social existente. Muestran que los fenómenos de fuga, exclusión y evasión pueden estar presentes. Existen programas bien diseñados y focalizados como los de transferencias, subsidios especiales, pensiones del régimen contributivo, educación y salud. Por el contrario, se deben mejorar los programas de beneficios al desempleo, becas y otras transferencias que son progresivos sólo en términos relativos. Por último, es esencial reformar la estructura de los impuestos indirectos que aumentan el nivel de pobreza, en especial en la canasta básica de alimentos.

Por otro lado, entre 2003 y 2009 el gasto social en Argentina aumentó en 7,6\% como parte de una reforma radical implantada por un régimen presidencial justicialista que tuvo por objetivo un plan redistributivo de gran escala. El cambio más significativo se dio entre 2006 y 2009 gracias a la implementación de un programa nuevo de pensiones no contributivo que redujo los niveles de pobreza y desigualdad. Dicho programa amplió la cobertura de 340 mil beneficiarios en 2003 a casi 3 millones de beneficiarios en 2009. Otro elemento con impacto pero en menor medida, fue el aumento de las transferencias en especie en salud y educación. El caso argentino presenta problemas relevantes. En primer lugar, a pesar de que el programa Moratoria Provisional tuvo efectos positivos al pasar del 9,3\% de la población recibiendo pensiones a un $47,8 \%$, generó distorsiones y se financió a un costo del $10 \%$ del PIB. Al financiar el programa en parte con recursos del régimen contributivo, y teniendo aumentos año a año menores frente al del régimen no contributivo, existen fuertes desincentivos a 
aportar al sistema formal. En segundo lugar, el caso de Argentina pone en tela de juicio la sostenibilidad de aquellas políticas con un efecto redistributivo importante dada la procedencia de sus fondos. Si estos recursos no son suficientes para cubrir el gasto social, el Gobierno opta por fuentes de financiación cada vez menos ortodoxas, poniendo en riesgo la sostenibilidad del sistema de transferencias y de la propia economía del país. Una recomendación de los autores es redireccionar esfuerzos a corregir el carácter regresivo de los subsidios indirectos para aportar a la sostenibilidad fiscal.

Finalmente en el caso de México al comparar los resultados de 2008 y 2010 se encuentra un aumento significativo de la capacidad del Estado para reducir la desigualdad, a pesar de haber tenido una disminución en los subsidios indirectos. Lo anterior demuestra una mejora en el nivel de progresividad del sistema fiscal y una baja efectividad de los subsidios indirectos frente a las transferencias directas. Los programas más progresivos y eficientes son las transferencias en especie y las transferencias en comida. Por el contrario, los subsidios al sistema de seguridad social para trabajadores públicos son regresivos e inequitativos. Las diferencias en la cobertura de ciertos programas como el régimen contributivo entre las áreas rural y urbana no reflejan problemas de focalización sino diferencias significativas en el nivel de ingreso de ambas. No obstante, se reconoce inefectividad en el sistema tributario y fallas en el diseño de algunos programas sociales.

De estos estudios a nivel de Colombia y América Latina se pueden destacar algunas tendencias generales obtenidas después de implementar un análisis de incidencia a la política social y fiscal en contextos de desarrollo. En primer lugar, es constante un efecto redistributivo importante de aquellos subsidios en especie enfocados hacia la formación de capital humano como es el caso de salud y educación. Se evidencia además un efecto muy bajo de la política de subsidios en servicios públicos domiciliarios sobre la distribución del ingreso. También se percibe un efecto muy bajo de las políticas de transferencias monetarias sobre la disminución de desigualdades, tal vez porque su objeto de política está más destinado a reducción de pobreza. Estos efectos diferenciados de los subsidios están explicados, en parte, por las capacidades de focalización de sus beneficiarios. En cuanto a los impuestos, el panorama para América Latina es desalentador en materia de efectos redistributivos, con alguna excepción como en el caso de Uruguay. En general, los impuestos son neutrales o en algunos contextos aumentan 
la desigualdad, hallazgos muy similares a los encontrados por Gallego et al. (2015) para el caso de Bogotá en el año 2011.

\section{Metodología para la identificación de subsidios y contribuciones}

Con el objeto de tener un análisis dinámico del balance financiero de los hogares bogotanos se parte de la información disponible en la Encuesta Multipropósito 2014 (EM2014), aplicada en la zona urbana de Bogotá D. C. y veinte (20) municipios de la Sabana: Soacha, Mosquera, Funza, Chía, Tocancipá, Cota, Sibaté, Cajicá, Madrid, Bojacá, Gachancipá, Sopó, Tenjo, Tabio, La Calera, Facatativá, Zipaquirá, Fusagasugá, Subachoque y El Rosal. Adicionalmente, se cuenta con información de once (11) cabeceras de provincia del departamento de Cundinamarca: Chocontá, Girardot, Guaduas, Villeta, Gachetá, San Juan de Ríoseco, Medina, Cáqueza, Pacho, La Mesa y Ubaté.

La encuesta contiene información de 20.518 hogares con 61.725 personas en Bogotá, y contiene información de 25.552 hogares y 80.845 personas residentes en municipios de Cundinamarca aledaños a Bogotá. Esta muestra es adecuada para una desagregación a nivel de localidad y estrato para Bogotá, y por estrato en los municipios y cabeceras de provincia de la Sabana de Bogotá. A partir de la información de la EM2014 se realizó la identificación de los rubros de gastos o servicios sobre los cuales los hogares e individuos reciben alguna clase de subsidio o asignación de aportes solidarios, y se calcularon los respectivos valores monetarios.

Metodológicamente para poder realizar un análisis de incidencia es fundamental identificar tanto los subsidios que reciben los hogares, como las contribuciones e impuestos que pagan. Para avanzar en este objetivo, un primer paso fue tipificar los subsidios, siguiendo características establecidas por la literatura o por su naturaleza misma. Para este efecto se clasificaron de acuerdo con tres tipologías, no excluyentes entre sí. Una primera tipología identifica los subsidios según el objetivo de la política social en dos aspectos generales: aquellos destinados a mejorar la formación de capital humano de los miembros del hogar (por ejemplo educación, salud, asistencia social, cuidado de los niños) y aquellos que buscan mejorar la infraestructura física del hogar (como son los servicios públicos domiciliarios y las ayudas a la compra y mejora de vivienda). Un segundo tipo de diferenciación 
depende de si la provisión es de carácter nacional, distrital o municipal. Esta precisión ayuda a entender los impactos redistributivos de los subsidios en bienes y servicios poniendo en evidencia las complementariedades entre los diferentes niveles de gobierno. Este enfoque permite tener una visión más integral de la política social. Finalmente, una tipología que considera el esfuerzo realizado por los residentes en Bogotá o demás municipios para financiar los subsidios. En este sentido, se tipifican subsidios financiados, en parte, con contribuciones directas dependiendo del uso o consumo del servicio, y otros subsidios financiados exclusivamente a través de presupuesto distrital, local o nacional.

Con el objeto de contar con el efecto completo de la política fiscal sobre la capacidad de pago del hogar, se adiciona al análisis las imputaciones o cálculos de los impuestos y contribuciones pagados por los hogares. En lo referente a impuestos, este estudio los diferencia según sean nacionales o locales. Es importante tener en cuenta la existencia de otras formas de clasificación, posiblemente más ilustrativas en un análisis tributario, como impuestos sobre el capital, impuestos sobre el ingreso o impuestos al consumo, pero sin un aporte al objetivo final de esta investigación.

\section{Resumen de los principales resultados}

A manera de resumen se presentan los resultados generales y las estadísticas más representativas sobre subsidios, contribuciones e impuestos, los cuales se discutirán con más detalle en los capítulos posteriores. La tabla 1.1 presenta los valores en millones de pesos de los ingresos corrientes (antes de la imputación), gastos corrientes, subsidios y contribuciones e impuestos del total de Bogotá para el valor mensual; además de discriminar por estrato y quintil de gastos. Es importante observar el aumento sustancial en la capacidad de generación de ingresos, y de mayor gasto, entre los años 2011 y 2014. Este aumento se relaciona con la dinámica de crecimiento experimentada en la ciudad. Es importante resaltar también el crecimiento significativo de los subsidios en el 2014. Esto se debe, en parte a las actualizaciones metodológicas en la imputación, y a la inclusión de subsidios de transporte y del mínimo vital de agua. Los subsidios netos totales imputados pasaron del $2 \%$ al $3 \%$ del ingreso corriente de los hogares. Por otra parte al desagregar el balance entre subsidios y contribuciones directas se observa para el 2014, unas transferencias a los hogares en Bogotá por cerca de 
328 mil millones de pesos mensuales. De este monto, un $40 \%$ se financió a través de diferentes formas de contribución. En el 2011 las transferencias fueron 223 mil millones de pesos, y los hogares financiaron el $60 \%$. La mayor parte de las contribuciones directas corresponden a los aportes de los hogares al sector salud. Aunque las cifras no sean exactamente comparables, es evidente un aumento importante en los subsidios. En particular, se resalta el crecimiento en los subsidios recibidos por los estratos 1,2 y 3 . Los cambios más significativos fueron el subsidio de mínimo vital de agua y los subsidios al SITP (Sistema Integrado de Transporte Público). Con respecto a los impuestos pagados por los hogares en Bogotá, entre el 2011 y el 2014 el aumento fue del $25 \%$.

Tabla 1.1. Impuestos, subsidios e ingresos. Valor mensual total expandido para Bogotá (millones de pesos de 2014)

\begin{tabular}{|c|c|c|c|c|c|c|c|c|}
\hline & \multicolumn{4}{|c|}{2014} & \multicolumn{4}{|c|}{2011} \\
\hline & $\begin{array}{l}\text { Ingreso } \\
\text { corriente }\end{array}$ & $\begin{array}{l}\text { Gasto } \\
\text { corriente }\end{array}$ & Subsidios & Impuestos & $\begin{array}{c}\text { Ingreso } \\
\text { corriente }\end{array}$ & $\begin{array}{l}\text { Gasto } \\
\text { corriente }\end{array}$ & Subsidios & Impuestos \\
\hline Total & 6.770 .048 & 7.879 .522 & 196.421 & 371.076 & 5.344 .572 & 5.667 .440 & 81.729 & 292.375 \\
\hline \multicolumn{9}{|c|}{ Por estratos socioeconómicos para Bogotá } \\
\hline Estrato 1 & 275.592 & 385.278 & 72.725 & 10.140 & 180.962 & 210.226 & 50.853 & 7.748 \\
\hline Estrato 2 & 1.570 .246 & 2.005 .120 & 217.631 & 64.003 & 1.143 .360 & 1.338 .726 & 161.936 & 56.197 \\
\hline Estrato 3 & 2.432 .832 & 2.949 .738 & 37.201 & 121.913 & 1.895 .053 & 2.099 .455 & 10.172 & 103.007 \\
\hline Estrato 4 & 1.263 .337 & 1.284 .655 & $(55.638)$ & 65.049 & 1.205 .340 & 1.138 .112 & $(70.225)$ & 67.393 \\
\hline Estrato 5 & 613.529 & 647.169 & $(37.422)$ & 36.556 & 460.035 & 426.180 & $(33.320)$ & 27.238 \\
\hline Estrato 6 & 614.513 & 607.562 & $(38.076)$ & 73.414 & 459.822 & 454.742 & $(37.687)$ & 30.793 \\
\hline \multicolumn{9}{|c|}{ Por quintiles de gasto para Bogotá } \\
\hline Quintil 1 & 430.631 & 482.309 & 104.393 & 19.235 & 160.831 & 535.709 & 93.991 & 19.733 \\
\hline Quintil 2 & 658.467 & 820.569 & 114.051 & 31.875 & 392.082 & 663.689 & 88.125 & 25.947 \\
\hline Quintil 3 & 987.614 & 1.163 .573 & 84.230 & 44.325 & 632.416 & 871.401 & 66.702 & 37.401 \\
\hline Quintil 4 & 1.465 .128 & 1.722 .959 & 26.518 & 67.027 & 1.065 .627 & 1.241 .995 & 20.240 & 59.630 \\
\hline Quintil 5 & 3.228 .207 & 3.690 .113 & $(132.771)$ & 208.614 & 3.151 .652 & 2.421 .925 & (187.329) & 152.331 \\
\hline
\end{tabular}

Fuente: EM2014, cálculos de los autores. 
En términos generales, los subsidios en salud y educación son los componentes más importantes en la política social, y no sólo en sus montos de balance total mensual, sino también en el impacto sobre el ingreso del hogar y la desigualdad del ingreso en Bogotá, como se verá más adelante. En cuanto a los servicios públicos domiciliarios, a pesar de estar en el centro del debate por problemas de eficiencia técnica del mecanismo utilizado para su focalización, como lo es la estratificación socioeconómica, siguen teniendo una representatividad significativa en montos a nivel global de Bogotá (Sepúlveda, López y Gallego, 2014).

La tabla 1.2 presenta los montos de subsidios netos por tipo de subsidio para el año 2014. De la tabla 1.2 se observa para el 2014, a precios corriente, un estimado mensual de los subsidios netos recibidos por los hogares bogotanos de 196.4 mil millones de pesos.

Tabla 1.2. Subsidios netos mensuales. Total Bogotá (millones de pesos de 2014)

\begin{tabular}{|c|c|c|}
\hline & Subsidios netos mensuales (\$) & Porcentaje (\%) \\
\hline Capital humano & 68.132 & \multirow{5}{*}{35} \\
\hline Salud & $(120.467)$ & \\
\hline Educación & 177.384 & \\
\hline Familias en acción nutrición & 4.645 & \\
\hline Jardín & 6.570 & \\
\hline Servicios Públicos & 74.135 & \multirow{4}{*}{38} \\
\hline AAA & 36.791 & \\
\hline Energía & 29.912 & \\
\hline Gas Natural & 7.432 & \\
\hline Vivienda & 9.970 & 5 \\
\hline Transporte & 44.183 & 22 \\
\hline Total & 196.421 & 100 \\
\hline
\end{tabular}

Fuente: EM2014, cálculos de los autores.

El 35\%, es decir, cerca de 68 mil millones de pesos mensuales, fueron destinados a la formación de capital humano. Estos subsidios se dividen en 120 mil millones en contribuciones netas destinadas a financiar el sistema de salud (es decir los hogares en Bogotá son contribuyentes netos al sistema de 
salud nacional), 177 mil millones en subsidios encaminados a la provisión de la educación pública de los miembros más jóvenes del hogar inscritos en educación básica primaria, secundaria y media, y en montos menores de 4.6 mil millones en Familias en Acción componente de nutrición, y 6.5 mil millones de pesos en cuidado de los niños. Por otra parte, el componente de servicios públicos domiciliarios representa el $38 \%$ de los subsidios netos recibidos por los hogares en Bogotá, de los cuales 37 mil millones son provisiones de servicios en acueducto, alcantarillado y aseo, 30 mil millones se destinan a energía y el resto es para gas. Los subsidios en vivienda representaron el $5 \%$, y los subsidios en transporte al SITP correspondieron al $22 \%$ de los subsidios netos recibidos por los hogares en Bogotá. Este último rubro se implementó en 2014, y se midió por primera vez con esta encuesta.

De las estadísticas anteriores se puede entender que los hogares en Bogotá realizan esfuerzos importantes por financiar, especialmente, las contribuciones en salud. La contribución de los hogares a la financiación de los otros subsidios es menos clara. Esto representa retos de focalización adecuada de subsidios, y demanda esfuerzos sustanciales en términos de financiación de la política social que finalmente deben impactar el esquema tributario al cual se enfrentan estos mismos hogares. Esta discusión sobre cuánto del costo de la provisión del servicio se recauda por consumo directo de los hogares plantea una reflexión acerca de las diferentes formas de justicia social posibles en una sociedad. En la mayoría de los países desarrollados, el criterio de justicia social se expresa en la oferta prioritaria de bienes y servicios a los más vulnerables, con financiación a través de impuestos generales. Sin embargo, para el caso colombiano los arreglos sociales son diferentes, y la justicia social se presenta en el consumo y uso de cada uno de los servicios donde se pretende proveer, por lo tanto, se observan escenarios de solidaridad para muchos de los servicios, implementados por medio de subsidios y contribuciones directas.

La tabla 1.2 muestra dos resultados estadísticos para destacar: primero, los hogares en Bogotá son contribuyentes netos al sistema de seguridad social en salud, es decir, cubren el costo de los subsidios con derecho a recibir por su aseguramiento al sistema, y, además, ayudan con una contribución neta a la cuenta de solidaridad del sistema nacional. En general contribuyen con 
120 mil millones de pesos mensuales generando un balance positivo en el esquema redistributivo del sistema de salud en Bogotá. Un segundo aspecto para resaltar es la situación contraria de los subsidios en servicios públicos domiciliarios. Los hogares bogotanos son subsidiados netos, y las contribuciones no alcanzan a recuperar los respectivos subsidios. En promedio, para todos los servicios públicos domiciliarios, los hogares de estrato 5 y 6 solo cubren el $12 \%$ de los subsidios que reciben los hogares en estratos 1, 2 y 3 . La razón ha sido ampliamente expuesta por diferentes académicos en los últimos años y reforzada recientemente para el caso de Bogotá por Sepúlveda et al. (2015) y Gallego et al. (2015), quienes calculan altos errores de inclusión que hacen fiscalmente inviable el sistema de estratificación actual como mecanismo de asignación de subsidios cruzados.

De las estadísticas antes mencionadas, podemos dejar un mensaje importante para desarrollar con mayor en detalle en los capítulos posteriores. A lo largo de diferentes estudios, la nueva actualización de la información para Bogotá muestra problemas importantes en la focalización en SPD, con números significativos de hogares beneficiarios con alta capacidad de pago (Meléndez, 2008; Econometría, 2008; Parra, 2011; Sepúlveda et al., 2014; Gallego et al., 2015). No obstante, a pesar de los errores de inclusión, para los más pobres, estos subsidios tienen un efecto local importante sobre sus ingresos, llegando a representar valores cercanos al $11 \%$ para el quintil más pobre, generando una discusión sobre la efectividad de la focalización, pero no sobre el subsidio, pues, para aquellos realmente necesitados, representa un porcentaje significativo de su capacidad de pago.

La tabla 1.3 presenta los valores de los impuestos mensuales pagados por todos los hogares en Bogotá para el año 2014. Como se mencionó anteriormente, se estimaron e imputaron los impuestos de vehículos, renta y complementarios, predial e IVA, resultando un monto mensual de 369 mil millones de pesos de 2014. La primera columna muestra el valor total de cada impuesto. Se resalta el IVA como el de mayor contribución al recaudo de la ciudad (76\%), con un monto mensual de 283 mil millones de pesos. Le sigue en importancia el predial, con un valor de 44 mil millones, después el impuesto a vehículos con un recaudo de cerca de 21 mil millones y, finalmente, el impuesto a la renta con un valor de 20 mil millones. 
Tabla 1.3. Impuestos mensuales totales pagados en Bogotá (millones de pesos de 2014)

\begin{tabular}{lccc}
\hline & Valor total (\$) & $\begin{array}{c}\text { Porcentaje del total } \\
(\%)\end{array}$ & $\begin{array}{c}\text { Porcentaje de hogares } \\
\text { contribuyen (\%) }\end{array}$ \\
\hline Vehículos & 20.809 & 6 & 17 \\
\hline Predial & 44.701 & 12 & 48 \\
\hline Renta y complementarios & 20.451 & 6 & 14 \\
\hline IVA & 283.289 & 76 & \\
\hline Total & 369.250 & 100 & \\
\hline
\end{tabular}

Fuente: EM2014, cálculos de los autores.

La columna 3 muestra el porcentaje de hogares contribuyentes. La observación más importante es el pago del $100 \%$ del IVA por parte de los hogares bogotanos, lo que permite suponer que no hay evasión de este tributo. Por el contrario, el impuesto a la renta lo pagan sólo el $14 \%$. Este porcentaje es muy superior al calculado en el 2011 por Gallego et al. (2015), y muestra un potencial para mejorar tanto el nivel de recaudo a través de renta, como la regresividad del esquema impositivo actual. El impuesto predial es pagado por el $48 \%$ de los hogares, y el impuesto por vehículos o rodamiento por el $17 \%$ de los hogares.

El objetivo de todas estas estadísticas es poder entender si realmente la política social y la tributaria mueven la distribución del ingreso. En la gráfica 1.1 se ilustra la curva de Lorenz del ingreso antes de la acción pública (línea roja oscura), después de imputar los subsidios recibidos (línea amarilla) y luego de adicionar a esto último los impuestos (línea verde). La línea azul (de 45 grados) representa una distribución del ingreso totalmente equitativa. Como habitualmente se lee, entre más cerca estén las curvas de Lorenz de la línea azul, mejor es la distribución del ingreso.

El resultado más importante a destacar es la contribución de la política fiscal en reducir en 8,6\% el índice de Gini cuando se calcula la capacidad de pago de los hogares en Bogotá. Este porcentaje es del 6,0\% para los municipios de la Sabana de Bogotá y Cundinamarca. El resultado es valioso al mostrar una mejora en el efecto redistributivo de la política fiscal en la capital colombiana. En estimaciones anteriores, como la de Gallego et al. (2015) con datos de la EMB2011, el efecto estimado se aproxima al $1 \%$ sobre el Gini, explicado principalmente por una baja efectividad redis- 
tributiva de los subsidios netos y alta regresividad de impuesto como el IVA. Para el 2014, el IVA sigue siendo regresivo, aumentando el coeficiente de Gini en 0,4\% pero muy por debajo del 1,4\% estimado en el 2011. También se destaca el aporte progresivo de todo el esquema impositivo para Bogotá, el cual reduce el Gini en 1,9\%. Estos resultados muestran un avance en la capacidad redistributiva de los diferentes instrumentos fiscales a través de subsidios, contribuciones e impuestos, pero aún con capacidad de avances respecto al contexto internacional.

Gráfica 1.1. Curva de Lorenz del ingreso por tipo de instrumento de política fiscal

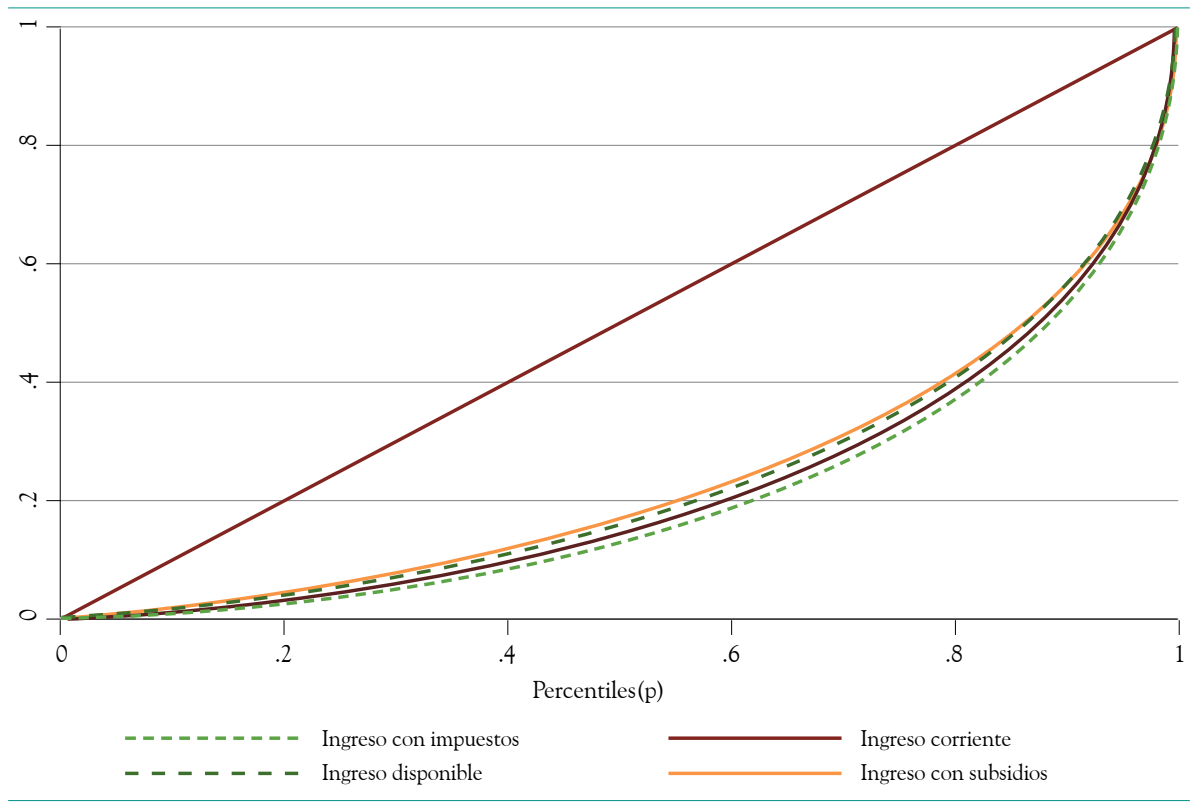

Fuente: EM2014, cálculos de los autores.

\section{Organización y estructura del libro}

Los capítulos siguientes desarrollarán más en detalle las dinámicas que en términos de redistribución del ingreso tiene la política social y tributaria en Bogotá y realizarán un comparativo con los otros municipios cercanos incluidos en la EM2014. El capítulo 2 desarrolla un análisis de condiciones de vida y pobreza y compara a Bogotá con el resto de municipios. En este capítulo se exponen brevemente las políticas sociales aplicadas por los gobiernos distritales, con el fin de contextualizar el marco de estudio. El capítulo 3, por su parte, presenta la metodología de análisis de incidencia 
desarrollada para identificar subsidios, contribuciones e impuestos en la base de datos. Este capítulo sigue la metodología planteada sobre análisis de incidencia. En el capítulo 4 se presentan las estadísticas descriptivas más generales del estudio, donde se analiza en más detalle el balance neto de los hogares en Bogotá por ubicación geográfica en localidades, por quintiles de ingreso y por estrato. En el capítulo 5 se calcula el efecto redistributivo de cada subsidio e impuesto y del consolidado de la acción del Estado a través de políticas sociales y tributarias. Y finalmente en el capítulo 6 se realiza un ejercicio de econometría espacial para observar si existe un efecto espacial en la capacidad redistributiva de los municipios cercanos a Bogotá considerados en la encuesta. 


\section{Capítulo 2 La política social y tributaria: descripción de los principales componentes}

Los retos de las administraciones distritales frente a las problemáticas sociales han incentivado, en las últimas décadas, el desarrollo de políticas sociales inclusivas y participativas, inmersas en los respectivos planes de desarrollo de la ciudad. Estas herramientas se han complementado además con programas y proyectos de carácter nacional, planteando la necesidad de una coordinación entre los diferentes niveles del Estado. Adicionalmente, las relaciones de la ciudad con los municipios de la región son cada vez más fuertes, y por ello es necesario hacer una revisión de la problemática social en estos municipios.

El objetivo de este capítulo es identificar y describir los principales mecanismos de focalización del gasto social. Se muestra, además, cómo afectan a los hogares y cuál es su incidencia en los ingresos. En el ejercicio analítico se le da especial importancia a la salud, los servicios públicos domiciliarios y la educación. El gasto en salud y educación básica fortalece el capital humano, y ello se refleja en mejoras en la productividad y en las condiciones de vida de las personas. Además, la educación y la salud favorecen el ejercicio de la libertad de los individuos. El gasto social en servicios públicos domiciliarios posibilita a los ciudadanos pobres un consumo vital mínimo, y les libera ingresos para consumir otros bienes y servicios. 


\section{Gasto público social con un propósito}

El gasto público social (GPS) debe tener como propósito mejorar las condiciones de vida de los ciudadanos, brindándoles la posibilidad de acceder a las oportunidades económicas y sociales. Dado el alto número de hogares en situación de desventaja, el gasto social se convierte en un instrumento privilegiado para ampliar el espacio de las capacidades de los individuos. En esta sección se muestra cómo la política fiscal, que incluye los impuestos y los subsidios, ha incidido en las condiciones de vida de los hogares de los bogotanos, y de los municipios cercanos a la ciudad que fueron considerados en la EM2014.

\section{Evolución de las condiciones de vida en Bogotá}

Desde el punto de vista de la pobreza monetaria, el Distrito Capital pasó de tener el $32 \%$ de su población con ingresos por debajo de la línea de pobreza en 2002 a ubicarse en el $13 \%$ en 2011 y en el $10 \%$ en 2014. Solamente la ciudad de Bucaramanga presenta un menor nivel de incidencia de la pobreza, y una disminución mayor a la que tuvo Bogotá en los periodos de análisis (gráfica 2.1). Resultados similares se encuentran a partir de la medición de pobres extremos, quienes pasaron de representar el 7,1\% de los bogotanos en 2002 a niveles tan bajos como el $2 \%$ en 2011 y 2014. Comparando estos datos con los promedios nacionales, la incidencia de la pobreza en Colombia disminuyó del 49,7 \% en 2002 al 28,5\% en 2014. La pobreza extrema, por su parte, disminuyó casi en 10 puntos porcentuales en ese periodo, al pasar de $17,7 \%$ en 2002 a $8,1 \%$ en 2014 .

Utilizando el grupo de medidas subjetivas, al preguntarles a los jefes de hogar sobre su condición de pobreza (tabla 2.1), se mantiene la dinámica positiva captada en las medidas anteriores. Entre 2003 y 2014, los hogares considerados pobres cayeron en 23 puntos porcentuales, disminuyendo del 46,6\% al 23,03\%. Las reducciones más significativas en la percepción de pobreza se presentaron en los estratos bajos. El porcentaje de jefes de hogar en estratos 1 y 2 considerados pobres disminuyó en 30 puntos porcentuales entre 2003 y 2014, mientras en el estrato 3 la caída fue de 25 puntos porcentuales. Al final del periodo, algo más de un tercio de las familias en estratos bajos y un quinto en estrato 3 aún se consideraban pobres. Entre 2011 y 2014 la disminución del número de hogares que se consideran pobres fue de 2 puntos porcentuales. 
Gráfica 2.1. Evolución de la pobreza monetaria en cinco ciudades de Colombia, 2002-2014

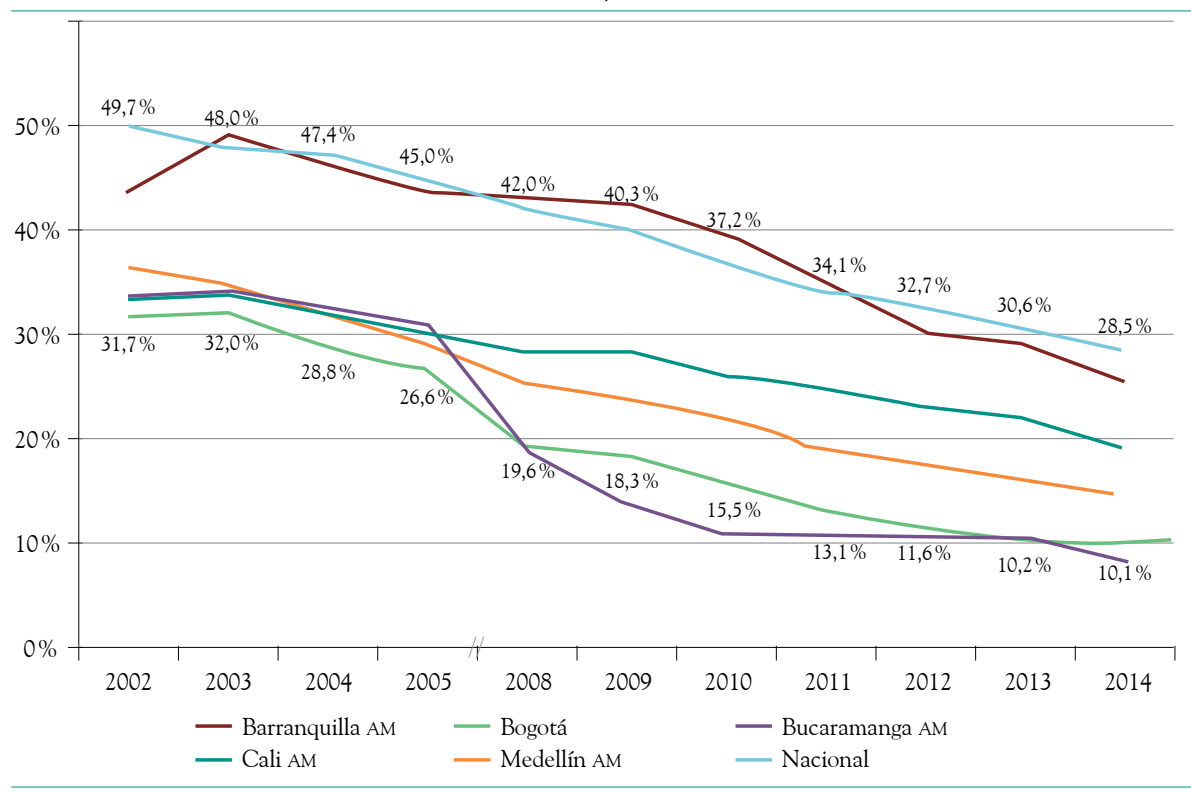

Datos no disponibles para 2006 y 2007

Fuente: DANE, cálculos de los autores.

Tabla 2.1. Opinión del jefe o del cónyuge respecto a si se considera pobre en Bogotá (porcentaje)

\begin{tabular}{ccccc}
\hline Estrato & 2003 & 2007 & 2011 & 2014 \\
\hline 1 y 2 & 61,90 & 49,30 & 33,00 & 32,01 \\
\hline 3 & 44,30 & 32,70 & 21,50 & 19,05 \\
\hline 4 & 20,60 & 11,00 & 7,10 & 6,14 \\
\hline 5 y 6 & 11,40 & 4,60 & 4,00 & 2,89 \\
\hline Total & 46,60 & 36,70 & 25,20 & 23,03 \\
\hline
\end{tabular}

Fuentes: DAPD 2004, ECV 2003, SDP ECV 2007, EMB 2011, EM2014.

El avance en reducción de la pobreza se confirma al analizar la percepción de los bogotanos sobre su situación económica y de calidad de vida. Comparando los datos de las encuestas de calidad de vida y multipropósito realizadas en la ciudad entre 1997 y 2014, se resaltan varios elementos respecto a la mejora en la percepción de los jefes de hogar sobre si sus ingresos llegan a cubrir los gastos mínimos (tabla 2.2). En primer lugar, se tiene una marcada mejoría, fundamentalmente entre los años 2003 y 2007. Entre 
1997 y 2003, en los diferentes estratos, la percepción sobre la capacidad de pago no varió fuertemente. Por ejemplo, entre 1997 y 2003, en los estratos 1 y 2 , el porcentaje de quienes consideraban que sus ingresos solamente alcanzaban para cubrir los gastos mínimos se redujo dos puntos, y pasó de $55,1 \%$ a $53,1 \%$. En general, los cambios fueron relativamente suaves.

Tabla 2.2. Opinión del jefe o del cónyuge sobre los ingresos de su hogar

\begin{tabular}{|c|c|c|c|c|c|}
\hline & 1 y 2 & 3 & 4 & 5 y 6 & Total \\
\hline \multicolumn{6}{|c|}{1997} \\
\hline No alcanza & 41,0 & 28,6 & 9,2 & 6,1 & 28,2 \\
\hline Solo alcanza a cubrir los gastos mínimos & 55,1 & 59,2 & 60,7 & 42,3 & 56,8 \\
\hline Cubren más que los gastos mínimos & 3,8 & 12,2 & 30,1 & 51,6 & 15,1 \\
\hline \multicolumn{6}{|c|}{2003} \\
\hline No alcanza & 42,0 & 27,0 & 13,4 & 7,6 & 30,3 \\
\hline Solo alcanza a cubrir los gastos mínimos & 53,1 & 62,1 & 58,1 & 53,6 & 57,4 \\
\hline Cubren más que los gastos mínimos & 4,9 & 10,9 & 28,5 & 38,8 & 12,3 \\
\hline \multicolumn{6}{|c|}{2007} \\
\hline No alcanza & 33,5 & 20,5 & 8,6 & 4,3 & 24,5 \\
\hline Solo alcanza a cubrir los gastos mínimos & 58,2 & 61,0 & 47,6 & 36,1 & 56,8 \\
\hline Cubren más que los gastos mínimos & 8,3 & 18,4 & 43,8 & 59,5 & 18,6 \\
\hline \multicolumn{6}{|c|}{2011} \\
\hline No alcanza & 26,3 & 17,1 & 5,7 & 4,7 & 20,1 \\
\hline Solo alcanza a cubrir los gastos mínimos & 62,2 & 57,1 & 41,5 & 29,5 & 57,0 \\
\hline Cubren más de los gastos mínimos & 11,6 & 25,8 & 52,7 & 65,8 & 22,9 \\
\hline \multicolumn{6}{|c|}{2014} \\
\hline No alcanza & 21,9 & 11,7 & 4,1 & 2,2 & 15,3 \\
\hline Solo alcanza a cubrir los gastos mínimos & 65,2 & 59,0 & 41,8 & 25,9 & 58,3 \\
\hline Cubren más de los gastos mínimos & 12,9 & 29,3 & 54,1 & 71,8 & 26,4 \\
\hline
\end{tabular}

Fuentes: ECV 1997, ECV 2003, SDP ECV 2007, EMB 2011, EM2014.

Entre 2003 y 2014, la dinámica es positiva y diferente respecto a los años anteriores. En todos los estratos socioeconómicos se redujo la proporción de 
quienes no alcanzaban a cubrir sus gastos mínimos y aumentó la de quienes sobrepasan dichos gastos. El mayor avance ocurrió entre 2003 y 2007, pero el crecimiento positivo se mantuvo hasta 2014. A lo largo de ese periodo (2003-2014), para los estratos más bajos (1 y 2), el porcentaje de quienes no cubrían lo mínimo disminuyó en 20 puntos porcentuales. A su vez en los estratos altos (5 y 6), quienes cubrían más de lo mínimo requerido, se incrementaron en 30 puntos porcentuales. Entre 2011 y 2014 en los estratos bajos el porcentaje de quienes consideran que los ingresos no cubrían los gastos mínimos bajó en 4 puntos porcentuales, mientras que en los estratos altos el porcentaje de los que consideran que los ingresos son más que suficientes para cubrir los gastos mínimos aumentó en 3,5 puntos porcentuales. Estos datos muestran, con claridad, que los hogares perciben una mejora en su situación económica.

Respecto a la opinión frente a la calidad de vida general de la ciudad, el $83,2 \%$ de los jefes de hogar la consideraban buena $(68,9 \%)$ o muy buena $(14,3 \%)$ en 2014, y solo el 1,1\% opinaba que era mala. Entre los años 2011 y 2014, se observa un avance significativo frente a los años anteriores. Para los hogares de los estratos 1 y 2, por ejemplo, entre el 2011 y el 2014, quienes consideraban a Bogotá con buena o muy buena calidad de vida aumentó 5 puntos porcentuales, ubicándose en el 76,7\%. El progreso en estratos altos se evidencia en la 'muy buena' percepción, con un incremento del 43,4\% en 2011 a 49,1\% en 2014 (casi 6 puntos porcentuales).

Estos avances en pobreza (objetiva y subjetiva), y en la percepción de los ciudadanos contrastan con el alto nivel de desigualdad que presenta la ciudad. Al estimar el promedio de desigualdad del ingreso (Gini), entre 2002 y 2014, Bogotá y Medellín son las ciudades con mayor desigualdad. En el 2014, tomando el grupo de 24 ciudades más grandes del país, el Gini de Bogotá de 0,51 sólo es superado por Medellín, Quibdó y Riohacha. Ni en Bogotá, ni en el conjunto del país, la política fiscal, entendida como el balance neto entre impuestos y subsidios, logra modificar el Gini. Mientras que en países como Bélgica la política fiscal modifica el Gini, que pasa de 0,5 a 0,2, en Colombia la distribución apenas se modifica en milésimas. Se podría decir que, lo que recibe un hogar a través de programas como Familias en Acción, se le quita a través de impuestos regresivos como el IVA. 


\section{Política social en Bogotá y su impacto en la pobreza y la desigualdad}

El Distrito Capital se caracteriza por tener una amplia gama de programas de ayuda social, que van desde seguridad alimentaria hasta apoyo a la población en condición de vulnerabilidad. Más específicamente, el esfuerzo social del gobierno local se enfoca, entre otros programas, en servicios públicos domiciliarios, educación, salud, movilidad intraurbana, protección a grupos en situación de vulnerabilidad.

El enfoque social se ha plasmado en planes de desarrollo durante las últimas décadas: a) 1995-1998: Formar ciudad; b) 1998-2001: Por la Bogotá que queremos; c) 2001-2004: Bogotá para vivir todos del mismo lado, d) 2004-2008: Bogotá sin indiferencia, e) 2008-2012: Bogotá Positiva y f) 2012-2016: Bogotá Humana. En este último plan se consolidaron varios programas conducentes a mejorar la calidad de vida, la situación de pobreza y la desigualdad en la ciudad. El plan de desarrollo actual Bogotá mejor para todos, aunque no forma parte del periodo de análisis en los datos de este libro, ha mantenido de igual forma los diferentes instrumentos sociales que se han venido construyendo a lo largo de diversas políticas distritales y de este modo los resultados que se presenten en este estudio pueden servir como marco de referencia para el desarrollo y continuación de las políticas fiscales que se promuevan durante el plan distrital actual.

A pesar del esfuerzo explícito por implementar acciones para reducir brechas sociales, poco son los estudios sobre el alcance de la política social de Bogotá y el impacto que ha tenido el gasto público social (GPS) sobre la pobreza y la desigualdad del ingreso. Dos estudios realizados en el 2005 y el 2012 han cuantificado dicha incidencia: el primero lo hizo la Contraloría de Bogotá para el periodo 1994-2004. Los autores encontraron que en 1994 el 20\% más pobre de la ciudad participaba solamente del 4,37\% del ingreso, mientras que el $20 \%$ más rico participaba del 54,9\% del ingreso. Cinco años más tarde, la desigualdad del ingreso se acentuaba aún más. El quintil más pobre de la ciudad solo alcanzaba el 3,7 \% del ingreso, mientras el quintil más rico obtenía el 55,4\%. Al final del periodo de estudio (2004), la situación continuaba agravándose con porcentajes del ingreso de los quintiles inferior y superior del 3,6\% y 55,9\% respectivamente. El estudio de la Contraloría de Bogotá de 2005 mostró una tendencia creciente de la participación del GPS en el gasto total. En el año 1994, la relación era de 
16,2\%, mientras en plena recesión económica del año 1999 el porcentaje se duplicó, ascendiendo al 35,7 \%. En el 2004 la participación del gasto social en el gasto total se ubicó en el 51,1\%. Durante el periodo 1994-2004 la tasa media de crecimiento del GPS fue del $14 \%$.

En un segundo trabajo, realizado en el 2012, la misma Contraloría Distrital ilustra la continuación de la tendencia creciente de la participación del GPS en el presupuesto de la ciudad, pasando del 50,5\% en 2003 al 66,4\% en 2010, con un pico del 70,9\% en 2009. Esta composición del gasto social se dirigió principalmente a la educación, con un promedio de participación en el periodo del $36 \%$, seguida por los gastos en vivienda (incluyen los subsidios a los SPD) con un $28 \%$, y salud con un $20 \%$.

Por otro lado, la relación entre el GPS y la distribución del ingreso ha sido disímil entre 1996 y 2009. Entre 1997 y 2004 se evidencia una estrecha relación positiva entre desigualdad y GPS, mientras a partir de 2005 la relación se rompe y el GPS presenta una pendiente positiva mucho más pronunciada respecto al leve aumento de la desigualdad. Dado lo anterior, se podría pensar que las recientes políticas de gasto no han tenido una influencia tan fuerte sobre la desigualdad.

\section{Política social y tributaria en los municipios aledaños}

En la Encuesta Multipropósito de 2014 se identifica, además de la información del Distrito Capital, la de veinte (20) municipios de la Sabana (Soacha, Mosquera, Funza, Chía, Tocancipá, Cota, Sibaté, Cajicá, Madrid, Bojacá, Gachancipá, Sopó, Tenjo, Tabio, La Calera, Facatativá, Zipaquirá, Fusagasugá, Subachoque y El Rosal), y la de once (11) cabeceras de provincia del departamento de Cundinamarca (Chocontá, Girardot, Guaduas, Villeta, Gachetá, San Juan de Ríoseco, Medina, Cáqueza, Pacho, La Mesa y Ubaté). Entre estos municipios y Bogotá se llevan a cabo algunos proyectos de alcance regional.

Con el fin de tener un contexto general, se analiza la participación de los ingresos tributarios, aquellos que son de capacidad de gestión de las entidades territoriales, en los ingresos totales para los 31 municipios. En la gráfica 2.2 se observa la evolución desde el año 2002 hasta el año 2012, mostrando una tendencia ligeramente creciente. También se muestra la participación del impuesto predial agregado para estos 31 municipios, resaltando este rubro como el de mayor aporte dentro de los ingresos de los municipios. 
Gráfica 2.2. Porcentaje de los ingresos tributarios y predial sobre ingresos totales (31 municipios, sin Bogotá)

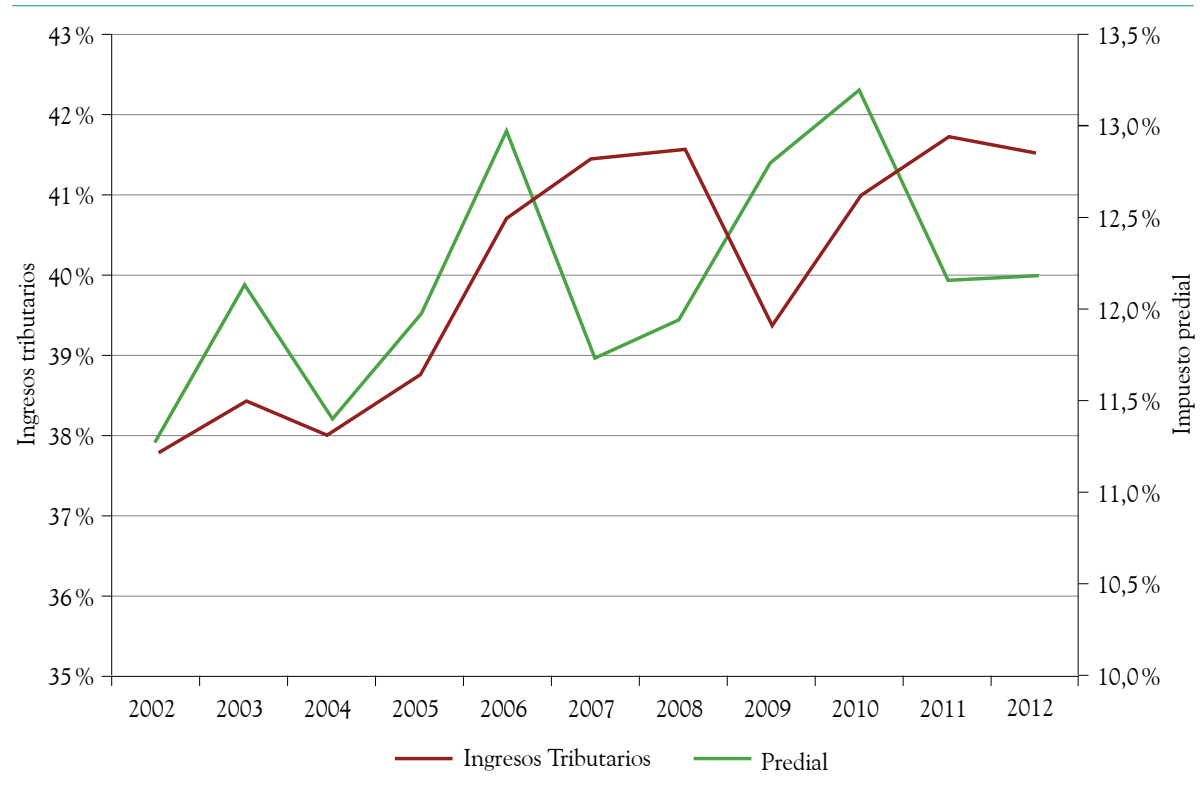

Fuente: ejecuciones presupuestales, Formulario Único Territorial (FUT), DNP.

La tendencia de la gráfica muestra pocos esfuerzos por aumentar los ingresos propios. Cuando la participación de los ingresos propios aumenta, las condiciones de vida de los municipios suelen mejorar. El municipio donde los ingresos tributarios representan mayor porcentaje de los ingresos es Cota donde este rubro corresponde al 86,6\% en 2014 y presenta uno de los niveles de pobreza monetaria más bajos (12,5\%). De otro lado, se observa que en Medina, Gachetá y San Juan de Rioseco los ingresos tributarios representan no más del 10\% de sus ingresos totales (tabla 2.3), mientras que estos mismos tres municipios presentan los niveles más altos de pobreza monetaria $(60,6 \%, 37,8 \%$ y $52,1 \%$ respectivamente). En general, en el país los impuestos prediales de los municipios son bajos. En parte por el notable atraso de los avalúos catastrales y, en parte, por la denominada "pereza" fiscal de los entes territoriales.

En términos de la política social se observa que la población de los 31 municipios representa cerca del $2 \%$ de la población atendida en los programas sociales que impulsa el gobierno. Particularmente existen 50.211 beneficiarios del programa Más Familias en Acción, 4.720 del programa 
Jóvenes en Acción, 22.759 del programa De Cero a Siempre y 30.997 del programa Colombia Mayor.

Tabla 2.3. Participación de los ingresos tributarios en los ingresos totales del municipio

\begin{tabular}{|c|c|c|c|c|c|c|}
\hline \multirow[b]{2}{*}{ Municipio } & \multicolumn{3}{|c|}{2011 (millones constantes de 2014) } & \multicolumn{3}{|c|}{2014 (millones de \$) } \\
\hline & $\begin{array}{l}\text { Ingresos } \\
\text { totales }\end{array}$ & $\begin{array}{l}\text { Ingresos } \\
\text { tributarios }\end{array}$ & $\%$ & $\begin{array}{c}\text { Ingresos } \\
\text { totales }\end{array}$ & $\begin{array}{l}\text { Ingresos } \\
\text { tributarios }\end{array}$ & $\%$ \\
\hline Cota & 66.572 & 57.267 & $86,0 \%$ & 89.524 & 77.484 & $86,6 \%$ \\
\hline Sopó & 25.391 & 17.785 & $70,0 \%$ & 28.185 & 20.526 & $72,8 \%$ \\
\hline Funza & 46.117 & 31.935 & $69,2 \%$ & 88.816 & 56.152 & $63,2 \%$ \\
\hline La Calera & 16.934 & 10.764 & $63,6 \%$ & 27.911 & 16.139 & $57,8 \%$ \\
\hline Madrid & 35.941 & 22.288 & $62,0 \%$ & 52.461 & 33.229 & $63,3 \%$ \\
\hline Cajicá & 48.006 & 29.369 & $61,2 \%$ & 74.811 & 39.701 & $53,1 \%$ \\
\hline Sibaté & 23.004 & 13.265 & $57,7 \%$ & 31.127 & 15.985 & $51,4 \%$ \\
\hline Tenjo & 34.264 & 19.344 & $56,5 \%$ & 49.846 & 30.507 & $61,2 \%$ \\
\hline Mosquera & 79.555 & 44.660 & $56,1 \%$ & 115.622 & 65.939 & $57,0 \%$ \\
\hline Chía & 105.222 & 54.580 & $51,9 \%$ & 125.303 & 69.393 & $55,4 \%$ \\
\hline Subachoque & 9.119 & 4.200 & $46,1 \%$ & 12.530 & 4.993 & $39,8 \%$ \\
\hline Tocancipá & 98.681 & 41.296 & $41,8 \%$ & 84.660 & 54.047 & $63,8 \%$ \\
\hline La Mesa & 20.211 & 7.904 & $39,1 \%$ & 34.539 & 9.065 & $26,2 \%$ \\
\hline Villeta & 14.345 & 5.520 & $38,5 \%$ & 27.183 & 6.401 & $23,5 \%$ \\
\hline Gachancipá & 9.377 & 3.453 & $36,8 \%$ & 27.053 & 6.560 & $24,2 \%$ \\
\hline Facatativá & 79.105 & 29.059 & $36,7 \%$ & 104.427 & 36.615 & $35,1 \%$ \\
\hline Tabio & 9.374 & 3.424 & $36,5 \%$ & 16.442 & 8.204 & $49,9 \%$ \\
\hline Villa de San Diego de Ubaté & 21.066 & 6.990 & $33,2 \%$ & 35.079 & 7.576 & $21,6 \%$ \\
\hline Girardot & 86.068 & 28.303 & $32,9 \%$ & 107.861 & 39.893 & $37,0 \%$ \\
\hline El Rosal & 10.447 & 3.284 & $31,4 \%$ & 12.636 & 4.572 & $36,2 \%$ \\
\hline Zipaquirá & 84.961 & 26.093 & $30,7 \%$ & 109.100 & 32.761 & $30,0 \%$ \\
\hline Fusagasugá & 84.177 & 20.896 & $24,8 \%$ & 127.951 & 37.077 & $29,0 \%$ \\
\hline Soacha & 238.071 & 57.329 & $24,1 \%$ & 292.955 & 66.342 & $22,6 \%$ \\
\hline Guaduas & 18.871 & 4.322 & $22,9 \%$ & 22.545 & 5.673 & $25,2 \%$ \\
\hline Chocontá & 12.759 & 2.871 & $22,5 \%$ & 20.677 & 4.607 & $22,3 \%$ \\
\hline Pacho & 12.598 & 2.697 & $21,4 \%$ & 23.720 & 3.800 & $16,0 \%$ \\
\hline Bojacá & 11.557 & 2.441 & $21,1 \%$ & 8.268 & 2.454 & $29,7 \%$ \\
\hline
\end{tabular}




\begin{tabular}{lrccccc} 
& \multicolumn{2}{c}{2011 (millones constantes de 2014) } & \multicolumn{2}{c}{2014 (millones de \$) } \\
\cline { 2 - 7 } Municipio & $\begin{array}{c}\text { Ingresos } \\
\text { totales }\end{array}$ & $\begin{array}{c}\text { Ingresos } \\
\text { tributarios }\end{array}$ & $\%$ & $\begin{array}{c}\text { Ingresos } \\
\text { totales }\end{array}$ & $\begin{array}{c}\text { Ingresos } \\
\text { tributarios }\end{array}$ & $\%$ \\
\hline Cáqueza & 9.220 & 1.835 & $19,9 \%$ & 18.908 & 3.459 & $18,3 \%$ \\
\hline Medina & 6.919 & 863 & $12,5 \%$ & 12.672 & 1.096 & $8,6 \%$ \\
\hline San Juan de Rioseco & 6.724 & 819 & $12,2 \%$ & 11.200 & 1.135 & $10,1 \%$ \\
\hline Gachetá & 7.380 & 797 & $10,8 \%$ & 17.699 & 1.595 & $9,0 \%$ \\
\hline Total municipios & 1.332 .037 & 555.651 & $41,7 \%$ & 1.811 .711 & 762.980 & $42,1 \%$ \\
\hline Bogotá & 9.517 .279 & 5.028 .063 & $52,83 \%$ & 10.242 .089 & 5.484 .586 & $53,55 \%$ \\
\hline
\end{tabular}

Fuente: FUT (Formulario Único Territorial), DNP, cálculos de los autores.

Tabla 2.4. Beneficiarios de programas sociales del gobierno en los 31 municipios

\begin{tabular}{lrrrrrr} 
& Población & Personas en & \multicolumn{3}{c}{ Beneficiarios de programas sociales } \\
\cline { 6 - 7 } & rural & el Sisbén & $\begin{array}{c}\text { Más familias en } \\
\text { acción (familias) }\end{array}$ & $\begin{array}{c}\text { Jóvenes en } \\
\text { acción }\end{array}$ & $\begin{array}{c}\text { Cero a } \\
\text { siempre }\end{array}$ & $\begin{array}{c}\text { Colombia } \\
\text { Mayor }\end{array}$ \\
\hline 31 Municipios & 359.028 & 1.437 .374 & 50.211 & 4.720 & 22.759 & 30.997 \\
\hline Nacional & 11.356 .470 & 35.235 .950 & 2.580 .247 & 179.552 & 1.984 .958 & 1.472 .000 \\
\hline Porcentaje & $3,2 \%$ & $4,1 \%$ & $1,9 \%$ & $2,6 \%$ & $1,1 \%$ & $2,1 \%$ \\
\hline
\end{tabular}

Fuente: DNP, DPS, Sisbén, MinTrabajo, MinSalud, cálculos de los autores.

Una forma ilustrativa de representar a los municipios por algún indicador que recoja sus condiciones sociales es utilizar el promedio del puntaje Sisbén y ordenar dichos municipios de menor a mayor (ver gráfica 2.3). De acuerdo con estas cifras, las situaciones más críticas se observa en Medina, San Juan de Rioseco y Guaduas. En el otro lado, con mejores condiciones se encuentran los municipios de Funza, Sopó y Subachoque, estos últimos más cercanos al área de influencia de Bogotá. Esta última observación plantea la importancia de las conexiones de Bogotá región con los municipios aledaños, lo cual puede tener un efecto positivo sobre mejores indicadores de calidad de vida.

También es válido observar información adicional a la del Sisbén, como indicadores de cobertura en educación y calidad de la educación. Con esta información, Chía es el municipio con las mejores condiciones sociales, tal y como se deriva de indicadores como cobertura de educación media, tasa de analfabetismo, acceso a los servicios públicos 
Gráfica 2.3. Puntaje Sisbén promedio por municipio (2014)

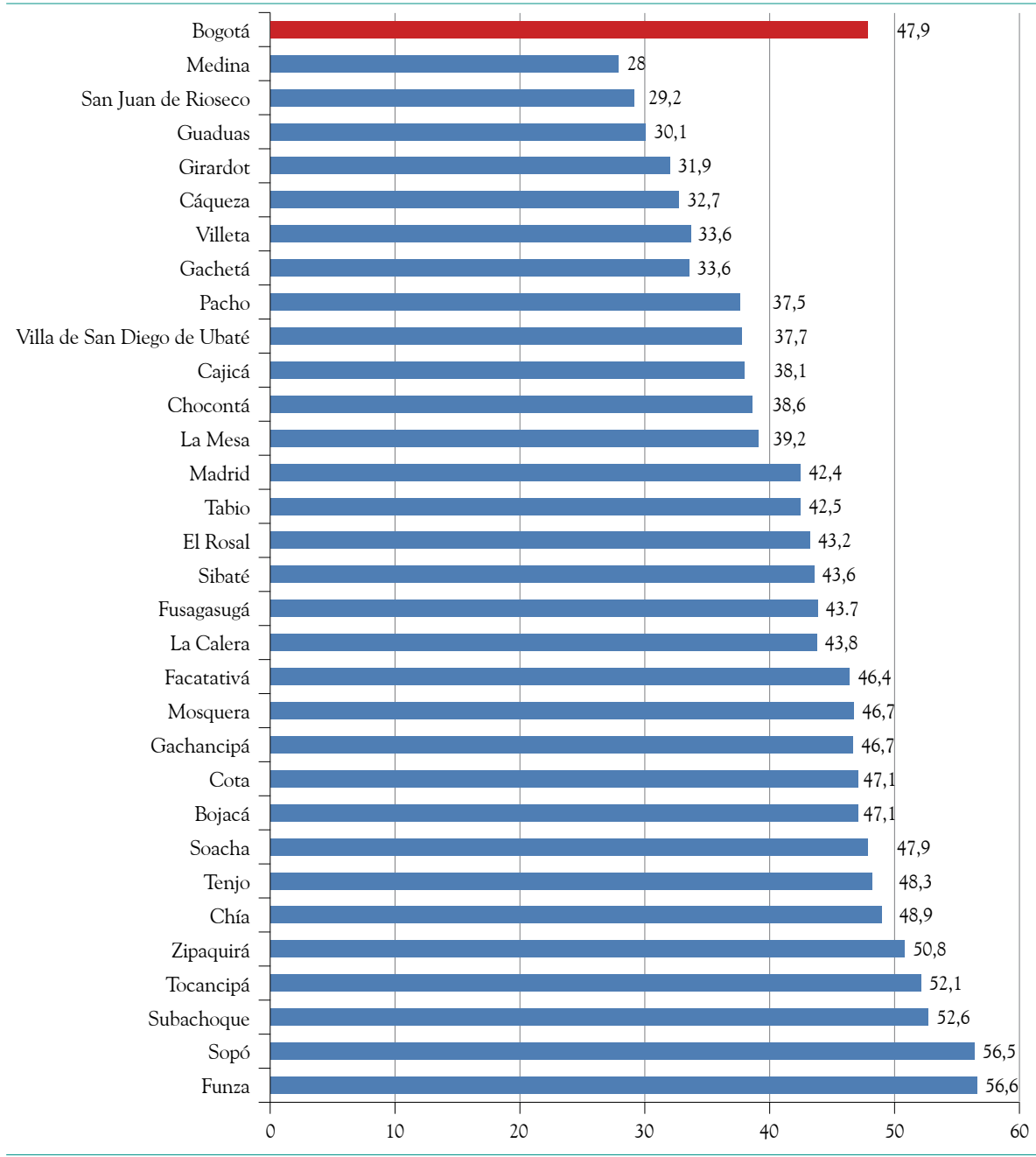

Fuente: DNP, cálculos de los autores.

domiciliarios y afiliación a salud. En el otro extremo aparecen nuevamente Medina y San Juan de Rioseco. Las brechas son significativas, quizás relacionadas con un efecto de aglomeración espacial donde la cercanía a Bogotá puede jugar un papel sustancial en las condiciones de vida de los residentes en municipios cercanos.

Estos resultados muestran una relación inversa entre los ingresos propios y las condiciones de vida de la población, evidenciada en la gráfica 2.4, la cual ilustra del porcentaje de ingresos tributarios en relación con la 
pobreza monetaria. En términos del coeficiente de correlación de Pearson esta relación es de $-75 \%$. Así mismo, en la tabla 2.5 se muestran los principales indicadores sociales de los municipios, reforzando la importancia de incentivar un mejor manejo de los recursos propios. Una posible interpretación de estos resultados es una brecha significativa entre los municipios y un proceso de convergencia muy lento en la región.

Gráfica 2.4. Porcentaje de ingresos tributarios sobre el total de ingresos y la pobreza monetaria

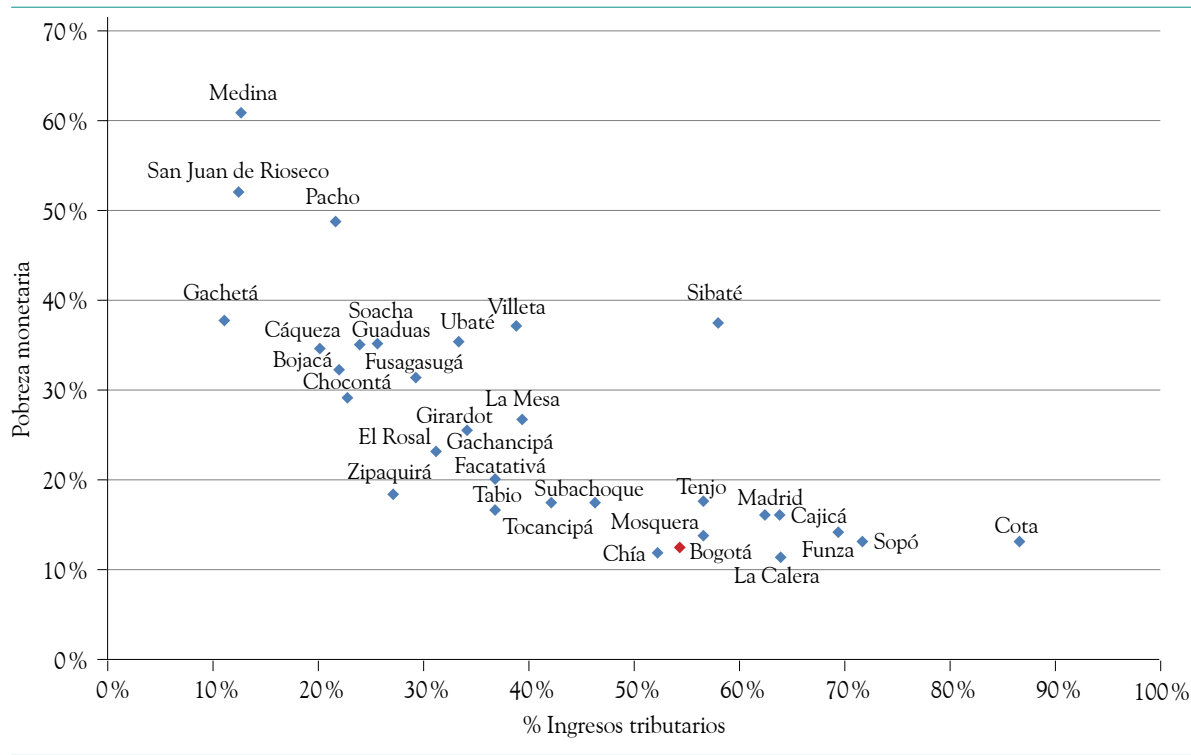

Fuente: FUT (Formulario Único Territorial), DNP, SDP, cálculos de los autores.

Tabla 2.5. Indicadores sociales por municipio (porcentajes)

\begin{tabular}{lcccccc} 
Municipio & $\begin{array}{c}\text { Cobertura } \\
\text { neta educación } \\
\text { media (2015) }\end{array}$ & $\begin{array}{c}\text { Tasa } \\
\text { analfabetismo } \\
\text { mayores a 15 } \\
\text { años (2015) }\end{array}$ & $\begin{array}{c}\text { Cobertura } \\
\text { total } \\
\text { acueducto } \\
(\mathbf{2 0 1 5 )}\end{array}$ & $\begin{array}{c}\text { Cobertura } \\
\text { energía } \\
(\mathbf{2 0 1 4})\end{array}$ & $\begin{array}{c}\text { Cobertura } \\
\text { Gas natural } \\
\text { (2016) }\end{array}$ & $\begin{array}{c}\text { Afiliados } \\
\text { al régimen } \\
\text { subsidiado }\end{array}$ \\
\hline Chía & 65,2 & 2,6 & 98,3 & 100,0 & 100,0 & 13,1 \\
\hline Tocancipá & 50,7 & 3,9 & 96,1 & 100,0 & 100,0 & 14,0 \\
\hline Sopó & 44,3 & 3,5 & 95,5 & 100,0 & 96,2 & 14,1 \\
\hline Zipaquirá & 51,7 & 3,4 & 96,2 & 100,0 & 100,0 & 19,7 \\
\hline Madrid & 47,9 & 3,2 & 94,2 & 100,0 & 96,9 & 20,2 \\
\hline
\end{tabular}


La política social y tributaria: descripción de los principales componentes

\begin{tabular}{|c|c|c|c|c|c|c|}
\hline Municipio & $\begin{array}{c}\text { Cobertura } \\
\text { neta educación } \\
\text { media ( 2015) }\end{array}$ & $\begin{array}{c}\text { Tasa } \\
\text { analfabetismo } \\
\text { mayores a } 15 \\
\text { años (2015) }\end{array}$ & $\begin{array}{l}\text { Cobertura } \\
\text { total } \\
\text { acueducto } \\
(2015)\end{array}$ & $\begin{array}{l}\text { Cobertura } \\
\text { energía } \\
\text { (2014) }\end{array}$ & $\begin{array}{l}\text { Cobertura } \\
\text { Gas natural } \\
\text { (2016) }\end{array}$ & $\begin{array}{l}\text { Afiliados } \\
\text { al régimen } \\
\text { subsidiado }\end{array}$ \\
\hline Funza & 69,0 & 2,9 & 95,9 & 100,0 & 100,0 & 20,7 \\
\hline Cajicá & 54,6 & 3,3 & 98,7 & 100,0 & 100,0 & 23,3 \\
\hline Facatativá & 44,9 & 3,3 & 94,5 & 99,6 & 100,0 & 24,4 \\
\hline Tenjo & 96,8 & 3,6 & 94,0 & 100,0 & 90,1 & 26,8 \\
\hline El Rosal & 40,0 & 4,6 & 85,6 & 98,6 & 65,8 & 27,0 \\
\hline Gachancipá & 30,3 & 3,9 & 91,8 & 99,7 & 61,8 & 27,2 \\
\hline Cota & ND & 3,0 & 91,7 & 100,0 & 100,0 & 28,1 \\
\hline Mosquera & 72,7 & 2,9 & 92,9 & 100,0 & 100,0 & 29,4 \\
\hline $\begin{array}{l}\text { Villa de San } \\
\text { Diego de Ubaté }\end{array}$ & 62,0 & 4,7 & 90,3 & 99,7 & 81,2 & 33,2 \\
\hline Tabio & 39,5 & 2,9 & 93,9 & 100,0 & 84,5 & 34,0 \\
\hline Soacha & 49,4 & 3,2 & 83,7 & 100,0 & 88,4 & 35,1 \\
\hline La Calera & 65,7 & 3,4 & 80,0 & 100,0 & 36,7 & 35,7 \\
\hline Girardot & 55,1 & 5,6 & 98,4 & 99,1 & 75,5 & 36,2 \\
\hline Bojacá & 25,3 & 5,1 & 86,8 & 98,7 & 96,2 & 41,7 \\
\hline La Mesa & 47,8 & 9,6 & 84,9 & 98,6 & 46,0 & 42,8 \\
\hline Subachoque & 72,9 & 5,6 & 88,4 & 98,4 & 80,9 & 43,2 \\
\hline Fusagasugá & 61,6 & 5,6 & 94,8 & 99,1 & 91,0 & 44,4 \\
\hline Villeta & 49,8 & 9,7 & 82,0 & 97,5 & 81,2 & 46,6 \\
\hline Sibaté & 36,0 & 10,5 & 96,1 & 99,0 & 81,4 & 55,3 \\
\hline Chocontá & 40,1 & 6,2 & 85,7 & 99,2 & 9,1 & 57,4 \\
\hline Cáqueza & 62,2 & 5,9 & 42,5 & 98,7 & 80,0 & 72,0 \\
\hline Pacho & 49,4 & 9,7 & 60,7 & 97,5 & 0,0 & 72,4 \\
\hline Guaduas & 31,1 & 12,9 & 67,2 & 98,7 & 86,8 & 75,6 \\
\hline Gachetá & 56,0 & 8,3 & 33,2 & 96,7 & 0,0 & 76,2 \\
\hline Medina & 26,5 & 11,0 & 56,4 & 99,0 & 93,5 & 89,6 \\
\hline $\begin{array}{l}\text { San Juan de } \\
\text { Rioseco }\end{array}$ & 42,3 & 17,6 & 59,4 & 98,6 & 66,9 & 89,7 \\
\hline Bogotá & 50,60 & 2,40 & 98,70 & 100 & 70,90 & 17,60 \\
\hline
\end{tabular}

Fuente: DNP, cálculos de los autores. ND: no disponible. 


\section{Descripción de la política social y tributaria en Bogotá}

¿Qué reciben los hogares bogotanos? A continuación se enumeran y describen los subsidios otorgados a los hogares bogotanos. Los planes de desarrollo proponen una agenda social amplia, pero a través de las encuestas de hogares no es posible hacerle el seguimiento a todos los subsidios. En este aparte se incluyen las dimensiones identificadas y medidas a partir de la EM2014.

\section{Formación de capital humano}

\section{Salud}

El año 1993 marcó un hito en la política en el campo de la salud y de la seguridad social con la expedición de la Ley 100 que buscaba, entre otros objetivos, la cobertura universal. La Ley obliga a que todas las personas estén afiliadas en alguno de dos regímenes: contributivo o subsidiado. Deben contribuir los empleados y trabajadores independientes, con ingresos totales mensuales superiores a un salario mínimo, incluyendo al cónyuge o compañero(a) permanente y adicionalmente a sus hijos o los de su pareja, (menores de 18 años) y los pensionados. En el régimen subsidiado, se afilian las personas desempleadas, o con bajos niveles de ingreso, clasificadas en los niveles 1 y 2 del Sisbén. Paralelamente, la Ley 60 de 1993 establece el sistema de transferencias del gobierno central para cubrir los subsidios otorgados a los colombianos inscritos en el régimen subsidiado. Posteriormente la Ley 715 de diciembre de 2001 establece las normas orgánicas que entran a regular recursos y competencias en sectores como salud y educación.

Subsidio al aseguramiento en salud: el subsidio al aseguramiento en salud está organizado bajo el Sistema General de Seguridad Social en Salud (SGSSS), el cual busca garantizar el acceso al servicio público de salud a la totalidad de la población colombiana. Cualquier individuo con bajos ingresos puede acogerse al régimen subsidiado (niveles 1 y 2 del Sisbén). En el régimen contributivo se deben afiliar "todas las personas vinculadas a través de contrato de trabajo, los servidores públicos, los pensionados, los trabajadores independientes con capacidad de pago, las madres comunitarias y los aprendices en etapa lectiva y productiva". Estas categorías de personas tienen la obligación de aportar al SGSSS. Quienes pertenecen al régimen contributivo cotizan el $12,5 \%$ de sus ingresos laborales (8,5\% son pagados 
por el empleador y $4 \%$ por el empleado). En caso de ser independiente, la totalidad del monto es pagada por el trabajador.

En el caso de la salud, para el cálculo del balance neto de los subsidios y de los pagos del hogar, es necesario estimar la unidad de pago por capitación (UPC), la cual depende del sexo y edad de cada miembro del hogar. Para el régimen subsidiado, la Comisión de Regulación en Salud determinó mediante Resolución 5522 de 2013 "fijar el valor anual de la Unidad de Pago por Capitación del régimen subsidiado (UPC-S) para el año 2014 en la suma de quinientos treinta y un mil trescientos ochenta y ocho pesos con ocho centavos moneda corriente $(\$ 531.388,08)$ equivalente a un valor diario de mil cuatrocientos setenta y seis pesos con ocho centavos moneda corriente $(\$ 1.476,08) "$. Para el régimen contributivo este valor se estipuló en $\$ 593.978,40$ (pesos colombianos). Cuando el hogar tiene personas no afiliadas al sistema de salud, se imputa un valor que depende de los gastos de servicio en No-POS y vinculados.

Subsidio atenciones No-POS: se entiende por atenciones No-POS todos aquellos tratamientos, tecnologías, medicamentos o servicios no contemplados dentro del Plan Obligatorio de Salud (POS). Las disposiciones generales para la prestación de servicios No-POS a usuarios afiliados al régimen subsidiado de salud, y posterior pago a las entidades prestadoras del servicio por parte del Estado vigentes en el año 2014, están descritas en la Resolución 5073 de 2013. De acuerdo con la resolución, la prestación de servicios y de tecnologías no cubiertas por el POS están sujetas a previa orden de una autoridad judicial o previa autorización de un Comité Técnico Científico, de acuerdo con el procedimiento descrito en Capítulo I de la Resolución 3099 de 2008.

De esta manera, la concesión de subsidios a atenciones No-POs depende de: (i) la afiliación del individuo al régimen subsidiado de salud, (ii) la aprobación, bajo criterios técnico científicos, de la prescripción excepcional de dichas atenciones explícitamente excluidas del pos por parte del Comité Técnico Científico.

Plan intervenciones colectivas-PIC: el PIC es el Plan de Salud Pública de Intervenciones Colectivas. Para el año 2014, la formulación general del PIC está descrita en el Título IV de la Resolución 0425 de 2008. El PIC es un 
programa complementario al POS y a los demás programas de ayuda social diseñados por el Estado, y busca "promover la salud y calidad de vida, la prevención y control de los riesgos y daños en salud de alta externalidad para alcanzar las metas prioritarias en salud definidas en el Plan Nacional de Salud Pública”. En otras palabras, el PIC es un programa social basado en intervenciones colectivas diseñadas a partir de la situación de salud específica de una población en particular.

El factor diferenciador de este tipo de subsidio a la salud es su gratuidad para la totalidad de la población, independientemente de su nivel de ingreso, o de su situación de aseguramiento. La atención es universal, ya que no hay requisitos de acceso. El Distrito es el encargado de ejecutar, seguir y evaluar el PIC.

\section{Educación}

Costo colegio: el gobierno (nacional y distrital) ofrece el servicio de educación formal de manera gratuita, pre-jardín hasta grado 11ํ. Además, el sistema oficial educativo de Bogotá comprende el grado 12 optativo, el ciclo complementario normal superior $(12,13$ y 14), la educación básica primaria para adultos, la educación básica secundaria para adultos, la educación media para adultos y los demás modelos educativos flexibles.

El artículo 32 de la Resolución 1457 de 2014 define el carácter gratuito del sistema oficial educativo en los niveles preescolar, primario, secundario y media. De acuerdo con el Decreto 4807 de 2011, "en ningún caso la asignación de cupo, matrícula o su renovación, estará condicionada al pago de derechos académicos, complementarios, de afiliación de seguro estudiantil, de afiliación a la asociación de padres de familia, examen de admisión, nivelación u otros pagos".

En Bogotá se presentan diversas formas de intervención del Estado en la oferta de los servicios sociales. Si la obligación del gobierno es garantizar cobertura y calidad de la educación, este objetivo se puede lograr a través de la oferta pública directa (público-público o pub-pub), o de manera indirecta por la vía de la oferta privada. Pero este camino tiene modalidades diversas: privado-privado (priv-priv), privado/público-convenio (priv/pub-con), público-concesión (pub-cos). El primer componente de las parejas corresponde al agente financiador. Y el segundo representa la modalidad de la 
administración. Estas clasificaciones tienen fronteras borrosas y apenas son indicativas. La administración de los planteles en convenio (priv/pub-con) es privada pero responde de manera directa al gobierno local en la medida en que este le entrega al plantel privado un monto de recursos por estudiante. La administración le exige al plantel el mejoramiento de algunas características de infraestructura y del proceso educativo. En los colegios en concesión ( $p u b-c o s)$ toda la financiación es pública, y en la gestión la incidencia del gobierno local es mayor a la de los colegios en convenio. El nivel de intervención es mayor en pub-pub. Le siguen, en su orden, pubcos, priv/pub-con y priv-priv. Este último debe seguir las normas generales, pero su margen de acción es más amplio que en las demás modalidades. Las cuatro modalidades se presentan en Bogotá. Los planteles pub-pub y pub-cos se financian, en su totalidad, con recursos públicos. Los priv/pubcon reciben algunos recursos públicos, dependiendo del número de niños definidos en el convenio.

Subsidio monetario condicionado: este tipo de subsidio, dado en forma de transferencia monetaria, es otorgado a aquellos estudiantes de colegios oficiales ubicados en localidades con mayor demanda educativa, quienes cursan entre $6^{\circ}$ y $11^{\circ}$ grado, y se destacan por su excelencia académica o compromiso institucional. La Secretaría de Educación del Distrito (SED) se encarga de establecer los compromisos educativos de los beneficiarios. Adicionalmente, les exige residir en Bogotá, asistir a la institución educativa en jornada diurna, ser menores de 19 años, no ser beneficiarios de otro subsidio otorgado por la SED, y pertenecer a un hogar con un puntaje en el Sisbén entre 30,56 y 55 según la Resolución 4059 de 2011. En total, el subsidio consta de cinco pagos bimestrales, cada uno por valor aproximado de $\$ 86.658$ pesos corrientes de 2014 . La continuidad del subsidio está condicionada a la asistencia del estudiante.

Subsidio monetario condicionado al transporte SED: consiste en una transferencia monetaria otorgada por la SED con el fin de cubrir los costos de transporte de los niños y jóvenes. El subsidio se otorga cuando el cupo asignado al estudiante lo ubica en un colegio oficial distante a su lugar de residencia. La transferencia está condicionada a la asistencia escolar del

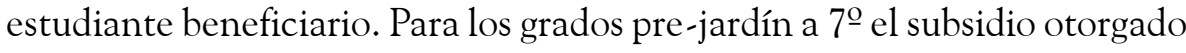


es doble, mientras que para los grados de $8^{\circ}$ a $11^{\circ}$ es sencillo. El capítulo III de la Resolución 1531 de 2014 define los principales lineamientos para otorgar el subsidio. Entre ellos se requiere residir en la ciudad de Bogotá a más de 2 kilómetros de distancia del colegio en el que se asignó el cupo. Además, la persona debe ser menor de 19 años, y no puede ser beneficiario de otro tipo de subsidio otorgado por la SED.

Rutas escolares oficiales SED: el programa de rutas escolares del Distrito ofrece de manera gratuita a los estudiantes beneficiarios el servicio de ruta para cubrir trayectos de ida y vuelta del lugar de residencia al colegio oficial en coordinación con los horarios y jornadas académicas de los establecimientos educativos. El capítulo II de la Resolución 1531 de 2014 define los principales lineamientos sobre los cuales este beneficio es otorgado. Entre ellos, se destacan: residir en la ciudad de Bogotá a más de 2 kilómetros de distancia del colegio en el cual se le asignó cupo al estudiante, ser menor de 19 años para los colegios en zona rural, y menor de 14 años para los colegios en zona urbana.

Subsidio monetario condicionado MFA: el programa Más Familias en Acción otorga transferencias monetarias directas a aquellas familias en situación de pobreza o vulnerabilidad con niños menores de 18 años. En el ámbito educativo su principal objetivo es garantizar la asistencia escolar de los niños pertenecientes a las familias beneficiarias por lo que condiciona el otorgamiento del subsidio a una asistencia mínima al $80 \%$ de las clases programadas durante el bimestre, y a la no pérdida de más de dos años escolares. Normalmente la transferencia directa es concedida a familias con hijos entre 4 y 18 años, pero también se le otorga a jóvenes de 18 y 19 años, siempre y cuando estén cursando grado 10ํㅡㄹ y a jóvenes de 20 años cursando 11을 (ver Tabla 2.6).

Este subsidio monetario es conferido a cada beneficiario y se liquida de manera bimestral durante los meses correspondientes al calendario escolar. En total se hacen cinco transferencias condicionadas al año. El Estado colombiano tiene la obligación de proveer los recursos necesarios para financiar este subsidio. 
Tabla 2.6. Tarifas de subsidios en educación por grado y tipología de municipio para 2014

\begin{tabular}{cccccc}
\hline Grupo de municipos & Transición & Grados 1-5 & Grado de 6-8 & Grado de 9-10 & Grado 11 \\
\hline 1 & N/D & N/D & $\$ 25,500.00$ & $\$ 30,600.00$ & $\$ 45,900.00$ \\
\hline 2 & $\$ 20,400.00$ & $\$ 10,200.00$ & $\$ 25,500.00$ & $\$ 30,600.00$ & $\$ 45,900.00$ \\
\hline 3 & $\$ 20,400.00$ & $\$ 15,300.00$ & $\$ 30,600.00$ & $\$ 35,700.00$ & $\$ 51,000.00$ \\
\hline 4 & $\$ 20,400.00$ & $\$ 15,300.00$ & $\$ 35,700.00$ & $\$ 40,800.00$ & $\$ 56,100.00$ \\
\hline
\end{tabular}

Fuente: Fuente: DNP, cálculos de los autores. ND: no disponible.

Subsidio de sostenimiento y tarjeta recargable: uno de los subsidios focalizados a los individuos cursando su educación terciaria es el de sostenimiento. Su principal objetivo es asistir a los estudiantes universitarios beneficiados de un crédito con el Icetex. En el 2014 el monto otorgado era de $\$ 684.432$ por semestre, cargado a una tarjeta débito. El valor se va actualizando de acuerdo con el índice de precios al consumidor (IPC). En el caso de Bogotá puede recibir el subsidio quien esté registrado en la versión III del Sisbén, y un puntaje no superior a 57,21. También pueden acceder al subsidio los beneficiarios de crédito Acces, pero en este caso el criterio no es el puntaje Sisbén sino que debe estar incluido en una de estas cuatro categorías: víctima del conflicto armado en Colombia, ser indígena, pertenecer a la Red Unidos o ser reintegrado.

Incentivo Programa Jóvenes en Acción: el programa Jóvenes en Acción está a cargo del Departamento para la Prosperidad Social (DPS) y tiene por principal objetivo estimular la formación de capital humano de los jóvenes en condición de pobreza o vulnerabilidad, así como el aumento de su nivel de empleabilidad. El programa permite realizar la formación en el SENA o en las universidades. En cualquiera de los dos casos se otorga a los jóvenes que cumplan con los requisitos (como puntaje del Sisbén), un incentivo económico, de $\$ 200$ mil mensuales en el 2014 , condicionados al cumplimiento de los compromisos adquiridos al momento de ingresar al programa. En el programa Jóvenes en Acción Universidades el beneficiario podía acceder a una transferencia adicional por el mismo monto si el promedio de notas era superior a 3,5 durante el semestre. Dichas transferencias están sujetas a la duración del calendario académico. 
Otros subsidios: tales como el proyecto de alimentación escolar o subsidios a útiles y uniformes.

Cuidado de los niños (Jardín ICBF) : el Instituto Colombiano de Bienestar Familiar (ICBF) tiene a su cargo el programa de Hogares Infantiles, Lactantes y Preescolares, mediante el cual se brinda cuidado a niños entre los 6 meses y los 5 años de edad con el objetivo de propiciar su desarrollo cognitivo, emocional y social. Este programa ofrece tarifas subsidiadas a familias con menores recursos económicos. Según lo estipulado en la Resolución 1740 de 2010, los padres o tutores de los niños beneficiarios deben contribuir, y la tasa se define con criterios de progresividad, de acuerdo con su nivel de ingreso. De esta manera, un hogar con un ingreso menor a un salario mínimo mensual legal vigente (SMMLV) deberá pagar únicamente un valor correspondiente al $3 \%$ del smmlv para poder acceder al servicio de jardín.

Componente nutrición Familias en Acción: el programa Más Familias en Acción otorga transferencias monetarias directas a aquellas familias en situación de pobreza o vulnerabilidad con niños menores de 18 años. Su principal objetivo en salud es mejorar las condiciones de alimentación de niños y niñas en edad temprana, así como mantener controles en su crecimiento y desarrollo. El subsidio del componente nutricional del programa solamente es otorgado cuando en la familia hay un menor de 7 años. La transferencia monetaria está condicionada a la asistencia del niño a todos los controles de crecimiento y desarrollo programados de acuerdo con su edad. Este tipo de subsidio no se otorga por cada niño menor de 7 años; se realiza una sola transferencia por familia beneficiaria. Los pagos son bimestrales.

\section{Movilidad}

Subsidio de transporte: existen dos subsidios de transporte ofrecidos por el Distrito. El primero está focalizado a personas con discapacidad permanente, inscritas en el "Registro para la localización y caracterización de las personas con Discapacidad permanente de la ciudad de Bogotá D. C.”. Las directrices bajo las cuales se otorga dicho subsidio están contenidas en el Decreto 429 de 2012, cuyo artículo 8 establece que el monto del subsidio en el Distrito Capital es creciente "iniciando con un descuento del $15 \%$ en 
el 2012, con incrementos anuales de 5 puntos porcentuales hasta llegar al $40 \%$ en el año 2017, con una asignación máxima de 50 viajes mensuales". El segundo va dirigido a la población con menor capacidad de pago, según puntaje del Sisbén. Las directrices bajo las cuales se otorga dicho subsidio están contenidas en el Decreto 429 de 2012. De acuerdo con el artículo 3, "el incentivo Sisbén consistirá en un porcentaje de descuento constante del $50 \%$ sobre la tarifa al usuario..., con una asignación máxima de hasta 40 viajes mensuales". Para acceder a dicho subsidio el individuo debe ser mayor de 16 años y estar registrado en el Sisbén modalidad III con un puntaje inferior a 40 .

\section{Mejorar infraestructura física del hogar}

Servicios públicos domiciliarios: el marco de la prestación y diseño de tarifas de los servicios públicos domiciliarios (SPD) en Colombia está definido en la Ley 142 de 1994. Bajo los criterios de eficiencia económica, suficiencia financiera, solidaridad y redistribución. De acuerdo con la norma (art. 87), el régimen tarifario tiene que permitir que los usuario de los estratos más altos, en conjunto con los del sector comercial e industrial, aporten a "fondos de solidaridad y redistribución", con el fin de subsidiar el pago del servicio a los estratos más bajos. El diseño tarifario debe realizarse de tal manera que garantice la recuperación de los costos y de los gastos de operación, sin dejar de remunerar el patrimonio de los accionistas. La estructura de costos debe diseñarse garantizando la no interrupción en la oferta del servicio, y la calidad del mismo.

Acueducto, alcantarillado y aseo: la Ley 1450 de 2011, en su artículo 125, establece los límites superiores en el caso de subsidios, e inferiores en el caso de contribuciones. La norma incluye los SPD de acueducto, alcantarillado y aseo:

los subsidios en ningún caso serán superiores al setenta por ciento $(70 \%)$ del costo del suministro para el estrato 1 , cuarenta por ciento $(40 \%)$ para el estrato 2 y quince por ciento $(15 \%)$ para el estrato 3. Los factores de aporte solidario... serán como mínimo los siguientes: Suscriptores Residenciales de estrato 5: cincuenta por 
ciento (50\%); Suscriptores Residenciales de estrato 6: sesenta por ciento (60\%); Suscriptores Comerciales: $(50 \%)$; Suscriptores Industriales: (30\%). (Ley 1450 de 2011)

Con respecto al artículo 99 de la Ley 142 de 1994, se modifica el límite superior de los subsidios atribuidos a estrato 1, pasando del $50 \%$ al $70 \%$. En general, los subsidios a acueducto, alcantarillado y aseo consisten en una reducción tarifaria por debajo del costo medio de largo plazo a estratos 1, 2 y 3 financiada principalmente a partir de las contribuciones de los estratos 5 y 6 y del sector no residencial. Cualquier posible déficit existente entre subsidios y contribuciones es cubierto con recursos de la nación, o de los presupuestos municipales y los fondos de solidaridad y redistribución de ingresos.

Mínimo vital de agua potable: el artículo $4^{\circ}$ del Decreto 485 de 2011 fue modificado por el artículo 1을 del Decreto Distrital 64 de 2012, ambos decretos provienen del Acuerdo 347 de 2008. En este último se establece que en el Distrito Capital de Bogotá se fija un Mínimo Vital de Agua que corresponde a seis metros cúbicos mensuales. El Mínimo Vital debe ser suministrado de manera gratuita a hogares de uso residencial y mixto pertenecientes a estratos 1 y 2. Los costos generados a las empresas prestadoras de dicho servicio serán cubiertos en su totalidad por la Administración Distrital.

Energía y gas: el numeral 6 del artículo 99 de la Ley 142 de 1994 establece que los subsidios a energía y gas no pueden ser superiores en ningún caso "al $15 \%$ del costo medio del suministro para el estrato 3, al $40 \%$ del costo medio del suministro para el estrato 2, ni superior al $50 \%$ de este para el estrato 1". El subsidio debe cubrir únicamente la porción de la tarifa destinada a recuperar el valor de las inversiones, y no la porción destinada a recuperar los costos de la prestación del servicio.

\section{Construcción o mejoramiento de la vivienda}

Subsidio familiar de vivienda urbano para ahorradores: otorgado por el Fondo Nacional de Vivienda (Fonvivienda). Es un subsidio monetario a cargo del Presupuesto Nacional. Las condiciones para otorgarlo se definen 
en el Capítulo II del Decreto 1432 de 2013. El monto de la transferencia no puede superar los 25 SMMLV y depende del nivel de ingreso del postulante, que en ningún caso puede superar los 2 smmlv. Los otros requisitos son no ser propietario de vivienda dentro del territorio nacional y contar con un ahorro mínimo equivalente al $5 \%$ del valor de la vivienda.

Subsidio familiar de vivienda otorgado por Caja de Compensación: algunas Cajas de Compensación en Colombia ofrecen subsidios a la construcción en sitio propio, mejoramiento de vivienda, adecuación de vivienda saludable, adquisición de vivienda nueva o usada. Si el afiliado cumple con los requisitos de ley no debe restituir el valor de dicha transferencia, otorgada por una sola vez. El Decreto 1432 de 2013 define los criterios para acceder a los subsidios monetarios para ahorradores con ingreso máximo de $2 \mathrm{smmlv}$. El subsidio es otorgado por las Cajas de Compensación y por Fonvivienda.

Subsidio Distrital de Vivienda en especie: consiste en un subsidio otorgado por el Distrito, por un monto de hasta 70 SMMLV, con el fin de cubrir parte del costo de la vivienda de interés prioritario. Los aportes del distrito consisten "en bienes fiscales de propiedad de cualquier entidad pública... en suelo, en estudios técnicos y diseños, obras de urbanismo o urbanización o cualquier otro tipo de inversiones financiadas con recursos del presupuesto distrital" (artículo 3, Decreto 539 de 2012). El monto específico de cada tipo de subsidio depende de cada modalidad del mismo. Puede ser utilizado tanto a vivienda rural como urbana.

El subsidio distrital de vivienda en especie tiene una focalización distinta a los otros programas de vivienda aplicados en Bogotá, dado que prioriza a las víctimas del desplazamiento forzado. El $57 \%$ de los recursos son destinados a esta población, y el porcentaje restante se dirige a los hogares en condiciones de vulnerabilidad, teniendo en cuenta elementos tales como el número de integrantes, la pertenencia a comunidades étnicas, el número de niños y el ingreso. 



\section{Capítulo 3 Ingreso disponible. Metodología de cálculo}

Este capítulo presenta la metodología para la medición del ingreso disponible de los hogares bogotanos, en un marco de análisis de incidencia, como insumo principal para revisar el efecto de la política social y tributaria en la ciudad de Bogotá, y municipios aledaños para los impuestos, contribuciones y subsidios factibles de imputación. La metodología se construye y extiende a la presentada en el trabajo de Gallego et al. (2015), quienes aplican un primer ejercicio de este tipo para la capital colombiana utilizando la Encuesta Multipropósito de 2011. En esta ocasión se cuenta con una nueva versión de la encuesta para el año 2014, permitiendo recoger ajustes dinámicos de la política fiscal y tributaria.

El capítulo comienza con una breve reflexión acerca del concepto de ingreso disponible y el manejo requerido para este estudio. Posteriormente, para implementar la medición de este concepto, se hace una descripción de la EM2014 como insumo de cálculo, y de otras fuentes de información utilizadas. Seguidamente se describe en detalle la metodología y se explica cada uno de los componentes de cálculo del ingreso disponible. Finalmente se buscan discutir mejoras metodológicas.

\section{El ingreso disponible de los hogares}

Un balance financiero neto de los hogares gira, en última instancia, alrededor del cálculo del ingreso disponible. Camelo (2001) define el ingreso disponible como la suma de los ingresos primarios y secundarios, menos la 
totalidad de los gastos. Por ingresos primarios se entienden todas las entradas generadas por el individuo a razón de salario, renta empresarial y renta de la propiedad. Por su parte, ingresos secundarios son todas aquellas transferencias corrientes, entendidas como "transacciones por las cuales una unidad institucional (por ejemplo los hogares) reciben bienes, servicios o activos de otra unidad institucional, sin entregar algo a cambio (o sea sin contrapartida)". Por el lado del gasto, se considera el gasto corriente en consumo de bienes y servicios, y el gasto por impuestos de renta y patrimonio, multas, contribuciones a sistemas de seguridad social, donaciones y transferencias a otros hogares, a instituciones sin fines de lucro y al gobierno. Bajo esta definición está especificada la metodología del DANE para la Encuesta Nacional de Ingresos y Gastos.

Una vez calculado el ingreso disponible es posible determinar el valor del ingreso disponible ajustado, definido como la suma del ingreso disponible y las transferencias sociales monetarias y en especie, una vez descontadas las contribuciones. Estas últimas incluyen transferencias dadas por particulares, por el gobierno o por instituciones sin ánimo de lucro, ya sea a título gratuito o a un precio económicamente significativo. Tanto para el caso del ingreso disponible como el de ingreso disponible ajustado, es posible calcular el monto mensual por hogar, sumando los ingresos disponibles (ajustados) de las personas que componen la unidad de gasto. En resumen:

Ingreso Disponible $=$ Ingresos Corrientes (Primarios + Secundarios) Gastos impositivos

Ingreso Disponible Ajustado = Ingreso Disponible + Transferencias sociales monetarias y en especie

\section{Componentes del ingreso disponible}

En esta sección se desarrolla cada uno de los componentes de cálculo del ingreso disponible, detallando su aplicación con la información contenida en la EM2014 y registros administrativos complementarios. Se detallan tres componentes de cálculo: 1) ingresos corrientes, 2) gastos corrientes y 3) subsidios y contribuciones. 


\section{Cálculo del ingreso y gasto corriente}

En el cálculo del ingreso individual de los hogares, ${ }^{1}$ se toma un ingreso inicial, conformado por la sumatoria de los ingresos laborales, los salarios en especie, las transferencias y los ingresos de capital a patrones y empleadores. De esta forma, hacen parte del ingreso corriente primario:

- Ingresos laborales: compuestos por el monto recibido el mes anterior por concepto de empleo, ganancias netas por actividad, negocio o profesión, ingresos adicionales diferentes de su ocupación u oficio principal, algún otro ingreso por concepto de trabajo, primas o bonificaciones recibidas cada mes, subsidio familiar en dinero, auxilio de transporte y subsidio de alimentación en dinero (capítulo $\mathrm{K}$, de "Fuerza de trabajo" del Anexo 1). El rubro se estima para todas aquellas personas que cumplan las siguientes condiciones: tener cualquier posición ocupacional, ganar algún ingreso proveniente del trabajo, afirmar en la encuesta que han trabajado la semana inmediatamente anterior, en alguna actividad o negocio por el que perciben ingresos y los trabajadores familiares no remunerados.

- Ingresos salariales en especie: en esta categoría se incluyen alimentos como parte de pago del trabajo, vivienda como parte de pago del trabajo, transporte de la empresa, otros ingresos en especie por su trabajo (electrodomésticos, mercados diferentes a alimentos, bonos Sodexo, etc.). Estos ingresos aplican a todas aquellas personas con posición ocupacional de asalariados.

- Transferencias: dentro de esta categoría se encuentran pensiones, dinero para sostenimiento de niños menores de 18 años, ayudas en dinero proveniente de otros hogares o instituciones, subsidio educativo, becas o subsidios de educación otorgados mensualmente y subsidio de vivienda.

1 Para el cálculo se parte de la identificación de la Unidad de Gasto, considerando como tal, de acuerdo con el DANE, a la persona que atiende sus propios gastos, o al grupo de personas que comparten la vivienda y tienen arreglos para satisfacer en común sus necesidades esenciales (gastos de alimentación, servicios de la vivienda, equipamiento y otros gastos del hogar). No hacen parte de la unidad de gasto el pensionista ni los empleados domésticos y sus hijos, a cuyas personas se les considera miembros del hogar pero no se les toma información de gastos. 
- Ingresos de capital y de patrones y empleadores: conformados por los préstamos a particulares, CDT o dividendos por acciones, ingresos por concepto de arriendos de casas, apartamentos, fincas de recreo, lotes, vehículos, maquinaria y equipo; y ganancias netas para empleadores y patrones (sólo aplica para aquellos que hayan contestado ser patrón o empleador en la pregunta de posición ocupacional).

Como ingresos secundarios se tomaron los subsidios percibidos por cada hogar y que se explicarán en más detalle en la parte de imputación de subsidios.

La EM2014 tiene dos módulos dedicados a indagar por los gastos semanales, quincenales, mensuales, semestrales y anuales de cada uno de los hogares. Cada uno de ellos es agregado por hogar y según la frecuencia, y transformados en valores mensuales. Estos gastos totales son una de las aproximaciones de la capacidad de pago de los hogares. Adicionalmente, se construye e imputa una serie de impuestos no incorporados en el módulo de la EM2014.

\section{De los impuestos}

Las facultades tributarias de los entes territoriales en Colombia están limitadas por el marco legal y por el Decreto Ley 1421 de 1993 (título IX), que define un régimen tributario especial para el Distrito Capital de Bogotá.

Una fuente adicional de información con que cuenta este estudio son los registros procesados por la Secretaría Distrital de Planeación (SDP) con apoyo de la Secretaría de Hacienda Distrital (SHD) sobre impuestos. Particularmente, a nivel de hogar en Bogotá D. C. se cuenta con el valor del impuesto de vehículos y el impuesto predial por cada hogar entrevistado. Para aquellos no residentes en Bogotá se toma el valor del impuesto de vehículos reportado en la EM2014.

De esta manera, los impuestos incorporados en los cálculos son los siguientes:

- Impuesto predial unificado: este tributo se impone sobre los bienes raíces ubicados en la ciudad y recae sobre la persona natural o jurídica, poseedora o usufructuaria de predios ubicados en la jurisdicción 
de la ciudad. El cálculo es sobre el auto-avalúo o al avalúo catastral vigente. Las tarifas oscilan entre el 5 y el 16 por mil según la categoría del impuesto predial. Si el predio no está urbanizado, la tarifa es del 33 por mil. Los tributos al año de 2014 por concepto de este impuesto fueron la segunda fuente de recursos y representaron casi un cuarto del recaudo del Distrito Capital. Este impuesto se identifica en la EM2014 a través del código predial donde se realizó la encuesta. Sin embargo, no es posible identificar quién paga el impuesto predial en el caso de que convivan varios hogares en un mismo predio. Por falta de esta información secundaria en los municipios, se toma el valor registrado por la fuente primaria, es decir el valor bruto de la encuesta.

- El impuesto sobre vehículos automotores: va dirigido a quienes tienen propiedad o posesión de un vehículo matriculado en Bogotá D. C. Es cancelado por el propietario del vehículo y las tarifas oscilan entre el 0,5 y 3,5\% según la categoría del automotor. En la encuesta se pregunta de manera directa por este impuesto pero su nivel de subregistro llevó a consultar en la Secretaría de Hacienda del Distrito, y a realizar un proceso de asociación de predios y propietarios de vehículos para obtener un mayor registro. En el caso de los otros municipios de la EM2014, se toma el valor registrado por el entrevistado en la pregunta "iDurante los últimos 12 meses de ... a ... , las personas de este hogar compraron o pagaron uno o más de los siguientes bienes o servicios? 12. Impuesto de vehículos o motos para uso del hogar".

- El impuesto al valor añadido IVA: este impuesto es de orden nacional y se aplica sobre muchos productos, bienes o servicios. Es un impuesto indirecto. Para cada producto o servicio de la EM2014 indagado en la encuesta, se identificó el porcentaje del impuesto y posteriormente se descontó del gasto en el producto o servicio, obteniendo así el valor del producto o servicio, y el monto del impuesto que tuvo que cancelar el hogar. En este ejercicio se supone que los hogares no evaden el pago del IVA.

- El impuesto a la renta y complementarios: este impuesto es de orden nacional y es el que deben pagar todas las personas por sus ingresos laborales o rentas sujetas de impuesto. Para el cálculo de este 
impuesto se imputan las tarifas aplicables a los salarios, e ingresos devengados por cada uno de los miembros del hogar según su base de declaración de impuestos.

\section{Subsidios y contribuciones del hogar}

El cálculo de los subsidios y las contribuciones mantuvo la misma estructura del estudio de Gallego et al. (2015), incorporando algunos elementos de la política social tenidos en cuenta en el año de referencia, en concordancia con lo descrito en el capítulo 2.

Similar a los tributos, el cálculo de subsidios se complementó con la información de registros administrativos para la imputación de subsidios en educación, obtenida por la Secretaría Distrital de Educación, así como la información sobre la asistencia en planes de acciones complementarias en salud PIC de la Secretaría Distrital de Salud, e información de resoluciones sobre los planes obligatorios de salud y del subsidio de transporte obtenidos por la Secretaria de Hacienda Distrital.

A continuación se detalla el cálculo del componente de subsidios y contribuciones.

\section{Subsidios enfocados a la formación de capital humano}

Según la legislación colombiana, todo usuario del sistema general de seguridad social (SGSS), independientemente del régimen al que pertenezca (contributivo-subsidiado), tiene derecho a un conjunto de servicios de atención de salud (POS). En este sentido, cada persona adquiere directamente un seguro por unidad de capitación (UPC). Si contribuye al sistema por medio de sus ingresos laborales, el individuo recibe un seguro por UPC que equivale al POS-contributivo. Esta UPC está diferenciada por edades y género.

Por otro lado, cuando la persona recibe ayudas a través del Sisbén y está afiliada al régimen subsidiado, recibe una UPC (subsidiada) equivalente al POS-s. Con la legislación de 2013, tiene una diferenciación por grupos de edad y de género, como en el caso de la UPC contributiva. Las contribuciones son los aportes realizados por las personas que pertenecen al régimen contributivo y cotizan al sistema de acuerdo con su ingreso base de cotización (IBC). Para computar la contribución se halla el ingreso base de cotización, 
el cual varía dependiendo de si la persona es asalariada, no asalariada o pensionada. El ingreso base de cotización se estima de la siguiente forma:

- Asalariados: el capítulo K (“Fuerza de trabajo”) y las categorías de ingresos laborales, permiten conocer el ingreso de la persona en el mes pasado por concepto de trabajo, en su empleo principal, más los ingresos provenientes de otros trabajos o negocios. Se calcula únicamente para las personas con las siguientes posiciones ocupacionales: obreros, empleado de empresa particular o del gobierno y jornalero o peón. Adicionalmente, cada uno reporta si es cotizante al sGss en el capítulo F ("Salud").

- Ocupados-independientes: para este rubro se tuvo en cuenta la ganancia neta u honorarios netos de los ocupados independientes por concepto de su actividad, negocio, profesión o finca. Este ingreso se contabiliza según la cantidad de meses a los que corresponde ese pago. Similar a los asalariados, los independientes también deben ser cotizantes al SGSS.

- Pensionados: se toma el ingreso base de cotización reportada como ingreso por pensión, luego se calculan las contribuciones de la siguiente manera: para asalariados, se tomó el ingreso reportado en la encuesta como bruto, y se imputa el $12 \%$ como su contribución. Para independientes, se tomó el $40 \%$ del ingreso bruto como base de cotización si el ingreso era superior a dos salarios mínimos y sobre esta cifra se calculó el $12 \%$. En caso contrario, la contribución era el $12 \%$ de dos salarios mínimos. Finalmente, en el caso de los pensionados, se calculó el $12 \%$ de su ingreso por concepto de pensión.

Las ayudas públicas en educación primaria y secundaria pueden ser otorgadas ya sea para cubrir la prestación directa del servicio o para pagar costos complementarios, como útiles, alimentación y transporte (Gallego et al., 2015). Para efectos de nuestro ejercicio, se entiende como subsidio el costo promedio de la prestación del servicio en que incurre el gobierno distrital. Para su cálculo, se tomó como fuente principal el capítulo $\mathrm{H}$ ("Educación") de la EM2014, teniendo en cuenta cinco tipos de ayudas, las 
cuales se describen a continuación destacando las actualizaciones y alternativas de mejora planteadas para la aplicación 2014.

Según la Resolución 5522 de 2013 del Ministerio de Salud y Protección Social se tiene el siguiente perfil demográfico y valor de UPC (tabla 3.1).

Tabla 3.1. Valores de la UPC para 2014 para el régimen subsidiado y contributivo

\begin{tabular}{lrc}
\hline Grupo de edad (perfil epidemiológico) & Valor UPC-S anual (\$) & Valor UPC-C anual (\$) \\
\hline Menores de un año & $1.469 .502,00$ & $1.762 .869,60$ \\
\hline 1-4 años & $434.624,40$ & $566.060,40$ \\
\hline 5-14 años & $173.606,40$ & $197.737,20$ \\
\hline 5-18 años hombre & $204.426,00$ & $188.470,80$ \\
\hline 5-18 años mujer & $339.080,40$ & $297.820,80$ \\
\hline 19-44 años hombre & $340.887,60$ & $335.361,60$ \\
\hline 19-44 años mujer & $539.571,60$ & $622.191,60$ \\
\hline 45-49 años & $551.368,80$ & $615.420,00$ \\
\hline 50-54 años & $689.371,20$ & $784.944,00$ \\
\hline 55-59 años & $836.298,00$ & $959.511,60$ \\
\hline 60-64 años & $1.034 .348,40$ & $1.234 .882,80$ \\
\hline 65-69 años & $1.281 .974,40$ & $1.536 .087,60$ \\
\hline 70-74 años & $1.563 .559,20$ & $1.843 .293,60$ \\
\hline 75 años y más & $1.943 .553,60$ & $2.316 .337,20$ \\
\hline
\end{tabular}

Fuente: Resolución 5522 de 2013, Ministerio de Salud y Protección Social.

- Subsidios por costo promedio estudiante en colegios públicos: la EM2014 identifica a los hogares con personas estudiando en el sector oficial. La tabla 3.2 presenta el valor del costo de la canasta educativa para los colegios públicos y en concesión en Bogotá. El objetivo es imputar el costo marginal de un estudiante en una Institución Educativa Oficial, tomando un valor diferencial dependiendo de las características de la institución educativa. Desafortunadamente, las tarifas anuales en colegios públicos y/o concesión no están disponible para los otros municipios, luego no fue posible de imputarlos para estos casos. 
Tabla 3.2. Valor del costo de la canasta educativa anual colegio públicos y en concesión (2014)

\begin{tabular}{lc}
\hline \multicolumn{1}{c}{ Nivel escolar } & Valor de la canasta educativa (\$) \\
\hline Preescolar & 2.095 .020 \\
\hline Primaria & 1.646 .931 \\
\hline Básica Secundaria & 1.984 .060 \\
\hline Básica Media & 2.026 .384 \\
\hline
\end{tabular}

Fuente: Pérez et al. (2015).

- Subsidios condicionados en dinero por asistencia escolar de la Secretaría de Educación: se calcula a través de una pregunta específica en la EM2014. Este subsidio es otorgado a menores de 18 años cursando secundaria $\left(6^{\mathrm{o}}-11^{\circ}\right)$ y con los requisitos establecidos en la Resolución 4059 de 2011. Se entrega a través de un pago de $\$ 80.000$ cada dos meses, por lo que la estructura de la imputación sería:

$$
\text { Subsidio mensual }=\frac{\$ 40.000 \times 10}{12}
$$

Nuevamente se presenta la dificultad metodológica para los otros municipios, pues no se pudo contar con dicha información.

- Subsidios condicionados en dinero al transporte escolar otorgados por la Secretaría de Educación de Bogotá: similar a Gallego et al. (2015) solamente se modifica el valor utilizado, el cual para el 2014 corresponde a $\$ 116.470$ cada dos meses por un total de 10 meses (año 2015), por lo que la imputación será:

$$
\text { Subsidio mensual }=\frac{\$ 58.235 \times 10}{12}
$$

- Subsidios condicionados en dinero a la asistencia escolar otorgados por el gobierno nacional a través del programa familias en acción: para recibir el subsidio, un niño debe, además encontrarse 
afiliado al programa Familias en Acción, tener menos de 18 años de edad, encontrarse en secundaria $\left(6^{\mathrm{o}}-11^{\circ}\right)$ y mantener un récord mínimo de asistencia escolar. Estos subsidios son diferenciados por grado académico. La imputación se realiza teniendo en cuenta la edad del menor y el nivel de escolarización, de acuerdo con la tabla 3.3 .

Tabla 3.3. Subsidios condicionados a la asistencia escolar

\begin{tabular}{ll}
\multicolumn{1}{c}{ Nivel escolar } & Subsidio \\
\hline Grados 6-8 & $\frac{\$ 25.500 \times 10}{12}$ \\
\hline Grados $9-10$ & $\frac{\$ 30.600 \times 10}{12}$ \\
\hline Grado 11 & $\frac{\$ 45.900 \times 10}{12}$ \\
\hline
\end{tabular}

Fuente: DPS, http://www.dps.gov.co/Paginas/Inicio.aspx

- Subsidios en dinero para estudiar por parte de una entidad pública: al hogar se le pregunta si algún miembro de la familia en edad escolar durante ese año recibió beca en dinero o en especie para estudiar (no incluye los subsidios condicionados ni matrícula subsidiada). Para calcular el subsidio total mensual por estudiante, se sumaron los dos valores reportados, tanto en dinero como en especie (preguntas 26 y 27 del módulo H). Para convertir el dato en cifra mensual se divide dependiendo de la periodicidad del subsidio reportada por el encuestado.

Un grupo adicional de subsidios destinados a la formación de capital humano incluye el costo de cuidado de los niños en jardines del ICBF, estas ayudas en especie se destinan a hogares beneficiarios con niños no escolarizados entre 0 y 7 años de edad. Y estos corresponden a alimentos suministrados por el jardín, ya sea en desayunos, almuerzos u onces de forma gratuita al niño y que la familia responde en la encuesta un valor monetario estimado de esos alimentos. 
Dentro de los subsidios enfocados en formación de capital humano también se consideraron aquellos otorgados por el programa Familias en Acción para nutrición, identificados directamente en la encuesta. Para los niños entre 0 y 6 años el subsidio es de $\$ 54.200$ y para los niños entre 7 y 11 años de $\$ 21.650$.

Finalmente se imputaron los subsidios recibidos por los miembros del hogar que eran beneficiarios del subsidio en transporte para uso del SITP. Este subsidio fue introducido en el año de referencia de este análisis y constituye una de las modificaciones metodológicas de este trabajo con respecto a estudios anteriores. En la encuesta se puede identificar quienes fueron acreedores de este subsidio y de este modo estimar su respectiva tarifa.

\section{Mejorar infraestructura física del hogar}

El cálculo de ayudas sobre servicios públicos domiciliarios se realiza de acuerdo con el estrato declarado en la EM2014 y los gastos reportados por los hogares para los servicios de Acueducto, Alcantarillado y Aseo (AAA), Energía Eléctrica y Gas Natural. Para cada uno se comparan las tarifas pagadas en cada estrato con respecto al costo de la prestación del servicio, tarifas y cargos fijos para el estrato 4 . De esta forma, la diferencia entre estos dos costos será el subsidio recibido o la contribución aportada. El costo de prestación de servicios y de las tarifas aplicadas para cada estrato se obtendrá de la Superintendencia de Servicios Públicos Domiciliarios (SSPD), de las Comisiones de Regulación Correspondientes o de las empresas que prestan los servicios públicos en el área de estudio de la EM2014. Cabe resaltar que para los servicios públicos sólo se cubre con subsidios hasta un tope de consumo y una vez se supera este consumo se aplican tarifas de costo de prestación.

En la gráfica 3.1 se representa con la línea amarilla el gasto en servicios públicos domiciliarios para un hogar que habita en una vivienda de estrato 4 con un consumo total. La pendiente de esta curva es la tarifa por costo de prestación, y como se aprecia la gráfica no inicia en el punto $(0,0)$ pues tiene un cargo fijo, que se debe pagar así no se consuma una sola unidad. Sin pérdida de generalidad, estos cargos se pueden igualar a cero para los servicios públicos donde no se tiene cargo fijo. 
Gráfica 3.1. Metodología para calcular los subsidios en SPD

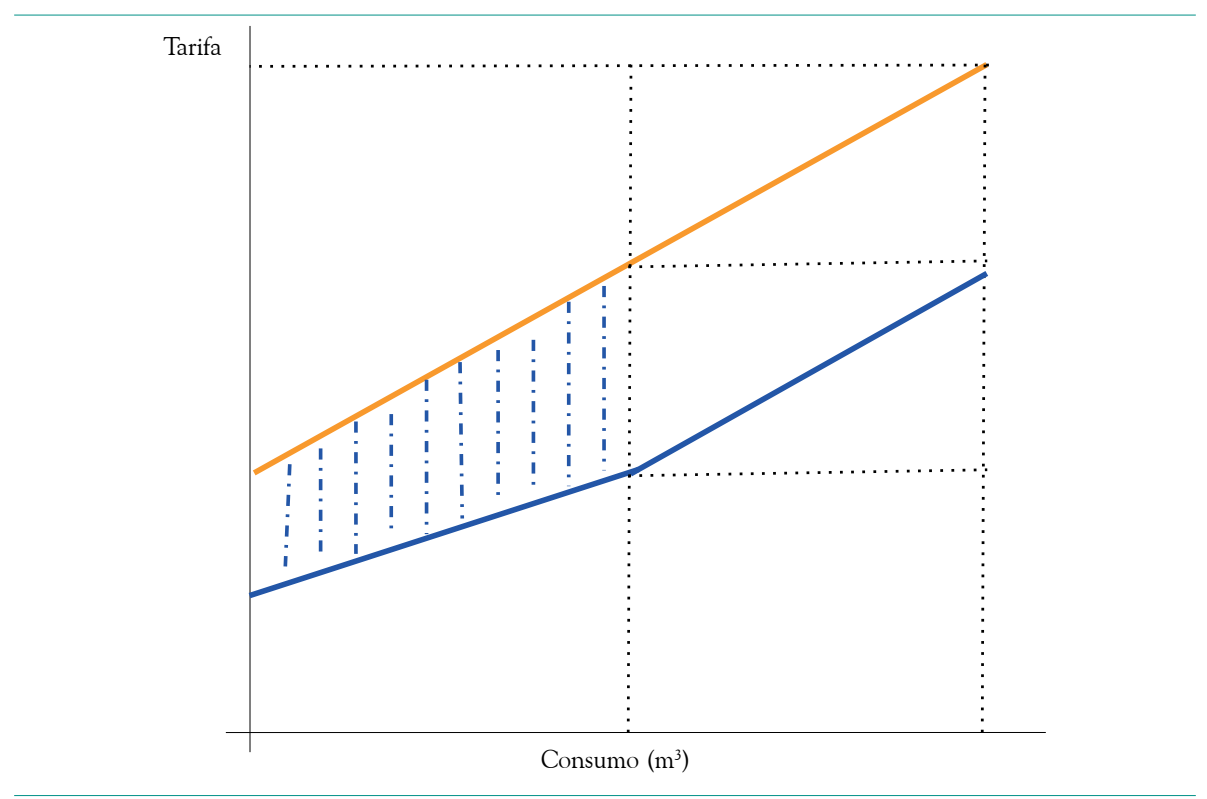

Fuente: Sepúlveda et al. (2014).

La línea azul representa el gasto en servicios públicos para un hogar habitando una vivienda con un estrato subsidiado. La pendiente de la línea azul es menor a la pendiente de la línea amarilla en el rango anterior a CB (consumo básico). Posteriormente, a partir de dicho punto, cambia de pendiente y se iguala a la de la línea amarilla. Eso significa que el hogar empieza a pagar el costo de prestación luego de consumir más del consumo básico. El área sombreada corresponde al subsidio monetario del cual se benefició el hogar por habitar una vivienda ubicada en un estrato beneficiario de subsidio.

Como en la encuesta se reporta el rubro del gasto por cada servicio público domiciliario y se conoce el estrato del hogar, se hará una imputación inicial para aquellos hogares sin ese valor monetario para acueducto, alcantarillado, aseo, energía eléctrica y gas natural.

Gallego et al. (2015) realizaron de la siguiente forma la imputación de los valores monetarios: por servicio público, los hogares que pagan los servicios con el arriendo, hicieron uso de la mediana por estrato para realizar la imputación. En la EM2014 se propone realizar la imputación 
a través del método del vecino más cercano, pero en lugar de tomar directamente el valor monetario, se le imputa el porcentaje que representa dicho valor frente al del arriendo pagado por el hogar. En otras palabras, para los hogares que pagan el servicio público domiciliario con el arriendo, se imputa un porcentaje del valor del arriendo. Dicho porcentaje se encuentra a partir del peso observado en aquellos hogares cuyo pago de arriendo y servicios es separado, pero coinciden en tamaño de hogar, estrato y localidad.

Con este ajuste metodológico habrá simetría en la estimación de estos subsidios con los ejercicios posteriores de estimación de consumo de los servicios públicos domiciliarios. Se tendrá en cuenta, además, el subsidio otorgado por el Decreto 64 de 2012 (monetario) correspondiente al consumo de mínimo vital para el servicio de acueducto $\left(6 \mathrm{~m}^{3}\right.$ mensuales para hogares que habitan viviendas de estrato 1 y 2). El valor del subsidio es mayor, puesto que la pendiente es cero (tarifa cero) para el consumo hasta el mínimo vital de Acueducto de $6 \mathrm{~m}^{3}$ mensuales (gráfica 3.2).

Gráfica 3.2. Metodología para calcular los subsidios en SPD considerando mínimo vital

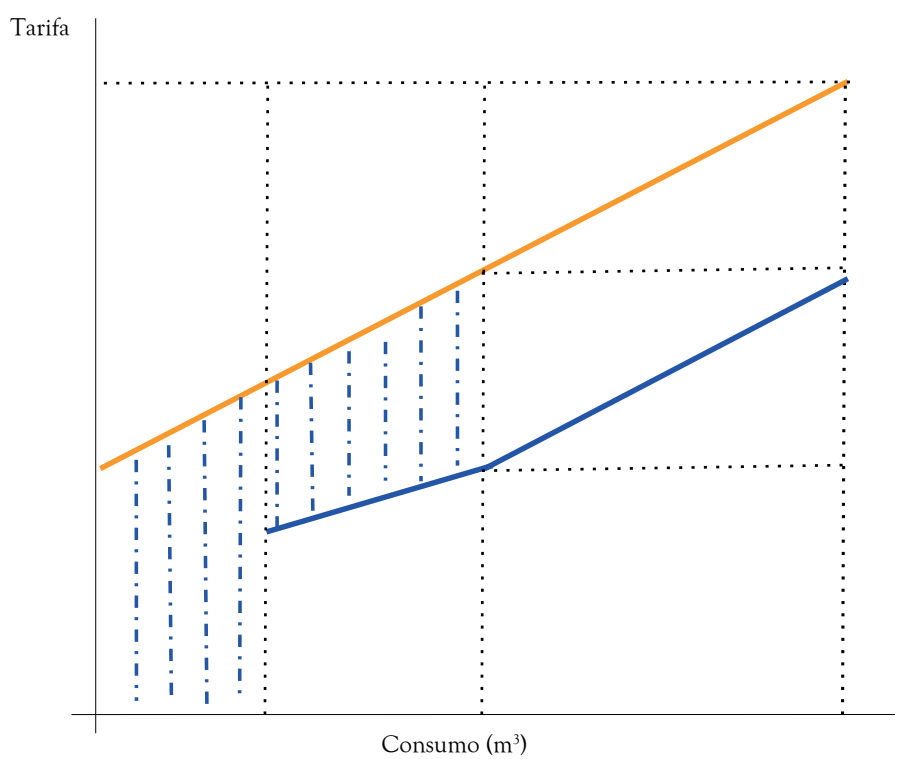

Fuente: cálculos propios con base en Sepúlveda et al. (2014). 
Adicionalmente en la EM2014 se pueden identificar subsidios en especie y/o monetario para mejoramiento en vivienda o para construcción de vivienda, computándose a partir de la información consignada en el capítulo C de la Encuesta. Luego se suman todos los valores monetarios recibidos por el hogar para este aspecto y se dividen en 12 para asignar un dato mensual al hogar. 


\section{Capítulo 4 \\ Resultados y análisis de la estimación del balance financiero neto}

El objetivo principal de este capítulo es estimar cuánto representa el Gasto Público Social (GPS) y la política tributaria en el balance financiero de los hogares bogotanos y en su capacidad de pago. Para la elaboración de dichos cálculos debe tenerse en cuenta la metodología esbozada en capítulos anteriores, donde se hacen explícitas las definiciones e implementación de los diferentes componentes de subsidio, contribuciones e impuesto que determinan un balance de las cuentas financieras de las familias. Para avanzar en este objetivo, en este capítulo se responden y discuten preguntas como ¿cuál es la composición del gasto de los hogares en Bogotá y cuánto destinan a los diferentes rubros financiados por el GPS? ¿Cuánto es el ingreso promedio neto de un hogar en la capital? ¿Cuánto pagan en impuestos y cuáles son las implicaciones en la capacidad de pago? ¿Cuánto reciben en subsidios y cuánto entregan en contribuciones? ¿Cuál es el peso de estos subsidios o contribuciones en el gasto de un hogar en el servicio subsidiado y en el total de gastos?

Se presentan así los resultados obtenidos a partir de la EM2014 frente al balance financiero neto de los hogares bogotanos. La existencia de un estudio precedente dirigido bajo la misma línea permite llevar a cabo un análisis comparativo y enriquecedor respecto a cómo ha evolucionado el rol de subsidios y contribuciones dentro del presupuesto de los hogares entre los años 2011 y 2014. 
El objetivo final del ejercicio es poder observar el nivel de las contribuciones e impuestos sobre los hogares y su impacto en el ingreso disponible como medida final para determinar su capacidad de pago. Tener un enfoque integral de transferencias, contribuciones e impuestos, se convierte en un ejercicio fundamental para aproximarse desde la unidad de gasto (el hogar) a los efectos redistributivos de las políticas fiscales y tributarias. En este libro se sigue el enfoque desarrollado por Gallego et al. (2015), actualizando las estimaciones de la incidencia del GPS sobre la capacidad de pago y la distribución del ingreso a 2014.

Una vez obtenido dicho balance, se puede diferenciar por características del hogar, o por su ubicación geográfica en el interior de la ciudad, ayudando a complementar el análisis del promedio, con una visión sobre el diseño y la focalización de las políticas sociales y tributarias en el espacio urbano. Esto contribuye a tener en cuenta no sólo aspectos de desigualdad y lucha contra la pobreza, sino también entender procesos de segregación urbana (social y económica).

A lo largo del desarrollo de los siguientes apartados se hará énfasis en el rol de los servicios públicos domiciliarios (SPD) dentro del balance financiero neto de los hogares, así como en el análisis de los resultados bajo la teoría de aglomeraciones urbanas. La estructura de la EM2014 avanza frente a la del 2011 al incluir en su muestra 20 municipios y 11 cabeceras de provincia además del Distrito Capital. No obstante, al no existir dichos datos para la misma encuesta en el 2011 se hace imposible llevar a cabo un análisis comparativo a nivel Bogotá-Región entre los periodos considerados.

\section{Cálculo del balance financiero neto de los hogares}

El cálculo del balance financiero neto de los hogares, una vez se consideran las intervenciones del Gobierno, permite hacer una comparación en el tiempo, del ingreso con el que cuentan para suplir sus necesidades. En el presente estudio se utilizó el enfoque de Análisis de Incidencia a fin de evaluar el efecto redistributivo de las políticas sociales y tributarias sobre el presupuesto de los hogares. De esta manera, es deseable que el ingreso disponible sea mayor al ingreso corriente, para aquellos hogares sin capacidad de pago suficiente para suplir sus necesidades básicas por sí solas. De ahí la importancia de focalizar la asistencia social en bienes básicos 
como la vivienda, los servicios de acueducto y alcantarillado, la salud y la educación. De no lograr un ingreso disponible mayor, la política de gasto público estaría empeorando las condiciones de vida de la población más pobre y alejándose de su objetivo de erradicación de la pobreza.

Para iniciar el análisis se calcula para Bogotá y la región el monto total mensual del ingreso corriente (ingreso antes de impuestos y subsidios) y el ingreso disponible (el cual tiene en cuenta la acción de la política pública fiscal en el hogar). De acuerdo con la definición de la CEPAL descrita en el capítulo 3, el ingreso disponible fue calculado como la suma del ingreso corriente y los subsidios menos los impuestos. Este monto representa el presupuesto real con que cuenta un hogar para organizar sus gastos en un periodo de tiempo determinado. La tabla 4.1 presenta el total mensual a nivel de Bogotá y la región para el ingreso disponible y corriente. Los dos montos agregados son estadísticamente equivalentes, significando un nivel de autosuficiencia financiera a nivel global en la ciudad y sus alrededores. Para profundizar sobre el impacto en diferentes rangos de ingreso se requiere diferenciar los grupos poblacionales por su ingreso e identificar de esta manera los hogares contribuyentes o subsidiarios netos.

Tabla 4.1. Ingreso corriente y disponible total mensual para Bogotá y región (millones de pesos de 2014)

\begin{tabular}{lcc}
\hline & Ingreso corriente & Ingreso disponible \\
\hline Total Bogotá y municipios & $7.625 .493,10$ & $7.571 .888,04$ \\
\hline Total Bogotá & $6.770 .048,44$ & $6.697 .100,16$ \\
\hline
\end{tabular}

Fuente: EM2014, cálculos de los autores.

Para poder entender el efecto puntual de la política social se realizaron dos ejercicios de cálculo global del balance financiero de los hogares en Bogotá y los municipios aledaños, desagregando los montos totales mensuales por estrato socioeconómico y por quintil de gasto corriente. El primer grupo de desagregación muestra el efecto de un instrumento tradicional de focalización en servicios públicos domiciliaros. El segundo conjunto de desagregación por gasto corriente permite observar los efectos para los hogares con menor presupuesto y comparar con el efecto por estrato. 
La tabla 4.2 presenta los montos mensuales totales para Bogotá y la región del ingreso corriente y del ingreso disponible por estrato. Para el 2014 la política fiscal agregada favoreció la capacidad de pago de los estratos 1 y 2 y redujo el presupuesto de aquellos estratos superiores, es decir del estrato 3 al 6. Lo anterior sugiere un análisis descriptivo de las posibilidades de los gobiernos nacionales y locales para redistribuir recursos de los hogares más adinerados hacia los menos favorecidos.

Las columnas 3 y 6 de la tabla 4.2 presentan el cociente entre el ingreso corriente y el ingreso disponible. Valores inferiores a la unidad indican efecto redistributivo del gasto social hacia un grupo poblacional, en este caso los hogares de estratos 1 y 2 . De igual forma, valores superiores a la unidad identifican a contribuyentes netos. Para el caso de los hogares en estrato 3, pese a tener subsidios en SPD y otros subsidios identificados en la encuesta, su carga impositiva tiene el efecto contrario. Al final, el ingreso disponible termina siendo menor al ingreso corriente. Este resultado puede darse por los altos errores de inclusión en la asignación de este estrato en Bogotá (Sepúlveda et al., 2014). Parte importante de hogares en el estrato 3 tienen ingresos suficientes para no recibir subsidios en servicios públicos domiciliarios. Una buena focalización tributaria por el lado de ingreso logra contrarrestar el efecto del error de inclusión de la estratificación.

Desde otra mirada, los coeficientes de la razón ingreso corriente contra ingreso disponible disminuye para estratos 1 y 2 al tener en cuenta sólo a Bogotá comparados con el mismo cálculo agregando toda la muestra. Esto ocurre en parte por la capacidad de las grandes urbes de mejorar sustancialmente, el bienestar de sus hogares residentes, a través de diversos instrumentos sociales, en comparación con ciudades o localidades pequeñas (Cap. 1).

El segundo ejercicio de análisis por quintiles de gasto confirma la conclusión anterior. La imputación de subsidios e impuestos genera una redistribución del ingreso de los hogares con mayor capacidad de pago hacia los de menores niveles de capacidad de pago. Para los quintiles del 1 al 3 se evidencia la acción del gasto público social al tener un impacto positivo en el ingreso disponible. Para quintiles altos (4 y 5), la relación es opuesta y el ingreso disponible disminuye frente al corriente, pasando a ser hogares contributivos dentro del sistema impositivo y redistributivo. 
Tabla 4.2. Total de ingreso corriente y disponible por estrato para todos los municipios de la EM2014 (valores en pesos de 2014)

\begin{tabular}{|c|c|c|c|c|c|c|}
\hline & & Bogotá & & Bog & otá y Región & \\
\hline & $\begin{array}{l}\text { Ingreso corriente } \\
\text { (IC) }\end{array}$ & $\begin{array}{l}\text { Ingreso disponible } \\
\text { (ID) }\end{array}$ & $\begin{array}{l}\text { Razón } \\
\text { IC/ID }\end{array}$ & Ingreso corriente (IC) & $\begin{array}{l}\text { Ingreso disponible } \\
\text { (ID) }\end{array}$ & $\begin{array}{l}\text { Razón } \\
\text { IC/ID }\end{array}$ \\
\hline 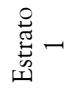 & $275.591 .722 .118^{*}$ & $358.621 .682 .744 *$ & $0,768^{*}$ & $387.813 .131 .114 *$ & $489.010 .325 .627 *$ & $0,793^{*}$ \\
\hline 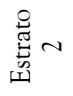 & $1.570 .246 .195 .134 *$ & 1.788.718.986.751* & $0,878^{*}$ & $1.934 .092 .366 .730 *$ & 2.170.963.850.410* & $0,891 *$ \\
\hline 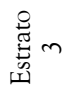 & $2.432 .831 .661 .896^{*}$ & $2.375 .443 .679 .887^{*}$ & $1,024 *$ & 2.676.394.960.748* & $2.612 .590 .523 .849 *$ & $1,024 *$ \\
\hline 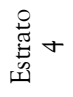 & $1.263 .336 .855 .101 *$ & $1.138 .248 .228 .608^{*}$ & $1,110 *$ & $1.366 .477 .830 .960 * *$ & $1.233 .209 .454 .129 * *$ & $1,108^{*}$ \\
\hline 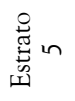 & $613.528 .671 .302 * *$ & $534.221 .674 .758 * *$ & $1,148^{*}$ & $632.351 .755 .586^{* * * *}$ & $551.325 .255 .468 * * *$ & $1,147^{*}$ \\
\hline 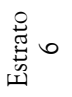 & $614.513 .330 .229 * *$ & $501.845 .904 .357 * *$ & $1,225^{*}$ & $624.801 .548 .632 * * *$ & $510.746 .936 .880 * * *$ & $1,223^{*}$ \\
\hline 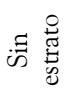 & & & & $3.561 .507 .852 * * * *$ & $4.041 .692 .879 * * * *$ & $0,880 *$ \\
\hline
\end{tabular}

*Coeficiente de variación inferior al $7 \%$ **Coeficiente de variación entre el 8 y el 14\%.***Coeficiente de variación entre 15 y $20 \%$. ****Coeficiente de variación superior al $20 \%$.

Fuente: EM2014, cálculos de los autores.

Tabla 4.3. Total de ingreso corriente y disponible por quintil de gasto corriente para todos los municipios de la EM2014 (valores en pesos de 2014)

\begin{tabular}{ccccccc}
\hline \multirow{2}{*}{$\begin{array}{c}\text { Quintil } \\
\text { Gasto }\end{array}$} & \multicolumn{3}{c}{ Bogotá } & \multicolumn{3}{c}{ Bogotá y región } \\
\cline { 2 - 7 } & $\begin{array}{c}\text { Ingreso corriente } \\
(\mathrm{IC})\end{array}$ & $\begin{array}{c}\text { Ingreso disponible } \\
(\mathrm{ID})\end{array}$ & $\begin{array}{c}\text { Razón } \\
\text { IC/ID }\end{array}$ & $\begin{array}{c}\text { Ingreso corriente } \\
(\mathrm{IC})\end{array}$ & $\begin{array}{c}\text { Ingreso disponible } \\
\text { (ID) }\end{array}$ & $\begin{array}{c}\text { Razón } \\
\text { IC/ID }\end{array}$ \\
\hline 1 & 430.631 .114 .067 & 548.169 .521 .414 & 0,79 & 588.347 .014 .741 & 734.471 .877 .842 & 0,80 \\
\hline 2 & 658.467 .491 .289 & 773.634 .738 .657 & 0,85 & 815.655 .034 .808 & 942.781 .207 .110 & 0,87 \\
\hline 3 & 987.614 .453 .488 & 1.055 .120 .453 .114 & 0,94 & 1.156 .829 .871 .609 & 1.225 .977 .986 .065 & 0,94 \\
\hline 4 & 1.465 .128 .364 .954 & 1.442 .505 .382 .833 & 1,02 & 1.623 .512 .408 .237 & 1.596 .209 .349 .555 & 1,02 \\
\hline 5 & 3.228 .207 .011 .983 & 2.877 .670 .061 .088 & 1,12 & 3.441 .148 .772 .226 & 3.072 .447 .618 .671 & 1,12 \\
\hline
\end{tabular}

Fuente: EM2014, cálculos de los autores. 


\section{Estimación de la capacidad de pago de los hogares}

Como medidas de la capacidad de pago se hará uso de dos métricas: i) el gasto del hogar como medida del presupuesto del hogar; y ii) el ingreso corriente del hogar. Medir la capacidad de pago utilizando el gasto del hogar contribuye al objetivo de comparar el impacto financiero de la política social en la distribución de gasto de los rubros objeto de subsidios. La segunda forma, por medio del ingreso corriente, permite entender el presupuesto corriente de los hogares destinado a la adquisición de determinados bienes y servicios, y construir una métrica de la distribución del ingreso, antes y después de la acción del Gobierno. La tabla 4.4 presenta el gasto total y el gasto promedio por hogar, discriminado de igual forma por estrato socioeconómico.

Tabla 4.4. Gasto total y gasto promedio mensual para todos los municipios de la EM2014 (valores en pesos de 2014)

\begin{tabular}{|c|c|c|c|c|c|c|}
\hline & \multicolumn{3}{|c|}{ Bogotá } & \multicolumn{3}{|c|}{ Bogotá y Región } \\
\hline & Gasto total & Gasto promedio & $\begin{array}{c}\mathrm{N}^{\circ} \mathrm{de} \\
\text { personas }\end{array}$ & Gasto total & Gasto promedio & $\begin{array}{c}\mathrm{N}^{\circ} \mathrm{de} \\
\text { personas }\end{array}$ \\
\hline Estrato 1 & $385.278 .169 .140 *$ & $1.730 .806^{*}$ & 4 & $529.214 .650 .084 *$ & $1.589 .586^{*}$ & 4 \\
\hline Estrato 2 & $2.005 .120 .369 .457^{*}$ & $2.133 .486^{*}$ & 3 & 2.429.270.813.285* & $2.081 .616^{*}$ & 3 \\
\hline Estrato 3 & 2.949.737.689.961* & $3.282 .357^{*}$ & 3 & $3.222 .628 .392 .806^{*}$ & $3.227 .328 *$ & 3 \\
\hline Estrato 4 & $1.284 .654 .700 .392^{*}$ & $5.580 .852 *$ & 3 & $1.390 .793 .435 .547^{*}$ & $5.533 .425 *$ & 3 \\
\hline Estrato 5 & $647.169 .193 .785^{*}$ & $8.093 .166^{*}$ & 3 & $667.804 .395 .829 *$ & $8.086 .000 *$ & 3 \\
\hline Estrato 6 & $607.562 .168 .296^{*}$ & $9.102 .973 *$ & 2 & $618.236 .342 .839 *$ & $9.132 .312 *$ & 2 \\
\hline Sin estrato & & & & $4.799 .133 .912 * * *$ & $1.201 .177 * * *$ & 3 \\
\hline Total & 7.879.522.291.031* & $3.231 .967^{*}$ & 3 & 8.862.747.164.303* & $3.051 .798^{*}$ & 3 \\
\hline
\end{tabular}

*Coeficiente de variación inferior al $7 \%$ **Coeficiente de variación entre el 8 y el 14\%.***Coeficiente de variación entre 15 y $20 \%$. ****Coeficiente de variación superior al $20 \%$.

Fuente: EM2014, cálculos de los autores.

Se tiene así un crecimiento del gasto promedio a través de los estratos, siendo el gasto promedio del estrato 6 unas 5,3 veces el gasto del estrato 1 . Sin embargo, al revisarlo frente al número de personas promedio, es decir el gasto per cápita, se duplica esta relación. Mientras en el estrato 1 gastan en promedio 432.702 por persona, para el estrato 6 la cifra asciende a $\$ 4.551,48$. Las estadísticas se mantienen cuando se adiciona el resto de los 
municipios de la encuesta. Al momento de considerar el análisis de política social, debe recordarse este gradiente de un mayor nivel socioeconómico medido a través del gasto y un menor número de miembros del hogar, a medida que aumenta el estrato socioeconómico. Varios subsidios se focalizan en las personas, variable a dimensionar dentro de los instrumentos de focalización.

La gráfica 4.1 presenta una comparación del promedio del ingreso corriente, el gasto del hogar y el ingreso disponible por estrato, y pone en evidencia el efecto del gasto público social pues los ingresos corrientes se ven afectados por los subsidios y los impuestos. De igual forma, compara las dos medidas de capacidad de pago, evidenciando patrones de distribución similares.

Gráfica 4.1. Ingreso corriente, ingreso disponible y gasto promedio mensual por hogar Bogotá + Región (valores en pesos de 2014)

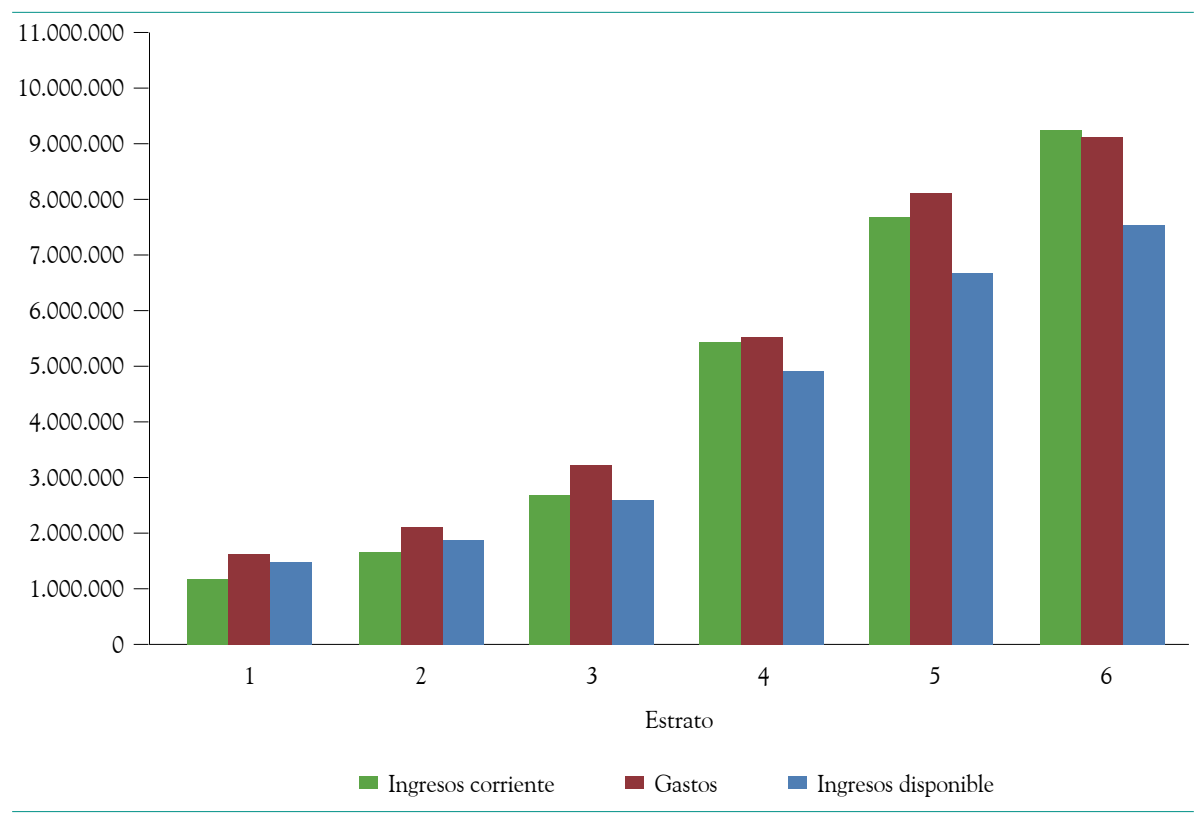

Fuente: EM2014, cálculos de los autores.

\section{Patrones de gasto en Bogotá}

El gasto total de los hogares a nivel agregado se estimó en 7,88 billones de pesos de 2014 y el gasto promedio mensual fue cerca de 3,2 millones 
(tabla 4.4). La tabla 4.5 muestra como un hogar promedio en Bogotá distribuye este presupuesto, diferenciando por estratos. Los dos rubros con mayor participación en el gasto son los de alimentos, representando un $34 \%$ del presupuesto, y vivienda, con valores cercanos al $24 \%$; de este modo, los dos rubros abarcan más de la mitad del gasto de un hogar. En tercer orden está el gasto en transporte urbano con un 7,8\% del gasto, indicando la relevancia que adquieren los costos de movilizarse al interior de la ciudad. Por la participación siguen tres grupos de gasto sujetos a ser financiados por el GPS: salud $(6,8 \%)$, educación $(5,47 \%)$ y SPD $(4,14 \%)$, sumado al $17 \%$ del total.

Tabla 4.5. Patrón de gasto del hogar por estrato según grandes rubros de gasto en la ciudad de Bogotá (porcentajes)

\begin{tabular}{ccccccccc}
\hline Estrato & Alimentos & Vivienda & Otros & Transporte & Salud & Educación & SPD & Total \\
\hline 1 & 44,62 & 20,68 & 13,70 & 8,98 & 4,69 & 3,72 & 3,61 & 100 \\
\hline 2 & 38,27 & 22,99 & 15,31 & 8,50 & 5,84 & 4,83 & 4,26 & 100 \\
\hline 3 & 32,30 & 25,11 & 17,44 & 7,39 & 7,15 & 6,18 & 4,42 & 100 \\
\hline 4 & 22,89 & 28,72 & 20,71 & 7,23 & 9,92 & 7,22 & 3,30 & 100 \\
\hline 5 & 20,36 & 30,41 & 20,81 & 7,32 & 11,02 & 6,57 & 3,51 & 100 \\
\hline 6 & 20,21 & 36,67 & 20,66 & 5,37 & 9,52 & 3,53 & 4,03 & 100 \\
\hline Total & 34,12 & 24,72 & 16,79 & 7,89 & 6,87 & 5,47 & 4,14 & 100 \\
\hline
\end{tabular}

Fuente: EM2014, cálculos de los autores.

Discriminar por estrato permite además dimensionar la importancia de ciertos subsidios focalizados bajo ese criterio (tabla 4.5). Para estratos 1 y 2 , por ejemplo, el porcentaje en educación, salud y SPD representa el $12 \%$ y $15 \%$ del gasto, respectivamente.

La distribución de gasto por estrato muestra otros patrones destacables. Entre mayor es el estrato, más importante es la participación del gasto en vivienda y salud. El gasto de vivienda recoge el valor de la tierra, una variable estática en nuestro marco de economías de aglomeraciones. En el caso puntual de Bogotá también está lógicamente explicado por su alto costo en sectores particulares de la ciudad donde se encuentran hogares con alta capacidad de pago, viviendas de alta calidad y un adecuado entorno; todas variables incluidas en la definición de estrato socioeconómico. Por 
su parte, el gasto en salud refleja el costo de los planes complementarios o de medicina pre-pagada adquiridos con mayor probabilidad por los hogares de altos ingresos.

Frente al grupo de gastos decrecientes por estrato, se encuentran los servicios públicos domiciliarios (SPD), los alimentos y el transporte. Los SPD no representan un porcentaje muy alto del presupuesto del hogar en estratos altos, a pesar de no recibir subsidios en este frente. La relación negativa entre el peso de los alimentos en el gasto y estrato, refleja la Ley de Engel bajo la cual la importancia de los alimentos en un hogar disminuye con mejoras en el ingreso, o en este caso con una proxy del mismo como es el estrato. Un mayor esfuerzo presupuestal en transporte para hogares de estrato bajo justifica, por otro lado, la existencia de políticas de focalización de subsidios hacia la movilidad que garanticen el libre desarrollo de las personas y su derecho a movilizarse para acceder a los beneficios de la urbe. Finalmente, el gasto en educación tiene un comportamiento creciente en el presupuesto del hogar desde el estrato 1 hasta el 4 y después decrece.

La estructura de gasto analizada anteriormente para el 2014 es muy similar a la explicada en estudios como el de Gallego et al. (2015). Aunque los montos y los porcentajes difieren, se mantienen los patrones de relevancia de los rubros y sus comportamientos a lo largo de la distribución por estrato.

La tabla 4.6 compara la dinámica de los gastos promedios de los hogares bogotanos y sus componentes para 1997, 2003, 2011 y 2014. Para el año 2014 se observan variaciones significativas en rubros como alimentación y transporte. El gasto en alimentos aumentó sustancialmente al $34 \%$ cuando en las estimaciones de años anteriores había fluctuado alrededor del $22 \%$. El gasto en transporte y comunicaciones disminuyó a un 9,6\%, frente a un promedio de comparación levemente superior al $12 \%$, lo cual sugiere un posible impacto positivo de política de subsidios a la movilidad. El aumento sustancial en alimentos puede estar explicado por una liberación de gastos en educación y salud de los hogares más pobres, los cuales son rubros que han venido disminuyendo sustancialmente debido al GPS. El gasto en salud experimentó la mayor caída como porcentaje del gasto total, lo cual puede estar asociado a mayores beneficios en salud, como por ejemplo, aumento en la cobertura del POS-S y disminución de precios. En especial se destaca la política de gratuidad en educación para el sector público. El gasto 
en vivienda presenta un comportamiento estable a lo largo de los años, reflejando la permanente importancia de este rubro para el presupuesto del hogar, y no muestra un cambio sustancial en el precio de la tierra de la ciudad que demande reestructuraciones de presupuesto por parte de las familias. Finalmente, se destaca la caída sustancial del gasto en cultura y esparcimiento (1,8 puntos porcentuales). Este rubro no tiene un foco en este estudio, pero amerita especial atención de mantenerse esta tendencia a lo largo del tiempo.

Tabla 4.6. Evolución-distribución del gasto de los hogares para la ciudad de Bogotá (porcentaje)

\begin{tabular}{|c|c|c|c|c|}
\hline Rubro & 1997 & 2003 & 2011 & 2014 \\
\hline Alimentos & 20,0 & 23,2 & 21,9 & 34,12 \\
\hline Vivienda & 29,7 & 27,7 & 28,4 & 28,86 \\
\hline Vestuario & 3,6 & 2,3 & 4,5 & 1,10 \\
\hline Salud & 9,2 & 5,8 & 12,2 & 6,87 \\
\hline Educación & 8,5 & 9,0 & 7,3 & 5,47 \\
\hline Cultura y esparcimiento & 2,3 & 2,5 & 2,3 & 0,51 \\
\hline Transporte y comunicaciones & 12,5 & 17,3 & 12,7 & 9,62 \\
\hline Gastos varios & 14,1 & 12,6 & 10,7 & 13,45 \\
\hline Gasto total & 100,0 & 100,0 & 100,0 & 100,0 \\
\hline
\end{tabular}

Fuente: actualización de la tabla 5.2 de Gallego et al. (2015).

\section{Valor de los subsidios y contribuciones directas percibido por los hogares}

Las diferencias entre los gastos por estrato socioeconómico resaltan el posible impacto del GPS como canal conducente a subsanar brechas en capacidad de pago, con implicaciones sobre las desigualdades en ingreso o gasto. En este contexto, es relevante preguntarse cuánto representa el monto en subsidios neto de contribuciones recibidas o aportadas por un hogar promedio, discriminando por estrato socioeconómico, quintil de gasto o localización geográfica. Y quizás aún más importante, cuánto representa ese subsidio o contribución como porcentaje del gasto total de los hogares. Como se ha planteado previamente, la política fiscal focaliza gran parte de su esfuerzo 
en grupos presupuestales básicos que ascienden a $18 \%$ del presupuesto de un hogar, sin tener en cuenta el rubro de vivienda. Considerándolo con grupos básicos como salud, educación y SDP, el objetivo del GPS podría tener influencia sobre cerca de la mitad del presupuesto de las familias. En muchos casos el Estado no logra subsidiar la totalidad de un servicio específico, y por tal motivo se diseñan esquemas donde el consumidor del servicio debe contribuir con un porcentaje a través de un pago directo. Los servicios públicos domiciliarios, por ejemplo, no son subsidiados en su totalidad y los niveles de consumo que superen los puntos de corte, entendidos como consumo de subsistencia, estarán sujetos por lo menos a la tarifa plena y en algunos casos a una contribución adicional.

\section{Subsidios promedio por hogar}

La tabla 4.7 presenta el subsidio promedio que recibe un hogar en Bogotá, en las seis áreas de gasto susceptibles del apoyo estatal, discriminado por estrato (panel A), quintil del gasto total (panel B) y localidades de Bogotá D. C. (panel C). El cálculo neto entre subsidios y contribuciones muestra, en promedio, la posibilidad para un hogar ubicado en la ciudad de llegar a ser un potencial beneficiario de un subsidio neto mensual por valor de $\$ 126.252$, de los cuales la mayor parte provienen del Distrito Capital a través de la provisión en educación, por un valor de $\$ 84.023$ pesos de 2014, y por el subsidio neto en SPD, el cual se ubica en $\$ 34.751$.

Otros subsidios positivos para un hogar promedio capitalino son vivienda con $\$ 3.189$, componente de nutrición de Familias en Acción por \$507 y el cuidado de los niños por un valor de $\$ 20.252$. Para el caso de salud un hogar promedio en Bogotá se constituye en un contribuyente neto con un promedio de $\$ 16.510$ mensuales. Con el fin de entender el efecto de los subsidios sobre la distribución del ingreso, vía efectos sobre el presupuesto del hogar, se discriminan por estratos socioeconómicos y por quintiles de ingreso, analizando correspondencia entre ambos. Una adecuada focalización de subsidios (cruzados) a través de la estratificación socioeconómica debería coincidir con una efectividad de esa focalización a partir de la distribución del ingreso.

Un hogar promedio del quintil inferior de ingreso percibió cerca de \$273 mil de subsidios en las cinco áreas de atención gubernamental tenidas 
en cuenta en este estudio (panel B). Como era de esperarse, la mayor proporción de ese monto lo constituyen las ayudas monetarias directas e indirectas en educación, salud y en menor proporción la correspondiente a SPD. Los hogares pertenecientes al segundo quintil de ingreso obtuvieron, en promedio, casi 23 mil pesos más frente a aquellos pertenecientes al quintil más bajo. Los quintiles de ingresos mayores ( 3 y 4), recibieron una menor asistencia social pero igualmente positiva, por valores de $\$ 228$ mil y $\$ 91$ mil, respectivamente. Por último, los hogares del quintil superior de ingresos/gasto contribuyeron en promedio con $\$ 258$ mil. El hecho de encontrar ayudas en los quintiles 3 y 4 llama la atención sobre problemas de focalización en la política social, en la cual, aquellos con mayor capacidad de pago reciben subsidios netos. Sin embargo, el resultado puede tener impactos, no medidos en este trabajo, sobre otros aspectos de las políticas sociales, como aquellos enfocados en la disminución de la segregación urbana; hogares con ingresos medio-alto buscan enviar a sus hijos a colegios distritales, para poder acceder a dichos subsidios, predominantes demandados por hogares ubicados de bajos ingresos. De igual manera, en Servicios Públicos Domiciliarios aumenta la demanda de arriendos y compra de bienes residenciales subsidiados (estratos 1, 2 o 3) o con relativa menor contribución (estrato 4 frente a 5 y 6). Lo anterior plantea un debate entre la integralidad de una política social de lucha contra la segregación y una política de lucha contra la desigualdad, lo cual no necesariamente puede generar resultados similares.

$\mathrm{Al}$ analizar las localidades de la ciudad, lo primero para resaltar es la recepción neta de subsidios en hogares en 16 de ellas. Sobresalen como receptores de subsidios Ciudad Bolívar y Usme, en donde una familia promedio recibió $\$ 342$ mil y $\$ 358$ mil, respectivamente, de los cuales cerca del $45 \%$ fueron ayudas enfocadas a educación. Como principales aportantes promedio, estuvieron los hogares de Chapinero y Teusaquillo, quienes contribuyeron con valores entre $\$ 320$ mil y $\$ 200$ mil. Este resultado refuerza lo expresado anteriormente sobre la localización geográfica de los subsidios. En este capítulo se observa a un nivel agregado de localidad y más adelante se analizará el nivel de correlación espacial de los subsidios. 
Tabla 4.7. Subsidios y contribuciones promedio mensual del hogar para la ciudad de Bogotá (valores en pesos 2014)

\begin{tabular}{|c|c|c|c|c|c|c|c|}
\hline & SPD & Vivienda & FA (Nutrición) & Jardín & Educación & Salud & Total \\
\hline \multicolumn{8}{|c|}{ Panel A: Estrato } \\
\hline 1 & 86.478 & 1.112 & 2.071 & 34.729 & 160.568 & 131.043 & 416.001 \\
\hline 2 & 68.082 & 4.457 & 761 & 27.023 & 115.063 & 82.007 & 297.393 \\
\hline 3 & 13.858 & 3.157 & 173 & 14.411 & 63.300 & $(22.365)$ & 72.534 \\
\hline 4 & 0 & 2.178 & 0 & 12.358 & 14.321 & $(257.936)$ & $(229.079)$ \\
\hline 5 & $(67.287)$ & 0 & 18 & 3.435 & 9.310 & $(418.632)$ & (473.156) \\
\hline 6 & $(83.679)$ & 0 & 0 & 2.616 & 575 & $(502.584)$ & $(583.072)$ \\
\hline \multicolumn{8}{|c|}{ Panel B: Quintiles de gasto } \\
\hline 1 & 50.496 & 1.974 & 853 & 24.120 & 93.795 & 102.015 & 273.253 \\
\hline 2 & 52.490 & 1.579 & 1.003 & 24.073 & 119.977 & 97.636 & 296.758 \\
\hline 3 & 44.650 & 5.186 & 557 & 22.378 & 108.575 & 46.703 & 228.049 \\
\hline 4 & 30.718 & 2.398 & 211 & 18.210 & 65.982 & $(26.017)$ & 91.502 \\
\hline 5 & $(4.584)$ & 4.809 & 111 & 12.478 & 31.810 & $(302.798)$ & $(258.174)$ \\
\hline \multicolumn{8}{|c|}{ Panel C: Localidades } \\
\hline Antonio Nariño & 17.324 & 1.996 & 288 & 21.034 & 78.090 & 25.812 & 144.544 \\
\hline Barrios Unidos & 7.685 & 2.685 & 507 & 10.936 & 59.463 & $(66.887)$ & 14.389 \\
\hline Bosa & 67.683 & 2.503 & 955 & 31.165 & 128.584 & 95.494 & 326.384 \\
\hline Chapinero & $(27.540)$ & 133 & 27 & 6.005 & 22.211 & $(321.528)$ & $(320.692)$ \\
\hline Ciudad Bolívar & 75.951 & 5.853 & 2.165 & 28.207 & 126.223 & 104.444 & 342.843 \\
\hline Engativá & 26.755 & 4.580 & 122 & 12.199 & 64.160 & $(26.107)$ & 81.709 \\
\hline Fontibón & 19.630 & 3.246 & 155 & 25.197 & 59.268 & $(99.051)$ & 8.445 \\
\hline Kennedy & 45.197 & 5.032 & 171 & 19.798 & 91.232 & 30.229 & 191.659 \\
\hline La Candelaria & 53.393 & 1.464 & 275 & 14.445 & 44.257 & $(47.303)$ & 66.531 \\
\hline Los Mártires & 17.494 & 829 & 354 & 15.591 & 75.057 & 42.348 & 151.673 \\
\hline Puente Aranda & 14.715 & 701 & 73 & 11.760 & 60.290 & 2.945 & 90.484 \\
\hline Rafael Uribe Uribe & 45.868 & 4.982 & 712 & 29.485 & 114.745 & 78.782 & 274.574 \\
\hline San Cristóbal & 63.196 & 1.190 & 693 & 22.781 & 137.169 & 95.516 & 320.545 \\
\hline Santafé & 50.948 & 1.410 & 655 & 19.450 & 93.515 & 35.730 & 201.708 \\
\hline
\end{tabular}




\begin{tabular}{lccccccc}
\hline & SPD & Vivienda & FA (Nutrición) & Jardín & Educación & Salud & Total \\
\hline Suba & 21.094 & 2.304 & 349 & 24.390 & 64.945 & $(98.041)$ & 15.041 \\
\hline Teusaquillo & $(305)$ & 3.220 & 24 & 8.768 & 17.768 & $(229.659)$ & $(200.184)$ \\
\hline Tunjuelito & 47.325 & 4.365 & 999 & 22.808 & 90.361 & 40.905 & 206.763 \\
\hline Usaquén & $(8.994)$ & 850 & 18 & 10.855 & 41.758 & $(174.322)$ & $(129.835)$ \\
\hline Usme & 75.623 & 3.137 & 1.588 & 23.633 & 144.175 & 110.800 & 358.956 \\
\hline Total & 34,751 & 3,189 & 547 & 20,252 & 84,023 & $(16.510)$ & 126,252 \\
\hline
\end{tabular}

Fuente: EM2014, cálculos de los autores.

\section{Impuestos}

En la ciudad de Bogotá, los hogares pagaron una suma mensual promedio de $\$ 164.963$ en impuestos (ver tabla 4.8), siendo aquellos residenciados en las localidades de Chapinero, Usaquén, Teusaquillo, Suba, Engativá, Fontibón, Barrios Unidos y La Candelaria, quienes se ubican por encima de este promedio mensual.

Tabla 4.8. Impuestos promedio mensual por hogar para la ciudad de Bogotá (valores en pesos de 2014)

\begin{tabular}{cccccc}
\hline & Rodamiento & Predial & IVA & Renta & Total \\
\hline Estratos & \multicolumn{5}{c}{ Panel A: Estrato } \\
\hline 1 & 61.852 & 25.296 & 36.626 & 7.426 & 131.200 \\
\hline 2 & 31.946 & 70.812 & 47.767 & 9.032 & 159.557 \\
\hline 3 & 49.222 & 76.366 & 83.317 & 12.534 & 221.439 \\
\hline 4 & 80.563 & 367.779 & 196.601 & 38.697 & 683.640 \\
\hline 5 & 83.597 & 217.766 & 313.514 & 36.893 & 651.770 \\
\hline 6 & 101.885 & 1.078 .864 & 385.400 & 93.969 & 1.660 .118 \\
\hline Quintiles & & Panel B: Quintiles de gasto & \\
\hline 1 & 30.793 & 57.809 & 24.705 & 6.798 & 120.105 \\
\hline 2 & 79.283 & 54.585 & 34.301 & 10.090 & 178.259 \\
\hline 3 & 33.550 & 89.804 & 52.634 & 10.559 & 186.547 \\
\hline 4 & 51.726 & 94.261 & 81.220 & 13.632 & 240.839 \\
\hline 5 & 75.398 & 526.232 & 301.180 & 54.169 & 956.979 \\
\hline & & & &
\end{tabular}




\begin{tabular}{|c|c|c|c|c|c|}
\hline & Rodamiento & Predial & IVA & Renta & Total \\
\hline Localidades & \multicolumn{5}{|c|}{ Panel C: Localidades } \\
\hline Antonio Nariño & 37.617 & 152.962 & 90.929 & 16.890 & 298.398 \\
\hline Barrios Unidos & 42.980 & 558.460 & 65.305 & 40.005 & 706.750 \\
\hline Bosa & 25.634 & 45.213 & 38.045 & 6.534 & 115.426 \\
\hline Chapinero & 162.413 & 297.722 & 228.075 & 41.293 & 729.503 \\
\hline Ciudad Bolívar & 28.036 & 11.494 & 43.793 & 4.999 & 88.322 \\
\hline Engativá & 141.366 & 37.245 & 126.038 & 18.279 & 322.928 \\
\hline Fontibón & 47.849 & 141.496 & 166.772 & 21.367 & 377.484 \\
\hline Kennedy & 30.522 & 56.109 & 95.138 & 10.906 & 192.675 \\
\hline La Candelaria & 181.681 & 197.105 & 77.578 & 27.382 & 483.746 \\
\hline Los Mártires & 37.775 & 75.004 & 56.760 & 10.172 & 179.711 \\
\hline Puente Aranda & 53.441 & 68.516 & 58.965 & 10.855 & 191.777 \\
\hline Rafael Uribe Uribe & 26.664 & 59.178 & 67.437 & 9.197 & 162.476 \\
\hline San Cristóbal & 43.304 & 13.626 & 101.235 & 9.490 & 167.655 \\
\hline Santafé & 70.761 & 187.253 & 111.782 & 22.188 & 391.984 \\
\hline Suba & 44.699 & 895.515 & 416.160 & 81.382 & 1.437 .756 \\
\hline Teusaquillo & 159.025 & 195.001 & 148.703 & 30.164 & 532.893 \\
\hline Tunjuelito & 26.544 & 56.210 & 64.986 & 8.864 & 156.604 \\
\hline Usaquén & 51.790 & 221.745 & 122.017 & 23.733 & 419.285 \\
\hline Usme & 19.858 & 23.926 & 73.493 & 7.037 & 124.314 \\
\hline Total & 27.212 & 48.850 & 79.563 & 9.338 & 164.963 \\
\hline
\end{tabular}

Fuente: EM2014, cálculos de los autores.

\section{Evolución del ingreso disponible de los hogares entre 2011 y 2014 en Bogotá}

Una comparación del ingreso disponible de los hogares entre 2011 y $2014^{1}$ muestra un panorama positivo. Durante este periodo hubo un aumento significativo en el presupuesto real con que los hogares bogotanos contaban para tomar sus decisiones de consumo. Dicho aumento fue superior al $25 \%$

\footnotetext{
1 Sólo se presentan cifras de Bogotá dado que en 2011 no hubo encuestas en otros municipios.
} 
y situó el ingreso disponible total mensual expandido para el 2014 en más de $\$ 6.696 .112$ millones de pesos. Gran parte de la mejora puede ser atribuida a un aumento significativo en los subsidios en educación que contuvo las caídas evidenciadas en los montos de subsidios a servicios públicos domiciliarios, especialmente energía, y en los montos de subsidios a vivienda. Según los estimados en la tabla 4.9 se muestra un resultado favorable para el 2014 que se mantiene para diferentes discriminaciones tipológicas de los hogares como estrato y quintiles de gasto.

Tabla 4.9. Comparación ingreso disponible a precios corrientes y constantes

\begin{tabular}{ccc} 
Año & $\begin{array}{c}\text { (\$ precios corrientes) } \\
\text { ingreso disponible }\end{array}$ & $\begin{array}{c}\text { (\$ precios de 2014) } \\
\text { ingreso disponible }\end{array}$ \\
\hline 2011 & 5.133 .925 .177 .714 & 5.551 .041 .420 .851 \\
\hline 2014 & 6.718 .681 .609 .416 & 6.718 .681 .609 .416 \\
\hline
\end{tabular}

Fuente: EM2014, cálculos de los autores.

Los cambios en los ingresos en el periodo de análisis evidencian un aumento en todos los estratos con excepción del 4, el cual presenta una caída. Es de resaltar también que para el año 2011, únicamente los estratos 1 y 2 percibían una mejora en el presupuesto del hogar tras tener en cuenta subsidios y tributos, mientras que para el año 2014, la cantidad de estratos socioeconómicos beneficiados en términos presupuestales por la política social pasaron a ser los tres primeros.

Tabla 4.10. Comparación ingreso disponible a precios constantes según estrato (total)

\begin{tabular}{cccc}
\hline Estrato & $\begin{array}{c}\text { Ingreso disponible }(\$) \\
(2011)\end{array}$ & $\begin{array}{c}\text { Ingreso disponible }(\$) \\
(2014)\end{array}$ & $\begin{array}{c}\text { Diferencia (\$) } \\
(\mathbf{2 0 1 1 - 2 0 1 4 )}\end{array}$ \\
\hline 1 & 242.271 .634 .737 & 358.253 .506 .772 & 115.981 .872 .034 \\
\hline 2 & 1.350 .583 .875 .032 & 1.787 .268 .346 .546 & 436.684 .471 .514 \\
\hline 3 & 1.948 .642 .800 .404 & 2.380 .782 .779 .122 & 432.139 .978 .718 \\
\hline 4 & 1.154 .472 .418 .662 & 1.148 .004 .656 .386 & -6.467 .762 .276 \\
\hline 5 & 431.933 .027 .810 & 540.625 .885 .715 & 108.692 .857 .905 \\
\hline 6 & 423.137 .664 .206 & 503.746 .434 .875 & 80.608 .770 .669 \\
\hline
\end{tabular}

Fuente: EM2014, cálculos de los autores. 
En el caso de los quintiles, los patrones permanecieron a través del tiempo. Entre 2011 y 2014, los quintiles 1, 2 y 3 presentaron un ingreso disponible mayor al ingreso corriente. De 2011 a 2014 todos los quintiles percibieron una mejora en el monto presupuestal disponible para tomar sus decisiones de consumo, teniendo en cuenta la asistencia social y los tributos. Dicho aumento se dio en una mayor proporción para los quintiles 1 a 3 y para el quintil 5 .

Tabla 4.11. Comparación ingreso disponible según quintil (total en pesos constantes 2014)

\begin{tabular}{cccc}
\hline Quintil de gasto total & $\begin{array}{c}\text { Ingreso disponible } \\
(\mathbf{2 0 1 1})\end{array}$ & $\begin{array}{c}\text { Ingreso disponible } \\
(\mathbf{2 0 1 4 )}\end{array}$ & $\begin{array}{c}\text { Diferencia } \\
(\mathbf{2 0 1 4 - 2 0 1 1 )}\end{array}$ \\
\hline 1 & 254.188 .465 .668 & 545.319 .870 .987 & 291.131 .405 .319 \\
\hline 2 & 491.168 .224 .243 & 772.700 .719 .250 & 281.532 .495 .007 \\
\hline 3 & 715.479 .774 .141 & 1.055 .889 .924 .278 & 340.410 .150 .137 \\
\hline 4 & 1.109 .616 .146 .300 & 1.445 .259 .183 .133 & 335.643 .036 .833 \\
\hline 5 & 3.040 .458 .081 .148 & 2.899 .511 .911 .767 & -140.946 .169 .380 \\
\hline
\end{tabular}

Fuente: EM2014, cálculos de los autores. 



\section{Capítulo 5 Efecto redistributivo de la política fiscal}

El objeto principal de este capítulo es profundizar en la estimación del impacto de la política fiscal, tanto en transferencias como en impuestos y contribuciones, sobre la capacidad de pago de los hogares en Bogotá y la región para 2014. En concreto se pretende analizar icómo se benefician los hogares de las políticas y transferencias nacionales y distritales? ¿Son estas transferencias redistributivas? ¿Cuáles son las transferencias monetarias y en especie más benéficas para residentes de Bogotá y la región? ¿Es la carga impositiva de los pobres relativamente baja?

Para poder responder a estas preguntas se realiza un análisis detallado de la desigualdad a través de una medida del coeficiente de Gini y de su descomposición por grupos como estratos, quintiles de gasto y regional. El coeficiente de Gini se observa antes y después de la política fiscal, entendida como la conjunción de impuestos y subsidios, para poder calcular el poder redistributivo de dichas políticas públicas que enfrentan los hogares. Adicional a esto, se harán análisis de índices de concentración y análisis gráficos de la progresividad, o en su defecto regresividad, de algunas transferencias e impuestos, aquellas que más han determinado cambios sustanciales en el coeficiente.

Como se explicó anteriormente, Colombia y particularmente Bogotá, D. C., exhiben altos niveles de desigualdad en el ingreso, los cuales deben ser objeto central por parte de la política social y tributaria. La lucha contra la desigualdad se justifica socialmente al permitir a los individuos con menores recursos mejorar sus condiciones con relación a quienes se ubican 
en la parte alta de la distribución. De este modo, personas con desventajas socioeconómicas pueden adquirir bienes y servicios en busca de potencializar sus capacidades y oportunidades, llevándolos a su vez a una mayor inserción en las dinámicas de la sociedad como un todo, y de manera particular dentro de la ciudad.

El resultado más importante a destacar es un efecto de la política fiscal de una reducción de 8,6\% del índice de Gini de capacidad de pago de los hogares en Bogotá (ver gráfica 1.1, cap. 1). Este porcentaje es del 6,0\% para los municipios de la Sabana de Bogotá y Cundinamarca, una mejora importante en el efecto redistributivo de la política fiscal. Autores como Gallego et al. (2015) para datos de la EMB2011 estimaron este valor en cerca del $1 \%$, explicados principalmente por una baja efectividad redistributiva de los subsidios netos y alta regresividad de impuesto como el IVA. Para el 2014, el IVA sigue siendo regresivo, aumentando el coeficiente de Gini en $0,4 \%$ pero muy por debajo del 1,4\% estimado en el 2011. También se destaca el aporte progresivo de todo el esquema impositivo para Bogotá, el cual reduce el Gini en 1,9\%. Estos resultados muestran una mejora en la capacidad redistributiva de los diferentes instrumentos fiscales a través de subsidios, contribuciones e impuestos, con oportunidades de ajustes para continuar la disminución de la desigualdad en ingreso, en particular cuando se revisan experiencias impositivas internacionales.

\section{Efectos de la política fiscal sobre la distribución del ingreso}

La tabla 5.1 presenta los coeficientes de Gini para el nivel de ingreso corriente (antes de imputar la acción de la política pública); el ingreso corriente más los subsidios netos imputados, los cuales incluyen todos el grupo de subsidios identificados; el ingreso corriente menos los impuestos pagados por los hogares, excluyendo contribuciones directas a la prestación de un servicio; y finalmente el ingreso disponible. Estas cuatro mediciones del ingreso nos permiten tener un panorama diferenciado del efecto de la política de subsidios y la política de impuestos por separado sobre la distribución del ingreso. Sin embargo, el resultado de interés es el efecto final, lo que entendemos como el balance financiero neto de la política fiscal, el cual recogemos en el análisis del ingreso disponible en las últimas dos columnas. 
Tabla 5.1. Efecto redistributivo de la política fiscal

\begin{tabular}{|c|c|c|c|c|c|c|c|}
\hline & \multicolumn{7}{|c|}{ Ingreso } \\
\hline & \multirow{2}{*}{ Corriente } & \multicolumn{2}{|c|}{+ Subsidios } & \multicolumn{2}{|c|}{ - Impuestos } & \multicolumn{2}{|c|}{ Disponible } \\
\hline & & Gini & $\%$ reducción & Gini & \% reducción & Gini & $\%$ reducción \\
\hline Bogotá & 0,522 & 0,493 & $5,6 \%$ & 0,512 & $1,9 \%$ & 0,477 & $8,6 \%$ \\
\hline \multirow[t]{3}{*}{ Región } & 0,519 & 0,496 & $4,4 \%$ & 0,511 & $1,5 \%$ & 0,488 & $6,0 \%$ \\
\hline & \multicolumn{7}{|c|}{ Descomposición del coeficiente de Gini por Bogotá y Región } \\
\hline & Corriente & \multicolumn{2}{|c|}{ + Subsidios } & \multicolumn{2}{|c|}{ - Impuestos } & \multicolumn{2}{|c|}{ Disponible } \\
\hline Intra grupos & $76 \%$ & \multicolumn{2}{|r|}{$76 \%$} & \multicolumn{2}{|r|}{$76 \%$} & \multicolumn{2}{|r|}{$75 \%$} \\
\hline Entre grupo & $9 \%$ & \multicolumn{2}{|r|}{$9 \%$} & \multicolumn{2}{|r|}{$8 \%$} & \multicolumn{2}{|r|}{$9 \%$} \\
\hline Ambos & $15 \%$ & \multicolumn{2}{|r|}{$15 \%$} & \multicolumn{2}{|r|}{$16 \%$} & \multicolumn{2}{|r|}{$16 \%$} \\
\hline
\end{tabular}

Fuente: EM2014, cálculos de los autores.

En la tabla 5.1 también se presenta el análisis de desigualdad por grupos geográficos, un efecto sobre el coeficiente Gini para los hogares residentes en Bogotá y en los municipios aledaños (región). Este análisis de descomposición sigue la metodología desarrollada por Pyatt (1976) y posteriormente mejorada por Lambert (1993) y Araar (2006), bajo la cual se considera la correlación entre los Gini de los diferentes grupos. Esto permite descomponer en cuanto las diferencias de ingreso entre grupos (entre) y al interior de los grupos (intra), explican la medida de desigualdad, además de considerar la correlación entre e intra grupos. En particular, para el caso de la tabla 5.1, al comparar las desigualdades de la región y Bogotá, la mayor parte de la desigualdad global es explicada por las diferencias de ingreso al interior de Bogotá (cerca del 76\%) y poco es explicado por comparar los hogares de Bogotá con similares de municipios aledaños y del departamento de Cundinamarca (solo 9\%). Lo más importante de esta descomposición para el caso de análisis regional es la poca variación ante la acción de la política fiscal.

Ahora bien, iqué ocurre con la desigualdad del ingreso en Bogotá y la región cuando se imputan los subsidios recibidos y los impuestos pagados? El coeficiente de Gini antes de la acción del Estado se estimó para la definición de ingreso corriente diseñada en el capítulo 3 en 0,522 en Bogotá, y 0,519 para el resto de los municipios considerados en la EM2014. Como se ha explicado anteriormente, los índices de desigualdad en Colombia, y 
en particular en Bogotá, son altos y justifican una intervención del Estado para mejorarlos. Además, Bogotá tiene un coeficiente levemente mayor a los otros municipios. Esto se explica por mayores desigualdades en el ingreso debido a una mayor aglomeración de residentes con altos ingresos, quienes aprovechan las economías de aglomeración, y la existencia de familias de muy bajos recursos que pueden encontrar mayores oportunidades de recibir asistencia social en la ciudad de Bogotá. El mismo coeficiente Gini del ingreso disponible, se reduce en Bogotá en 8,6\%, llegando a un nivel de 0,477. Para el caso de la región, este coeficiente se reduce en 6,0\%, ubicándose en 0,488.

Los hogares en Bogotá enfrentan un esquema más progresivo en la política fiscal comparado con los otros municipios. Los determinantes de esta reducción son principalmente explicados por los esfuerzos de la política social. Por ejemplo, en Bogotá al imputar los subsidios netos recibidos, se reduce la desigualdad del ingreso en 5,6\%, mientras que al tener en cuenta los impuestos pagados, se reduce la desigualdad solo en 1,9\%. En el caso de los municipios de la región estas reducciones son del 4,4 \% y 1,5\%, respectivamente.

A pesar de la relativa capacidad de Bogotá en canalizar la política fiscal en reducir la desigualdad, el esquema tributario sigue siendo insuficiente para cambiar sustancialmente la distribución del ingreso. Claramente el rol redistributivo de los impuestos en Bogotá, ha mejorado respecto al 2011, pasando de afectar la distribución del ingreso a 0,3 \% a 1,9\%. Aun así, el impacto sigue siendo muy inferior frente a otros países con esquemas impositivos progresivos, los cuales reducen sustancialmente los índices de desigualdad. El impacto de los subsidios netos son algo mayores, pero sin garantizan cambios sustanciales en la distribución del ingreso, tal vez porque sus objetos están más encaminados a mejorar calidad de vida y reducir pobreza.

La tabla 5.2 presenta un ejercicio similar, desagregando por estratos socioeconómicos y quintiles de gasto. El objeto de esta descomposición es observar el efecto de los subsidios netos y los impuestos a lo largo de la distribución de grupos por estatus socioeconómico. En primer lugar, los índices de desigualdad al interior de los estratos es menor al agregado en Bogotá, algo lógico al ser los estratos un método de agrupación basado en la capacidad de pago de los hogares. Sin embargo, al comparar dichos índices con aquellos por quintil de gasto, estos últimos son más bajos y homogéneos. Esto 
explica, en parte, un menor aporte de la estratificación a la desigualdad del ingreso (57\%), comparado con una medida estándar de quintiles de gasto (72\%). Los estratos pueden estar conteniendo altos errores de inclusión y por tanto no van a ser significativos como instrumento de clasificación, pero podrían estar actuando como una especie de contenedor de la segregación urbana, contrarios a otras visiones.

Tabla 5.2. Efecto de la política fiscal sobre la desigualdad por estrato y quintiles de gasto para Bogotá

\begin{tabular}{|c|c|c|c|c|}
\hline & \multicolumn{4}{|c|}{ Ingreso } \\
\hline & Corriente & + Subsidios & - Impuestos & Disponible \\
\hline Total Bogotá & 0,522 & 0,493 & 0,512 & 0,477 \\
\hline \multicolumn{5}{|c|}{ Gini estratos } \\
\hline \multicolumn{5}{|l|}{ Estratos } \\
\hline 1 & 0,405 & 0,362 & 0,403 & 0,361 \\
\hline 2 & 0,437 & 0,428 & 0,434 & 0,422 \\
\hline 3 & 0,456 & 0,491 & 0,457 & 0,469 \\
\hline 4 & 0,416 & 0,469 & 0,416 & 0,427 \\
\hline 5 & 0,470 & 0,538 & 0,458 & 0,465 \\
\hline 6 & 0,387 & 0,336 & 0,387 & 0,337 \\
\hline Entre grupo & $57 \%$ & $51 \%$ & $54 \%$ & $48 \%$ \\
\hline Ambos & $23 \%$ & $28 \%$ & $25 \%$ & $30 \%$ \\
\hline Intra grupo & $20 \%$ & $21 \%$ & $21 \%$ & $22 \%$ \\
\hline \multicolumn{5}{|c|}{ Gini quintil de ingresos } \\
\hline 1 & 0,367 & 0,352 & 0,369 & 0,355 \\
\hline 2 & 0,325 & 0,294 & 0,328 & 0,297 \\
\hline 3 & 0,343 & 0,319 & 0,342 & 0,315 \\
\hline 4 & 0,357 & 0,348 & 0,356 & 0,341 \\
\hline 5 & 0,443 & 0,455 & 0,440 & 0,434 \\
\hline Entre grupo & $72 \%$ & $67 \%$ & $70 \%$ & $66 \%$ \\
\hline Ambos & $12 \%$ & $16 \%$ & $13 \%$ & $17 \%$ \\
\hline Intra grupo & $16 \%$ & $17 \%$ & $16 \%$ & $17 \%$ \\
\hline
\end{tabular}

Fuente: EM2014, cálculos de los autores. 
Después de calcular el ingreso disponible, la reducción del impacto entre variación de grupos al coeficiente de Gini en Bogotá cae, tanto por estratos como por quintiles de gasto, observándose una independencia más alta por estratos, donde la diferencia entre grupos explica solo el $48 \%$ del Gini; en quintiles, esta explica el $66 \%$. El resultado refleja, una vez más, una menor capacidad de focalización de la estratificación, así como un panorama desalentador respecto a la capacidad de la política fiscal en reducir la desigualdad en Bogotá y lograr acercar los quintiles de gasto (una mayor homogeneidad). El Gini del ingreso después de imputar los impuestos pagados, es explicado en un $70 \%$ por la diferencia entre quintiles, tan solo 2 puntos porcentuales menor que al ingreso no imputado.

Un panorama similar ocurre para el global de los otros municipios de la región. Aunque las tendencias por estrato y quintiles son iguales, la estratificación es mucho menos importante para explicar desigualdades en el ingreso. Además el esquema de impuestos es casi nulo para mejorar diferencias entre quintiles o estratos en términos de desigualdades (ver tabla 5.3).

Dado lo anterior es importante entrar en un análisis más completo del efecto redistributivo de cada uno de los subsidios y contribuciones.

\section{Efectos de los subsidios sobre desigualdad en el ingreso}

La tabla 5.4 presenta el coeficiente de Gini para los ingresos corrientes y los ingresos imputados por cada tipo de subsidio neto y muestra el porcentaje de reducción (o aumento) de cada tipo de subsidio tanto para Bogotá como para los municipios aledaños. La primera fila de dicha tabla muestra el coeficiente de Gini sobre el ingreso corriente, el cual es igual al calculado en la tabla 5.1. Este pasa a ser el punto de referencia básico sobre el cual se basa la evaluación de cambios. La segunda fila recoge el coeficiente de Gini después de imputar los subsidios netos en capital humano (salud, educación, componente nutrición de familias en acción y cuidado de los niños), presentando su impacto desagregado en las cuatro filas siguientes. Los subsidios netos destinados a incrementar la acumulación de capital humano presenta la reducción más importante en las desigualdades, con un 19\% en Bogotá y $18,2 \%$ en el resto de los municipios. Estas reducciones tan significativas están explicadas sustancialmente por reducciones en gasto para el cuidado de los niños, educación y salud para Bogotá y un efecto neutral por parte 
Tabla 5.3. Efecto de la política fiscal sobre la desigualdad por estrato y quintiles de gasto para municipios de la Región

\begin{tabular}{|c|c|c|c|c|}
\hline & \multicolumn{4}{|c|}{ Ingreso } \\
\hline & Corriente & + Subsidios & - Impuestos & Disponible \\
\hline Total Región & 0,519 & 0,496 & 0,511 & 0,488 \\
\hline \multicolumn{5}{|c|}{ Gini Estratos } \\
\hline 1 & 0,403 & 0,371 & 0,398 & 0,367 \\
\hline 2 & 0,463 & 0,440 & 0,458 & 0,435 \\
\hline 3 & 0,484 & 0,484 & 0,479 & 0,477 \\
\hline 4 & 0,583 & 0,610 & 0,577 & 0,604 \\
\hline 5 & 0,383 & 0,437 & 0,378 & 0,417 \\
\hline 6 & 0,279 & 0,411 & 0,282 & 0,315 \\
\hline Entre grupo & $44 \%$ & $41 \%$ & $43 \%$ & $39 \%$ \\
\hline Ambos & $29 \%$ & $32 \%$ & $29 \%$ & $33 \%$ \\
\hline Intra grupo & $27 \%$ & $27 \%$ & $27 \%$ & $28 \%$ \\
\hline \multicolumn{5}{|c|}{ Gini quintil de ingresos } \\
\hline 1 & 0,372 & 0,353 & 0,371 & 0,353 \\
\hline 2 & 0,341 & 0,327 & 0,340 & 0,328 \\
\hline 3 & 0,379 & 0,367 & 0,377 & 0,365 \\
\hline 4 & 0,440 & 0,433 & 0,440 & 0,430 \\
\hline 5 & 0,496 & 0,501 & 0,493 & 0,496 \\
\hline Intra grupo & $70 \%$ & $66 \%$ & $69 \%$ & $65 \%$ \\
\hline Ambos & $16 \%$ & $19 \%$ & $17 \%$ & $20 \%$ \\
\hline Entre grupo & $14 \%$ & $15 \%$ & $14 \%$ & $15 \%$ \\
\hline
\end{tabular}

Fuente: EM2014, cálculos de los autores.

del componente de Familias en Acción. Para el resto de municipios, el impacto sustancial está en cuidado de los niños y algo en salud. Educación no afecta significativamente el índice de desigualdad y Familias en Acción lo aumenta levemente. El caso de salud es consistente con lo encontrado anteriormente, el cual ha jugado un papel sustancial en mejorar la calidad de vida de los hogares. Llama la atención el efecto diferenciado de educación 
entre Bogotá y los municipios de la EM2014. Una posibilidad es la menor proporción de colegios de carácter privado en los municipios de la región, por lo que la gratuidad en el servicio de educación afecta por igual a todos los hogares con miembros en edad escolar; diferente para el caso de Bogotá, donde existe un porcentaje importante de estudiantes en el sector privado con altos gastos en matrícula y pensiones. El efecto mayor sobre la reducción del Gini se debe a asistencia para el cuidado de los niños, el cual aporta un 7,9\% en Bogotá y 10,8\% en los otros municipios. Esto es consistente con políticas activas de carácter nacional y local sobre intervenciones tempranas en los niños como programas de Cero a Siempre o Jardines del ICBF.

Tabla 5.4. Efectos de los subsidios netos sobre desigualdad

\begin{tabular}{|c|c|c|c|c|c|c|}
\hline & \multicolumn{2}{|c|}{ Bogotá } & \multicolumn{2}{|c|}{ Resto } & \multicolumn{2}{|c|}{ Bogotá y resto } \\
\hline & Gini & $\%$ cambio & Gini & $\%$ cambio & Gini & $\%$ cambio \\
\hline Ingreso Corriente & \multicolumn{2}{|c|}{0,522} & \multicolumn{2}{|c|}{0,519} & \multicolumn{2}{|c|}{0,526} \\
\hline Capital Humano & 0,423 & $19,0 \%$ & 0,424 & $18,3 \%$ & 0,428 & $18,6 \%$ \\
\hline Salud & 0,511 & $2,1 \%$ & 0,507 & $2,3 \%$ & 0,515 & $2,1 \%$ \\
\hline Educación & 0,506 & $3,1 \%$ & 0,517 & $0,4 \%$ & 0,513 & $2,5 \%$ \\
\hline Familias en Acción nutrición & 0,522 & $0,0 \%$ & 0,52 & $-0,2 \%$ & 0,527 & $-0,2 \%$ \\
\hline Cuidado niños & 0,481 & $7,9 \%$ & 0,463 & $10,8 \%$ & 0,482 & $8,4 \%$ \\
\hline Servicios Públicos & 0,53 & $-1,5 \%$ & 0,533 & $-2,7 \%$ & 0,535 & $-1,7 \%$ \\
\hline AAA & 0,531 & $-1,7 \%$ & 0,535 & $-3,1 \%$ & 0,537 & $-2,1 \%$ \\
\hline Energía & 0,535 & $-2,5 \%$ & 0,533 & $-2,7 \%$ & 0,541 & $-2,9 \%$ \\
\hline Gas Natural & 0,533 & $-2,1 \%$ & 0,527 & $-1,5 \%$ & 0,536 & $-1,9 \%$ \\
\hline Vivienda & 0,522 & $0,0 \%$ & 0,519 & $0,0 \%$ & 0,526 & $0,0 \%$ \\
\hline Transporte & 0,526 & $-0,8 \%$ & $\mathrm{ND}$ & & ND & \\
\hline Total subsidios & 0,493 & $5,6 \%$ & 0,496 & $4,4 \%$ & 0,499 & $5,1 \%$ \\
\hline
\end{tabular}

Fuente: SPD, cálculos de los autores.

Es preocupante el impacto de los otros subsidios sobre las desigualdades. Los subsidios en SPD, mejoramiento de vivienda y subsidios a transporte del SITP, no mejoran el coeficiente de Gini, y en la mayoría de los casos aumenta las desigualdades. En particular preocupa el impacto de todos subsidios 
en SPD, los cuales aumentan el Gini en 1,5\%. Esto está en línea con otros estudios para Bogotá y el país, los cuales han resaltado la incapacidad del instrumento de focalización de subsidios en SPD, la estratificación, para ser flexibles y eficientes en identificar adecuadamente los beneficiarios y contribuyentes de estas ayudas sociales (Sepúlveda et al., 2014; Gallego et al., 2015). Finalmente genera alarma el impacto ligeramente negativo del subsidio a transporte. Vale la pena revisar su diseño y enfocarlo hacia aquellos con requerimientos de movilidad ligados a su mercado de trabajo al interior de la ciudad. Este subsidio requiere un análisis más detallado en otros impactos como los presentados sobre empleabilidad y movilidad (ver Rodríguez et al., 2016).

La tabla 5.5 presenta la descomposición del Gini para los ingresos corrientes, los ingresos imputados con subsidios en salud, imputados con subsidios en educación, imputados con capital humano e imputados con subsidios netos en SPD, discriminados por grupos de estrato y quintiles de gasto. El panel superior muestra la descomposición del Gini por estratos socioeconómicos en tres dimensiones: entre grupos de estrato, al interior de cada estrato y un porcentaje explicado por la interacción entre y intra grupo que denominamos ambos. Estos mismos componentes de la desagregación del Gini se observan por grupos de quintiles de gasto corriente del

Tabla 5.5. Descomposición del Gini de ingresos imputados por estrato y quintiles de gasto

\begin{tabular}{lccccc} 
& \multicolumn{5}{c}{ Ingreso } \\
& Corriente & Salud & Educación & Capital Humano & SPD \\
\hline Entre grupo & $57 \%$ & $54 \%$ & $55 \%$ & $51 \%$ & $54 \%$ \\
\hline Ambos & $23 \%$ & $25 \%$ & $24 \%$ & $25 \%$ & $25 \%$ \\
\hline Intra grupo & $20 \%$ & $21 \%$ & $21 \%$ & $24 \%$ & $21 \%$ \\
\hline & $72 \%$ & $69 \%$ & $70 \%$ & $73 \%$ & $69 \%$ \\
\hline Entre grupo & $12 \%$ & $15 \%$ & $13 \%$ & $13 \%$ & $15 \%$ \\
\hline Ambos & $16 \%$ & $16 \%$ & $16 \%$ & $14 \%$ & $16 \%$ \\
\hline Intra grupo & & Quintiles & \\
\hline
\end{tabular}

Fuente: EM2014, cálculos de los autores. 
hogar. La desigualdad explicada por la diferencia entre quintiles de gasto es mayor que aquella observada entre grupos de estratos y este diferencial se observa para todos los ingresos imputados por cada tipología de subsidio. Esto refuerza el efecto de los errores de inclusión al interior de los estratos socioeconómicos cuando se compara con otras medidas de capacidad de pago como es, por ejemplo, el gasto corriente.

A continuación se presenta de manera gráfica el efecto redistributivo de los ingresos con los subsidios imputados. La curva de Lorenz representa la distribución del ingreso y entre más cercana esté la curva a la línea de $45^{\circ}$ más equitativa es la distribución del ingreso. Gráficamente la curva de Lorenz de los ingresos corrientes está determinada por la línea roja más alejada de la curva de $45^{\circ}$. Después se presenta la gráfica la curva de Lorenz del ingreso imputado con subsidios netos en capital humano (salud, educación, cuidado de los niños y familias en acción), el ingreso imputado para los subsidios en SPD y el ingreso para el capital humano. El análisis gráfico ratifica lo discutido en las tablas anteriores: el ingreso con subsidios en SPD no cambia la distribución del ingreso; la línea punteada se sobrepone a la curva de ingreso corriente. Los subsidios en capital humano mueven sustancialmente la curva de Lorenz, pero al considerar todos los subsidios, el efecto global de los subsidios netos, aunque cambian en algo la distribución del ingreso, no evidencias efectos claros.

Hemos subrayado una serie de subsidios y beneficios sociales existentes tendientes a mejorar la capacidad de pago de los hogares más pobres y su impacto sobre el índice de desigualdad. Las gráficas 5.2 a 5.4 ilustran el grado de progresividad de estos beneficios en Bogotá. La gráfica 5.2 presenta las curvas de progresividad para los subsidios destinados a mejorar el capital humano de los hogares. Entre más a la derecha de la gráfica se encuentre la curva, la transferencia neta tiene un carácter más progresivo con respecto al ingreso corriente. El subsidio con mayor progresividad es el subsidio a la salud, el cual tiene el componente de contribución directa para su financiación. Siguen en orden de progresividad el subsidio a cuidado de los niños y el subsidio en educación. El subsidio en nutrición de Familias en Acción no tiene un esquema de progresividad por el bajo monto y diseño. 
Gráfica 5.1. Curva de Lorenz de ingresos imputados

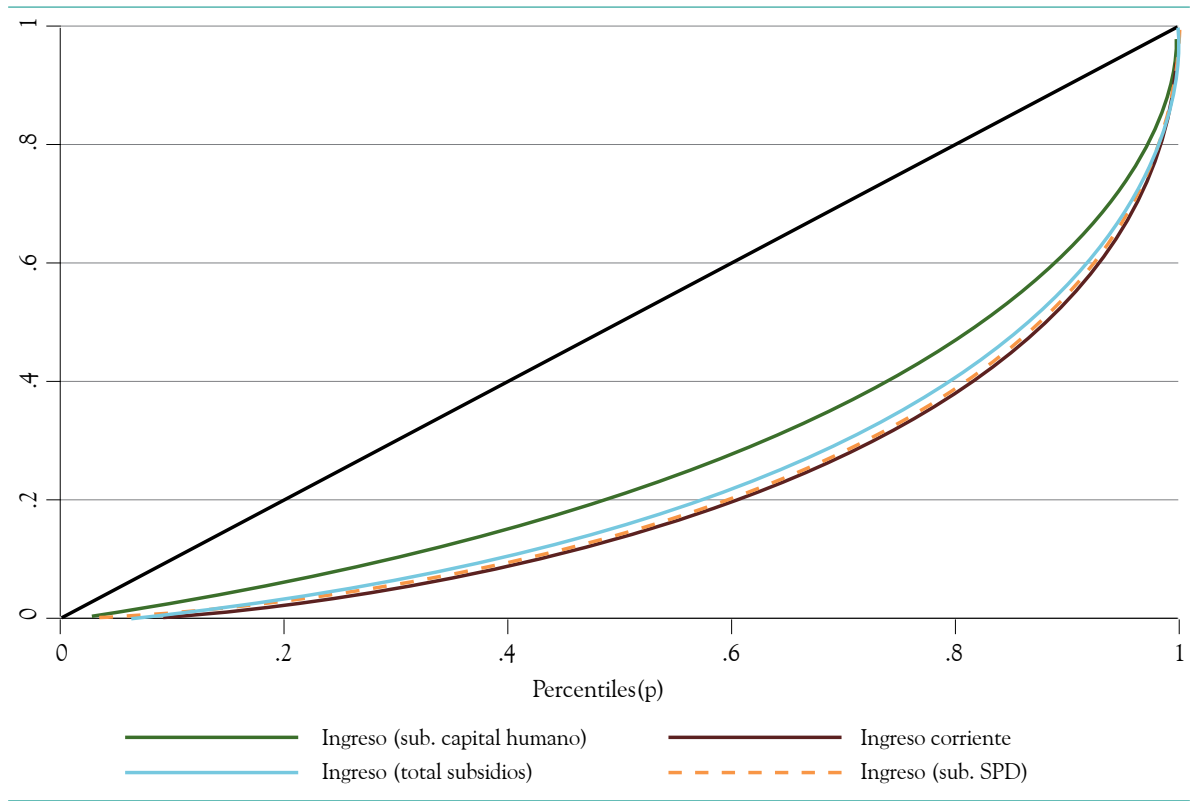

Fuente: EM2014, cálculos de los autores.

Gráfica 5.2. Progresividad de los subsidios netos al capital humano

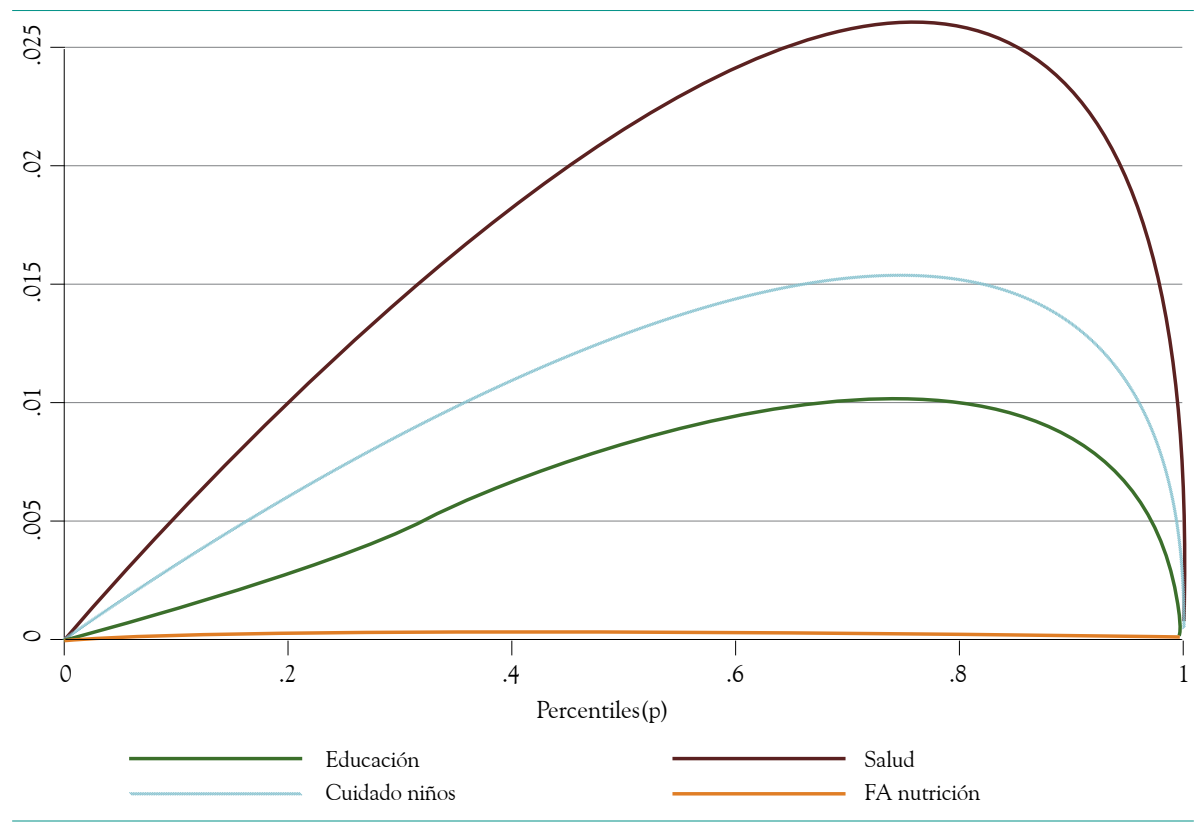

Fuente: EM2014, cálculos de los autores. 
En términos comparativos con respecto a los subsidios enfocados directamente a formación de capital humano, el nivel de progresividad de los SPD evidencia una baja capacidad redistributiva (gráfica 5.3). El de mayor progresividad con respecto al ingreso es el subsidio en acueducto, alcantarillado y aseo, pero aún con niveles muy bajos comparado con los subsidios en salud o educación. Estos resultados refuerzan las preocupaciones anteriores sobre el instrumento de focalización, porque similar a salud, el componente de contribución directa debería hacer de estos subsidios un esquema adecuado de mejoras en la distribución del ingreso. Los resultados son similares a los encontrados por Gallego et al. "el subsidio más progresivo es acueducto, alcantarillado y aseo, seguido por gas y, posteriormente, energía. Las tarifas en SPD, aunque llegan a hogares pobres, también benefician de manera significativa a aquellos con ingresos altos, y, en especial en el consumo de energía, dicho comportamiento puede ser explicado por la focalización inadecuada de los subsidios cruzados en SPD debido a significativos errores de inclusión" (2015, p. 156).

Gráfica 5.3. Progresividad subsidios netos en SPD

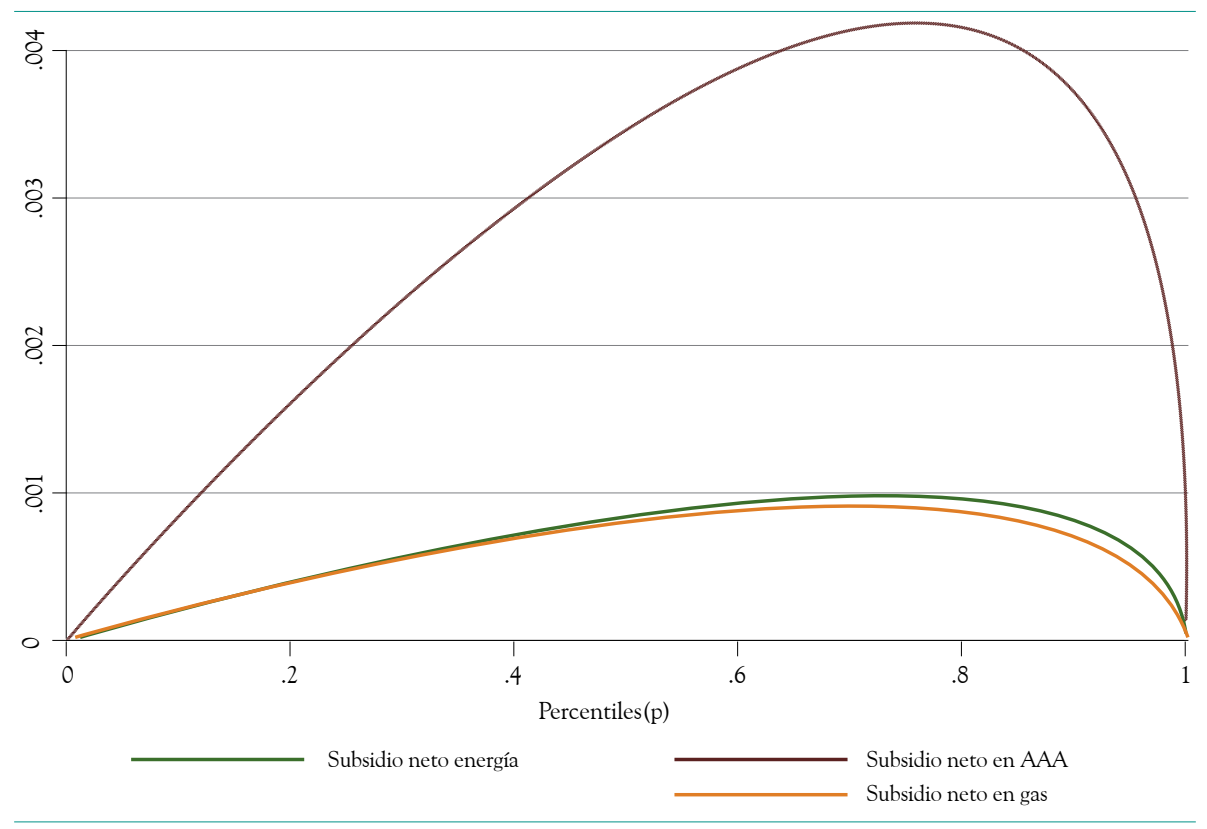

Fuente: EM2014, cálculos de los autores. 
Gráfica 5.4. Progresividad de subsidios en transporte y vivienda

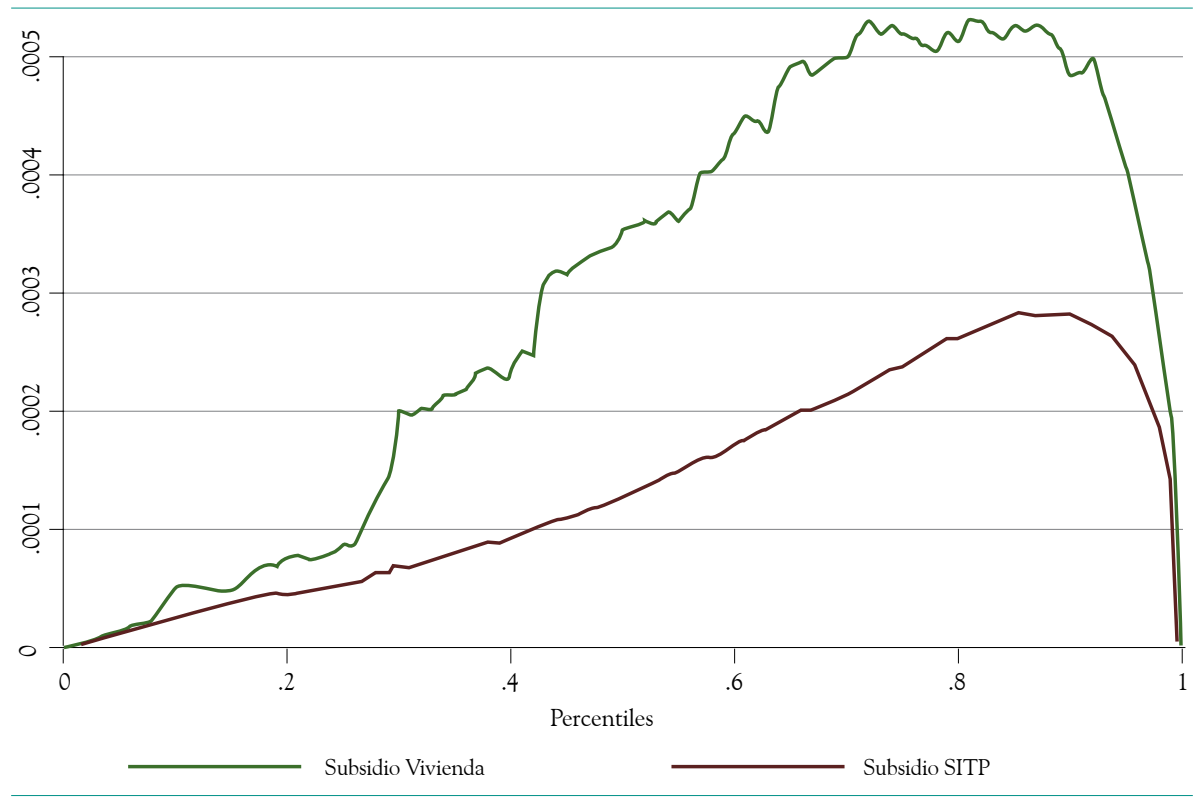

Fuente: EM2014, cálculos de los autores.

Finalmente, la curva de progresividad de los subsidios de vivienda y transporte ilustra su poca progresividad y su rol neutro sobre la distribución del ingreso.

Desagregar los componentes de ayudas es importante para diferenciar y entender en más detalle las fuentes de la progresividad de la política social. De esta manera, como resumen sobre la asignación de los subsidios en Bogotá, se tiene: i) una asignación de los subsidios totales netos, es decir, la suma de ayudas otorgadas por todos los servicios, de carácter progresivo; ii) la asignación de cada uno de los subsidios sobre los diferentes servicios también es progresiva, y la focalización utilizada es en promedio la adecuada, excepto en SPD; y iii) unos subsidios son más progresivos y esto se puede evidenciar en la curvatura de las gráficas, siendo el de Salud el mejor focalizado.

\section{Impacto de los impuestos sobre el ingreso y la desigualdad}

Para analizar el rol desagregado de los impuestos sobre la redistribución del ingreso, se presentan dos ejercicios de ilustración. El primero, muestra el grado de concentración de un determinado impuesto a través de la curva de concentración comparada con la curva de Lorenz. El segundo, observa si 
los impuestos son progresivos o regresivos a lo largo de la distribución de la población. Ambos ejercicios se comparan por estrato. Estas gráficas deben complementarse con los efectos sobre el coeficiente de Gini (reducciones o aumentos en el Gini) de imputar al ingreso corriente cada uno de los impuestos. La tabla 5.6 presenta el Gini después de imputarle cada impuesto al ingreso corriente y calcula el porcentaje de reducción o aumento de dicha medida de desigualdad. La mayoría de los impuestos son neutrales, y no cambian el efecto sobre desigualdad de manera individual. El IVA, en cambio, aumenta la desigualdad. Recordemos que, en conjunto, la carga impositiva alcanza a disminuir la desigualdad de 0,522 a 0,512 en Bogotá, es decir, en un $1,9 \%$, y en 1,5\% para el resto de los municipios.

Tabla 5.6. Efectos de los subsidios netos sobre desigualdad

\begin{tabular}{lcccccc}
\hline & \multicolumn{2}{c}{ Bogotá } & \multicolumn{2}{c}{ Resto } & \multicolumn{2}{c}{ Bogotá y resto } \\
\cline { 2 - 7 } & Gini & Cambio (\%) & Gini & Cambio (\%) & Gini & Cambio (\%) \\
\hline Ingreso Corriente & \multicolumn{2}{c}{0,522} & \multicolumn{2}{c}{0,519} & \multicolumn{2}{c}{0,526} \\
\hline Vehículos & 0,522 & $0,0 \%$ & 0,519 & $0,0 \%$ & 0,527 & $0,0 \%$ \\
\hline Predial & 0,522 & $0,0 \%$ & 0,519 & $0,0 \%$ & 0,527 & $0,0 \%$ \\
\hline Renta y complementarios & 0,521 & $0,2 \%$ & 0,519 & $0,0 \%$ & 0,525 & $0,0 \%$ \\
\hline IVA & 0,524 & $-0,4 \%$ & 0,522 & $-0,6 \%$ & 0,528 & $-0,4 \%$ \\
\hline Total & 0,512 & $1,9 \%$ & 0,511 & $1,5 \%$ & 0,516 & $2,0 \%$ \\
\hline
\end{tabular}

Fuente: EM2014, cálculos de los autores.

El análisis gráfico recupera la idea económica de progresividad de un impuesto si la curva de concentración que representa dicho impuesto cae por debajo de la curva de Lorenz, es decir, si los pobres pagan, relativo a sus ingresos, una menor proporción de impuestos que los ricos. Lo contrario explica la regresividad de un impuesto porque hogares más pobres aportan en mayor medida en ese impuesto frente a aquellos con mayor capacidad de pago.

La curva de Lorenz relaciona el porcentaje acumulado de la población con el porcentaje acumulado del ingreso del respectivo grupo poblacional. Además, permite representar gráficamente la concentración del ingreso en ciertos segmentos. Por otro lado, las curvas de concentración de los impuestos, en el mismo espíritu de la curva de Lorenz, miden el impuesto acumulado pagado por el porcentaje de población. 
La gráfica 5.5 presenta las curvas de concentración de todos los impuestos identificados y la curva de Lorenz del ingreso antes de la acción pública. El panel A muestra la curva de concentración del total de impuestos pagados por los hogares bogotanos y de ella se puede deducir que la carga tributaria es regresiva para toda la curva de la distribución del ingreso en la ciudad. El resultado anterior demanda un entendimiento detallado de los tipos de impuestos que pueden mejorar o empeorar la distribución del ingreso. En el panel B de la gráfica 5.5 se visualizan las características progresivas o regresivas de cada uno de los impuestos identificados en esta investigación. Los segmentos de las curvas por encima de la curva de Lorenz, la línea gruesa y gris en dicha gráfica, representan un impuesto regresivo; por el contrario aquellas curvas por debajo, clasifican a los impuestos como progresivos. La primera observación importante es que los impuestos observados individualmente no son todos progresivos o regresivos; y esto corresponde con el diseño de cada uno de estos impuestos como lo plantea la teoría económica.

En el panel B se observa al IVA, como un impuesto regresivo y siguiendo la tendencia del resto del país (Joumard y Londoño, 2013), y en línea con lo encontrado por varios estudios de análisis de incidencia para América Latina (Lustig, Pessino y Scott, 2014). El impuesto al valor agregado es un impuesto indirecto por lo que, al no estar focalizado, a medida que aumenta la capacidad de pago del contribuyente, disminuye la tarifa del impuesto a pagar. El segundo impuesto con menor progresividad es el predial, el cual está cercano a la curva de Lorenz y tiene segmentos por encima de esta en los extremos de la distribución, es decir en los ingresos más bajos y los más altos. Bogotá ha ido avanzando hacia la búsqueda de un predial más progresivo, y para ello se requiere ir aumentando la tarifa a medida que sube el avalúo catastral. El tercer impuesto con segmentos regresivos es el impuesto a la valorización, el cual está por encima de la curva de Lorenz para el 20 \% más pobre de los hogares. Por su naturaleza, la valorización es una contribución que permite un diseño progresivo. En general, los impuestos regresivos para los hogares más pobres el IVA se encuentra en manos de la política fiscal del gobierno central, pero el grupo de impuestos sobre la vivienda es objeto de la política tributaria del Distrito. En esta medida, lograr una mejora en la distribución del ingreso, requiere de una coordinación entre política tributaria nacional y política social a nivel distrital. 
Por otro lado, la progresividad de los impuesto de renta y complementarios se ilustran en el panel B, al ubicarse en una curva por debajo y bastante alejada a la curva de Lorenz. Al ser un impuesto directo asociado con la capacidad de generar ingresos por parte de los miembros del hogar, está diseñado de tal forma que la tarifa crece proporcionalmente con dichos ingresos. En Colombia la tarifa del impuesto a la renta es progresiva, pero débilmente. Ante incrementos de la base (el ingreso) los cambios marginales son menores, y después de un determinado límite, la tarifa llega a un punto a partir del cual no crece más, independientemente del monto de los ingresos del contribuyente. El segundo impuesto más progresivo es el de vehículos. La curva en café muestra que su tenencia y su valor son una proxy la capacidad de pago de los hogares. Este impuesto podría favorecer las políticas distributivas del Distrito, pero se debe tener en cuenta que solamente un $20 \%$ de los hogares tienen vehículo, y que este tributo representa cerca del $6 \%$ del total del recaudo. Estos mismos inconvenientes se presentan en el impuesto a la renta, que corresponde a menos del $10 \%$ del recaudo total, y apenas contribuyen el $7 \%$ de los hogares.

Gráfica 5.5. Curva de concentración de impuestos en Bogotá y municipios 2014

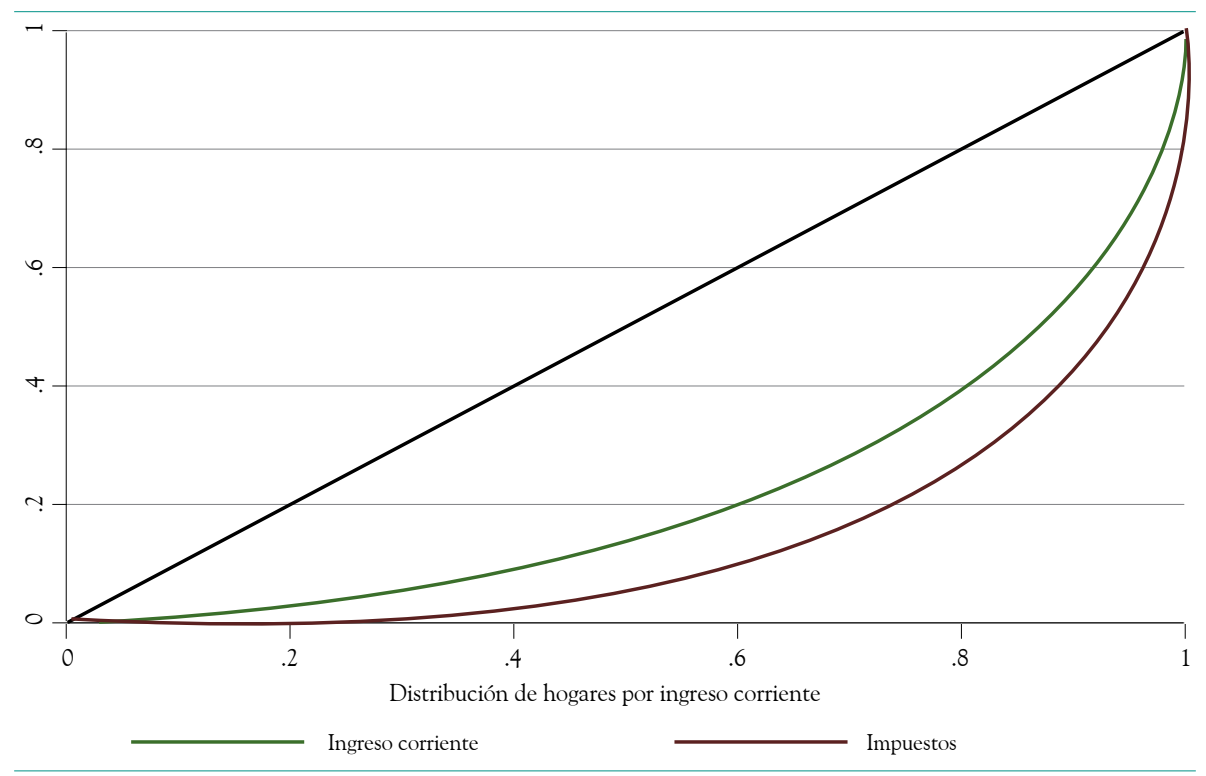

Panel A: Curva de concentración del total de impuesto Bogotá. 
Efecto redistributivo de la política fiscal

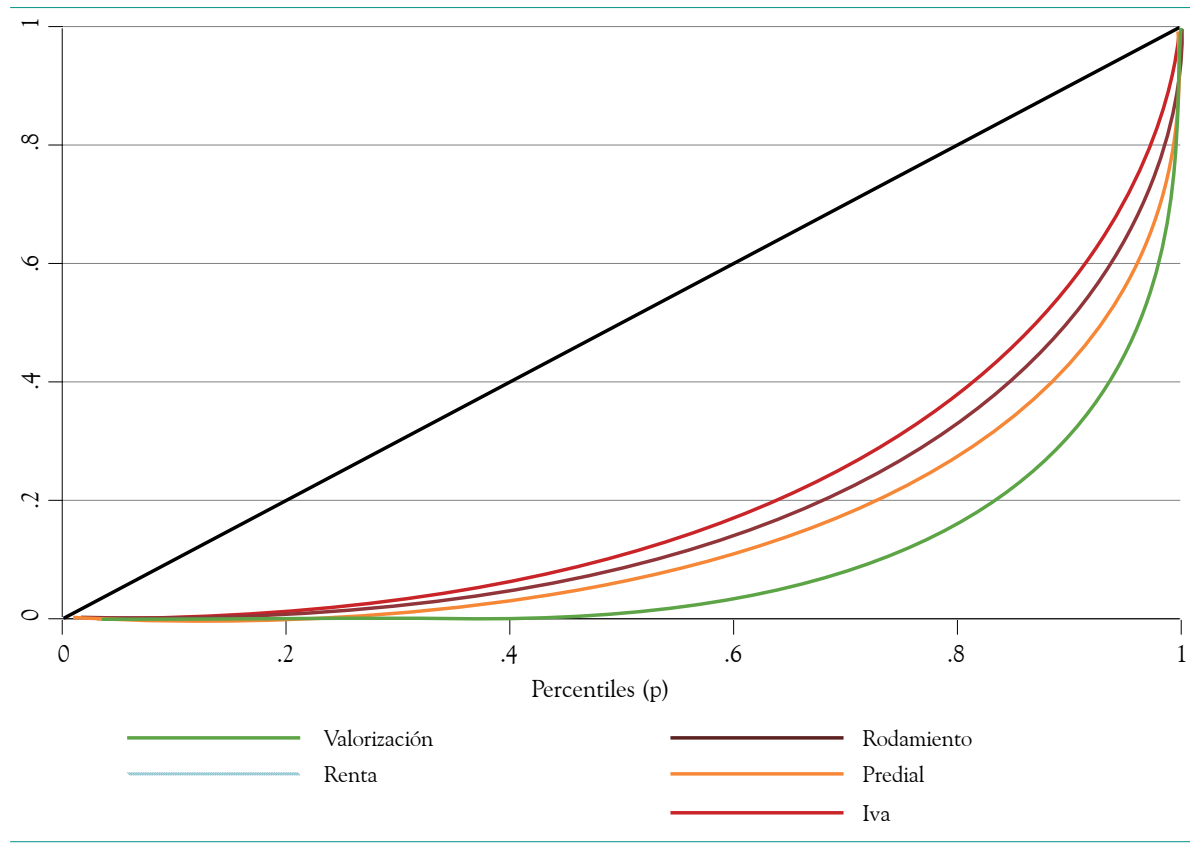

Panel B: Curva de concentración por tipo de impuesto en Bogotá.

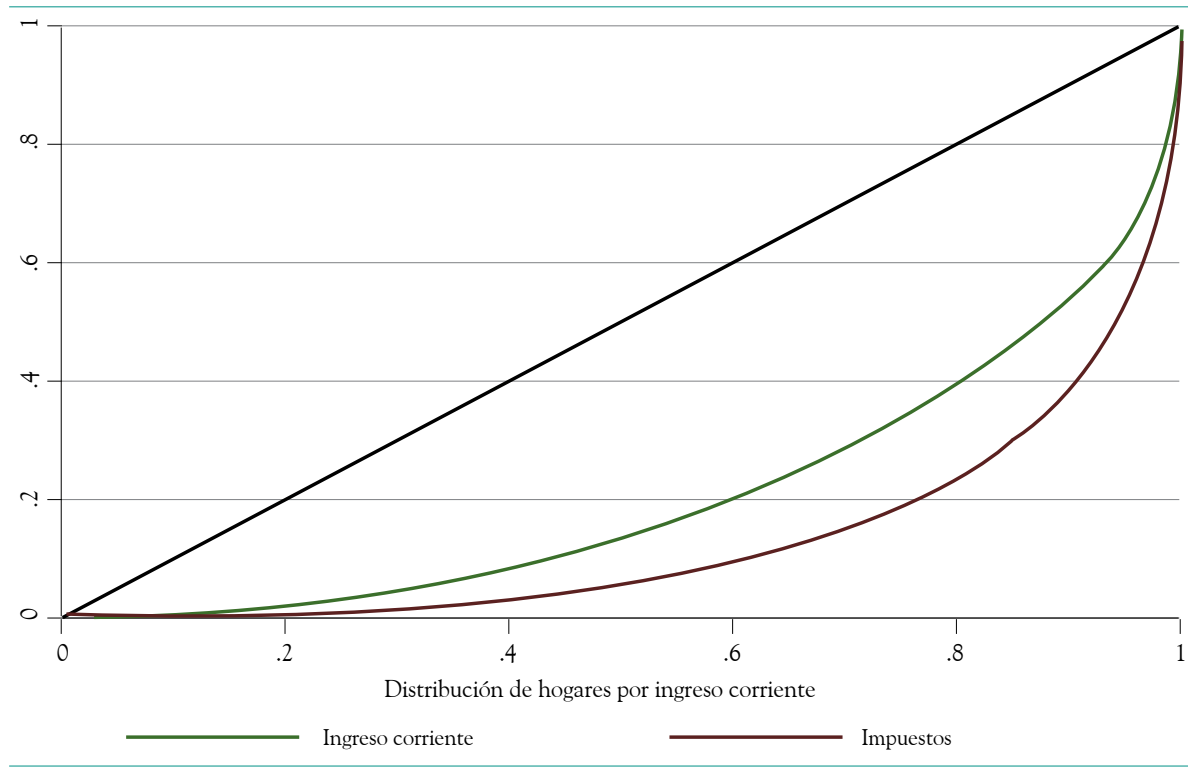

Panel C: Curva de concentración del total de impuesto municipios de la región.

Fuente: EM2014, cálculos de los autores. 
Una vez analizados los impactos individuales de los subsidios e impuestos cabe preguntarse por el resultado conjunto de todos los subsidios anteriores y el de los diferentes impuestos que afectan el gasto sobre la distribución del ingreso en la ciudad. Es decir, se trata de indagar por el balance global de la política fiscal. Es importante tener en cuenta que el IVA presentaba un esquema regresivo, mientras que los impuestos a la renta y a los vehículos son progresivos.

Esto plantea interrogantes con respecto al efecto negativo que puede estar generando la regresividad de los impuestos. Una reforma tributaria debería considerar el efecto negativo que tiene un alto impuesto al consumo (IVA) sobre la capacidad de pago de los hogares. Los hogares más pobres y vulnerables siguen presentando un esquema de impuestos altamente regresivos, y ello acentúa su fragilidad. A diferencia de los impuestos, los subsidios tienden a ser progresivos. En síntesis, el gasto público social del Distrito y de la Nación, focalizado en los hogares residentes en Bogotá, es progresivo y contribuye a mejorar la distribución del ingreso. Pero esta tendencia positiva es contrarrestada por la regresividad de los impuestos, así que en el balance global los cambios distributivos son mínimos.

La gran mayoría de los subsidios contabilizados a partir de la EM2014 no fueron transferencias monetarias directas recibidas por las familias. Los subsidios fueron contabilizados como imputaciones del desembolso hipotético por parte de los hogares de no existir la acción pública social. Los porcentajes de reducción de la pobreza cercanos al $50 \%$, bien sea a nivel de algunos estratos o localidades, refleja esas imputaciones. Si el propósito del gasto social es mejorar las condiciones de vida y ampliar las capacidades de las personas, las mediciones anteriores evidentemente ayudan a evaluar los efectos de las políticas públicas, e indican alternativas para lograr una progresividad en el futuro de la conjunción de subsidios y de impuestos, así como una mayor efectividad en la distribución del ingreso. 


\section{Capítulo 6 \\ Análisis espacial del balance financiero de los hogares}

El ingreso disponible de los hogares ha sido calculado a partir de la diferencia entre el agregado de sus ingresos corrientes y los subsidios recibidos, menos su carga impositiva. Además se ha realizado un análisis de la distribución de este ingreso disponible a nivel de estratos socioeconómicos, incluyendo un análisis del balance financiero neto de los hogares. Sin embargo, estos análisis no incorporan las relaciones espaciales posibles en el ingreso disponible y entre los elementos que los componen, de los cuales se presentó evidencia de un relacionamiento de Bogotá y los municipios de la región en términos de distribución del ingreso.

El propósito de este capítulo es establecer los niveles de correlación espacial, para el ingreso disponible y sus componentes, existentes al interior de la ciudad de Bogotá y de los municipios en relación con su cercanía a la capital. Para tal efecto, primero se describen las consideraciones metodológicas tenidas en cuenta en los cálculos, para posteriormente mostrar los resultados de auto-correlación espacial y del modelo de econometría espacial que incorpora todas las variables al análisis. Finalmente se exponen algunas conclusiones a partir de los resultados encontrados.

El ejercicio de análisis espacial realizado en este capítulo tiene dos propósitos: identificar el grado de correlación espacial del ingreso disponible de los hogares y de sus componentes, y establecer el efecto de cada componente sobre el ingreso disponible tomando en cuenta la ubicación espacial. Para la realización de dicho análisis, es necesario primero establecer algunas 
consideraciones metodológicas, que surgen a partir del estado de la información disponible. Se plantean, dos niveles de análisis: un análisis espacial al interior de la ciudad de Bogotá, y otro análisis espacial a nivel de Bogotá-Región

Para el análisis de Bogotá se establecen como unidad espacial los sectores cartográficos del Marco Geo-estadístico Nacional del DANE, por lo que se generaron agregados a nivel del sector censal, que reúne al menos una manzana censal con por lo menos diez hogares, (este ejercicio tiene en cuenta el efecto de cómo la ubicación espacial puede afectar las decisiones de los hogares observados en la EM2014, pero debe reconocerse que no se puede hacer análisis de representatividad de muestra a este nivel de desagregación geográfica). Para el análisis Bogotá-Región se establece cada municipio como unidad espacial y en el caso de Bogotá los sectores censales. Las agregaciones en unidades espaciales fueron llevadas a cabo a través del cálculo de la mediana para cada uno de los indicadores de análisis.

Con la información a nivel de unidad espacial se considera la matriz de vecindades tipo Queen, la cual contempla los movimientos de la Reina en el juego de ajedrez, para definir los vecinos de un punto cartográfico en particular. En este documento se considera la unidad espacial vecina como toda aquella que comparte límites geográficos con la unidad espacial objeto de estudio. Se recurre a este tipo de vecindad dado que las características de los municipios y en particular de Bogotá, no corresponden a una vecindad estrictamente definida. Es necesario, entonces, considerar todo el conjunto de posibilidades y el método Queen lo permite. La gráfica 6.1 describe la conformación de la matriz de vecinos tipo Queen de un sector censal particular (cuadro gris). Los vecinos que serán considerados para la construcción del modelo econométrico espacial son los cuadros de color azul.

El primer objetivo, el análisis de correlación espacial, es desarrollado mediante el cálculo del Índice de Moran Global (I) cuya forma general es la siguiente:

$$
I M G=\frac{n}{S_{0}} \frac{\sum_{i=1}^{n} \sum_{j=1}^{n} w_{i, j} z_{i} z_{j}}{\sum_{i=1}^{n} z_{i}^{2}}
$$

Donde, $z_{i}=x_{i}-\underline{X}, w_{i, j}$ es la ponderación espacial entre la unidad $i$ y la unidad $j, n$ es el número total de unidades espaciales en el análisis y $\mathrm{S}_{0}=\sum_{i=1}^{n} \sum_{j=1}^{n} w_{i, j}$ 
Este índice permite establecer, con el apoyo de una prueba de hipótesis, si existe correlación espacial para la variable $(x)$ de análisis o si por el contrario se observa un patrón aleatorio en la distribución espacial de los valores. Así mismo, es posible determinar el grado y el sentido de correlación espacial en una escala entre -1 y 1 , indicando que valores cercanos a 1 refieren a que valores altos de la variable están cerca de otros valores altos y viceversa, mientras que valores cercanos a -1 refieren a que valores altos de la variable están cerca de valores bajos.

Gráfica 6.1. Matriz de vecindades tipo Queen

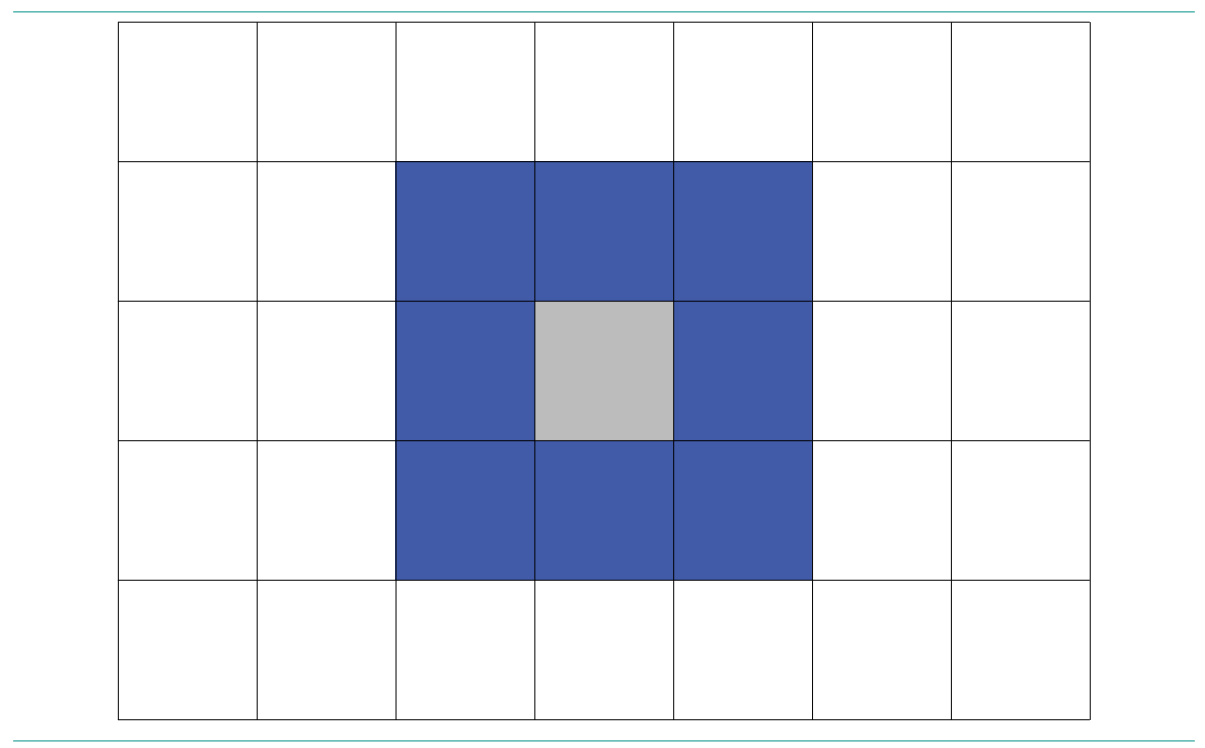

Fuente: elaboración propia.

El segundo objetivo, la medición de los efectos de los componentes del ingreso disponible de forma espacial, requiere la aplicación de un modelo econométrico. Para determinar el tipo de modelo a estimar que permita capturar el efecto espacial y realizar pruebas estadísticas para identificar si el modelo propuesto controla por endogeneidad espacial en la variable dependiente o en los residuos del modelo. Para ello, se hace uso de la prueba del Multiplicador de Lagrange, allí se compara el modelo SAR (por sus siglas en inglés de Spatial Auto Regressive) y el modelo SEM (por sus siglas en inglés de Spatial Error Models). 
El modelo SAR es:

$$
y=\rho W y+X \beta+\varepsilon
$$

Mientras el modelo SEM es:

$$
y=X \beta+\varepsilon \quad \varepsilon=\lambda W \varepsilon+u
$$

Es decir, el primero considera endogeneidad de la variable dependiente, el ingreso disponible, mientras que el segundo considera auto-correlación espacial de los residuos; para la estimación de este tipo de modelos se hace uso del método de máxima verosimilitud para obtener parámetros insesgados. Paralelo al modelo de econometría espacial se realiza la estimación del modelo simplificado a través de MCO, de la forma:

Ingreso Disponible $=\beta_{0}+\beta_{1}$ IngresoCorriente $+\beta_{2}$ Subsidios $+\beta_{3}$ Impuestos $+\varepsilon$

Esto con el fin de realizar comparaciones entre los modelos obtenidos con y sin auto-correlación espacial. Previo al cálculo del índice y la estimación de los modelos, se realiza un análisis exploratorio de valores atípicos para el ingreso disponible. Estos datos se excluyen del modelo econométrico mediante el criterio de Tukey (Dovoedo, 2011).

\section{Auto-correlación espacial en el ingreso disponible}

Antes de realizar el cálculo de la correlación espacial se realiza un análisis espacial exploratorio de la distribución de las variables en los dos niveles de análisis presupuestados. Con este fin se muestra en los Mapas 1 y 2 la distribución del ingreso disponible, ingreso corriente, subsidios e impuestos a nivel de los sectores censales en la ciudad de Bogotá y a nivel de municipios y localidades para el análisis de Bogotá-Región. 
Mapa 1. Distribución espacial del ingreso disponible y sus componentes en la ciudad de Bogotá

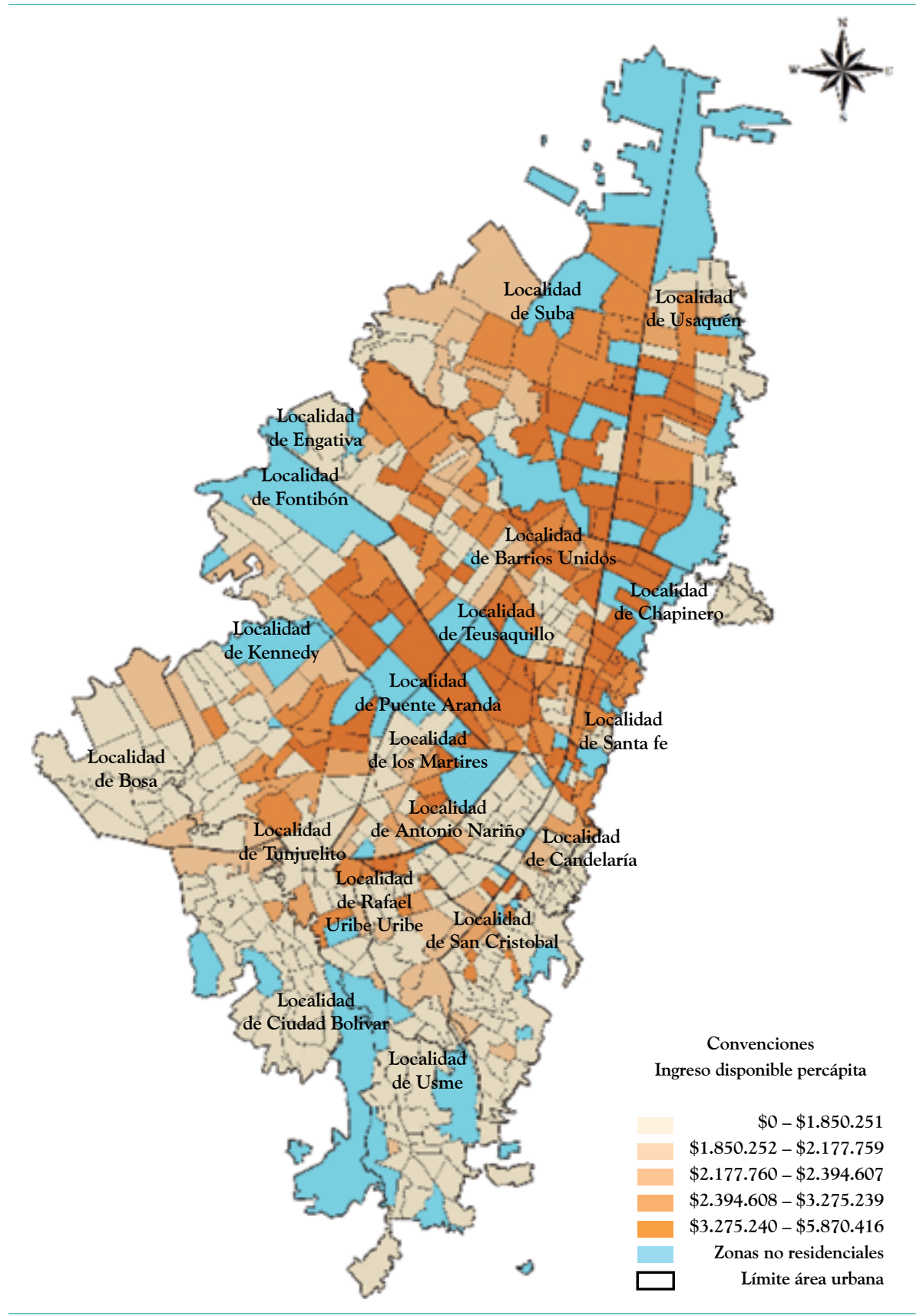

Distribución ingreso total en Bogotá D. C., Colombia.

Fuente: EM2014, elaboración propia. 


\section{Componente 1. Ingreso corriente}

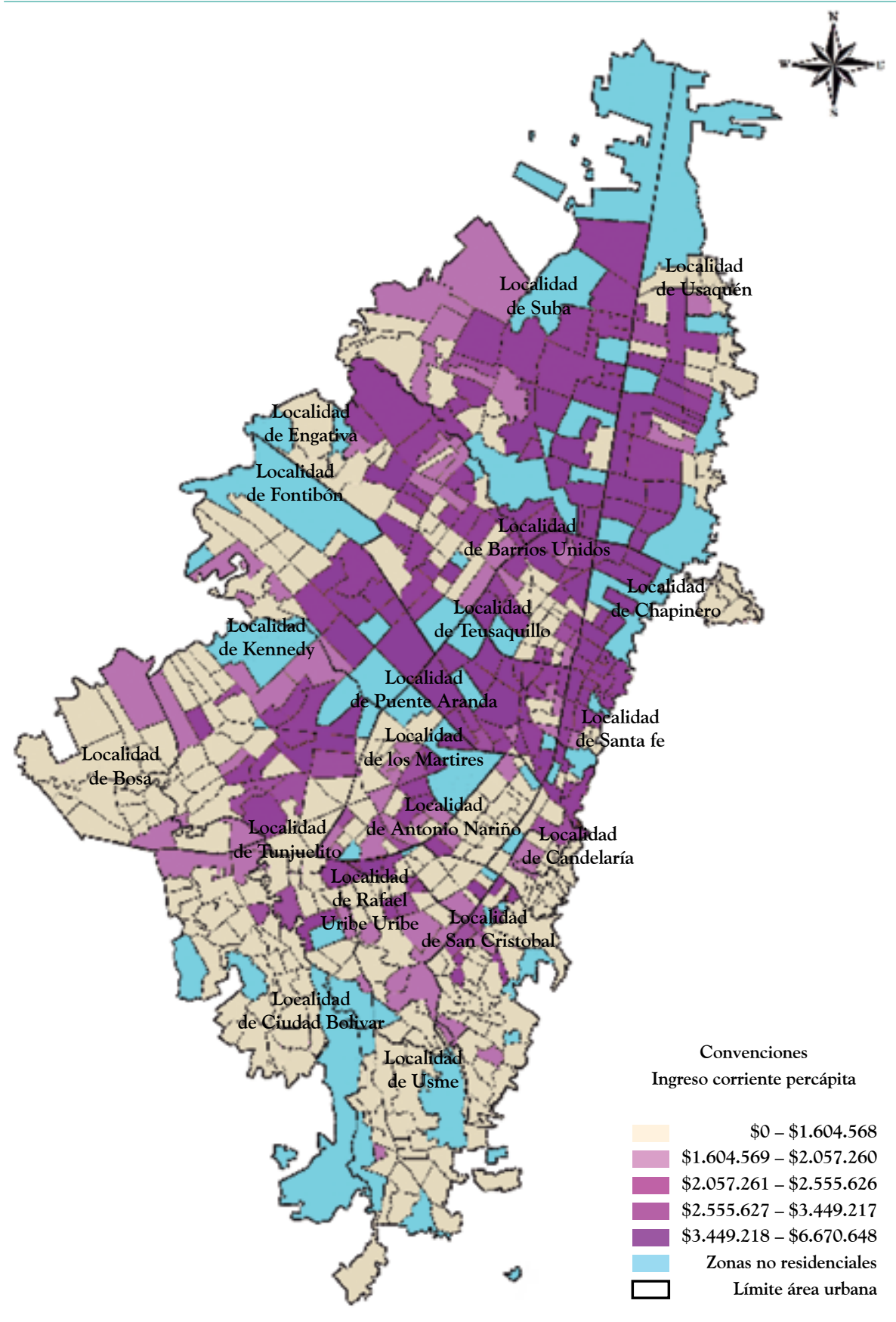

Fuente: EM2014, elaboración propia. 


\section{Componente 2. Subsidios}

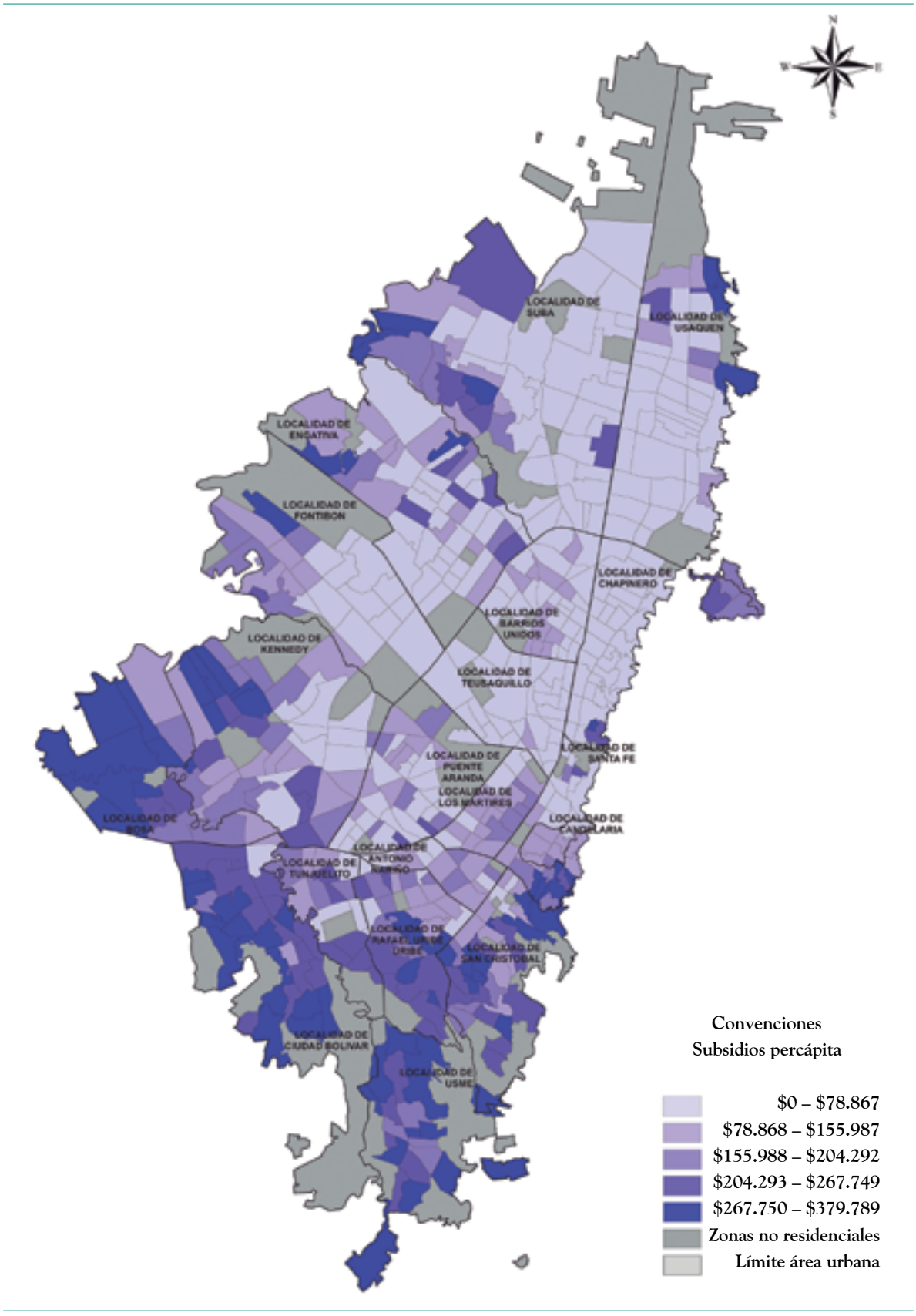

Fuente: EM2014, elaboración propia. 


\section{Componente 3. Impuestos}

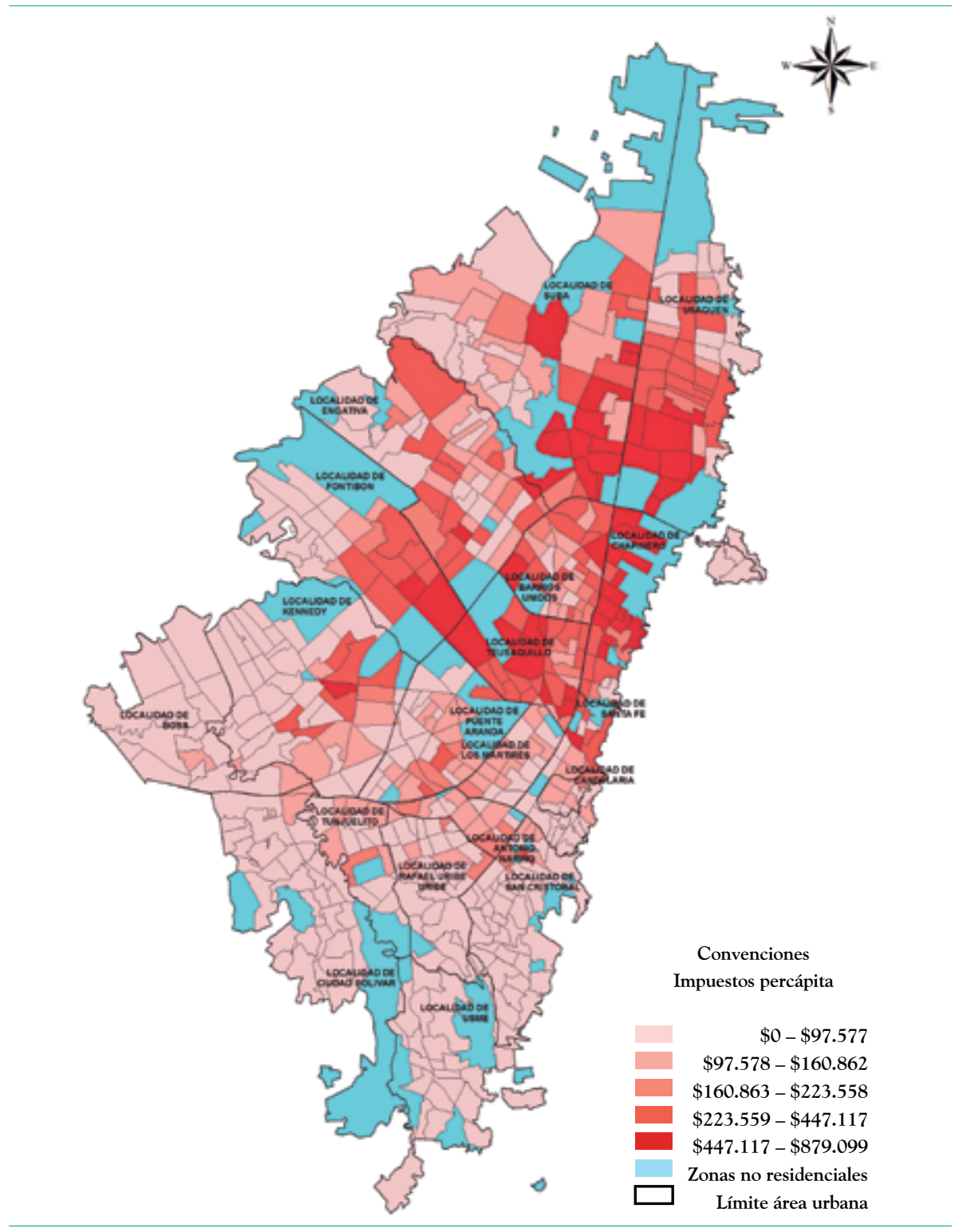

Fuente: EM2014, elaboración propia.

Se observan niveles bajos de ingreso al sur de la ciudad y las zonas periféricas, mientras que en el norte se presentan los ingresos más altos. Los subsidios, como segundo componente del ingreso disponible, alcanzan unos $\$ 380$ mil promedio por sector en las zonas donde el ingreso no tiene 
los mayores niveles, mostrando concentración espacialmente de los subsidios en las zona sur y periférica de la ciudad. Caso contrario sucede con los impuestos concentrados en los sectores cartográficos con mayor nivel de ingreso. Estos recursos gráficos dan cuenta de cómo el ingreso disponible, a través de subsidios, busca mitigar las diferencias entre los ingresos y los impuestos de los hogares.

Mapa 2. Distribución espacial del ingreso disponible y sus componentes para Bogotá-Región Distribución ingreso disponible en Bogotá y Cundinamarca

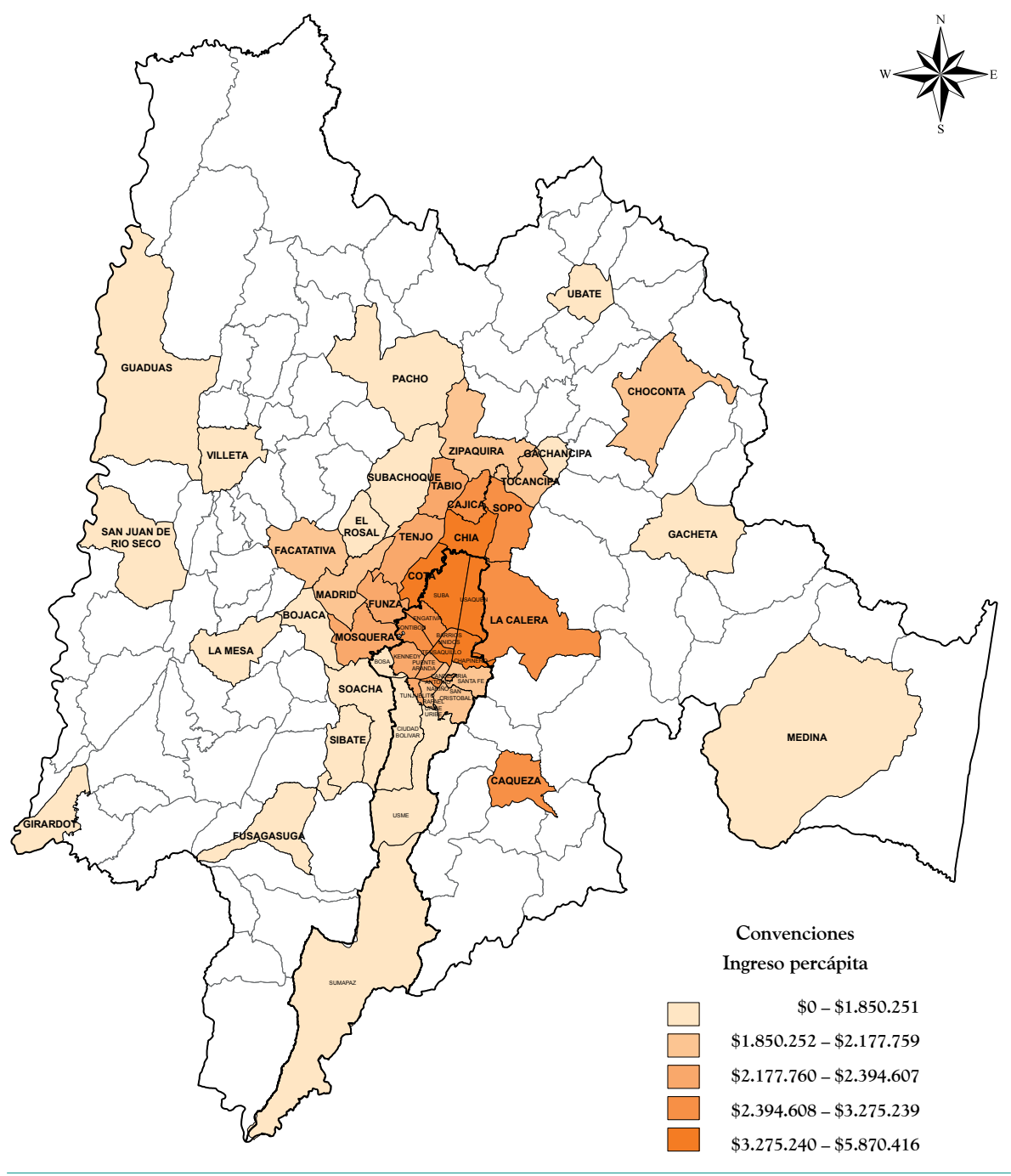

Fuente: EM2014, elaboración propia. 


\section{Componente 1. Ingreso corriente}

Distribución ingreso total en Bogotá y Cundinamarca

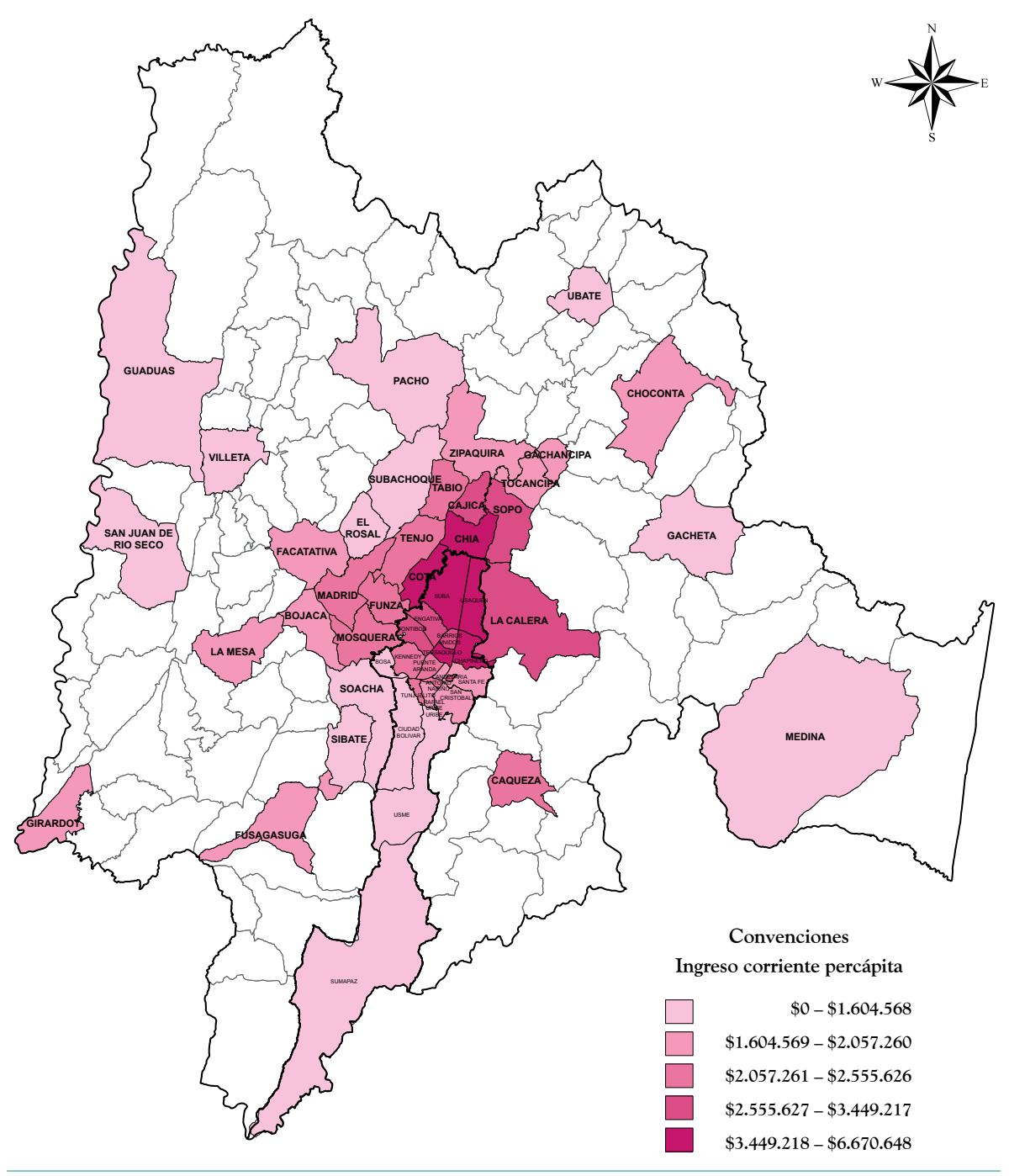

Fuente: EM2014, elaboración propia. 


\section{Componente 2. Subsidios}

Distribución subsidios total en Bogotá y Cundinamarca

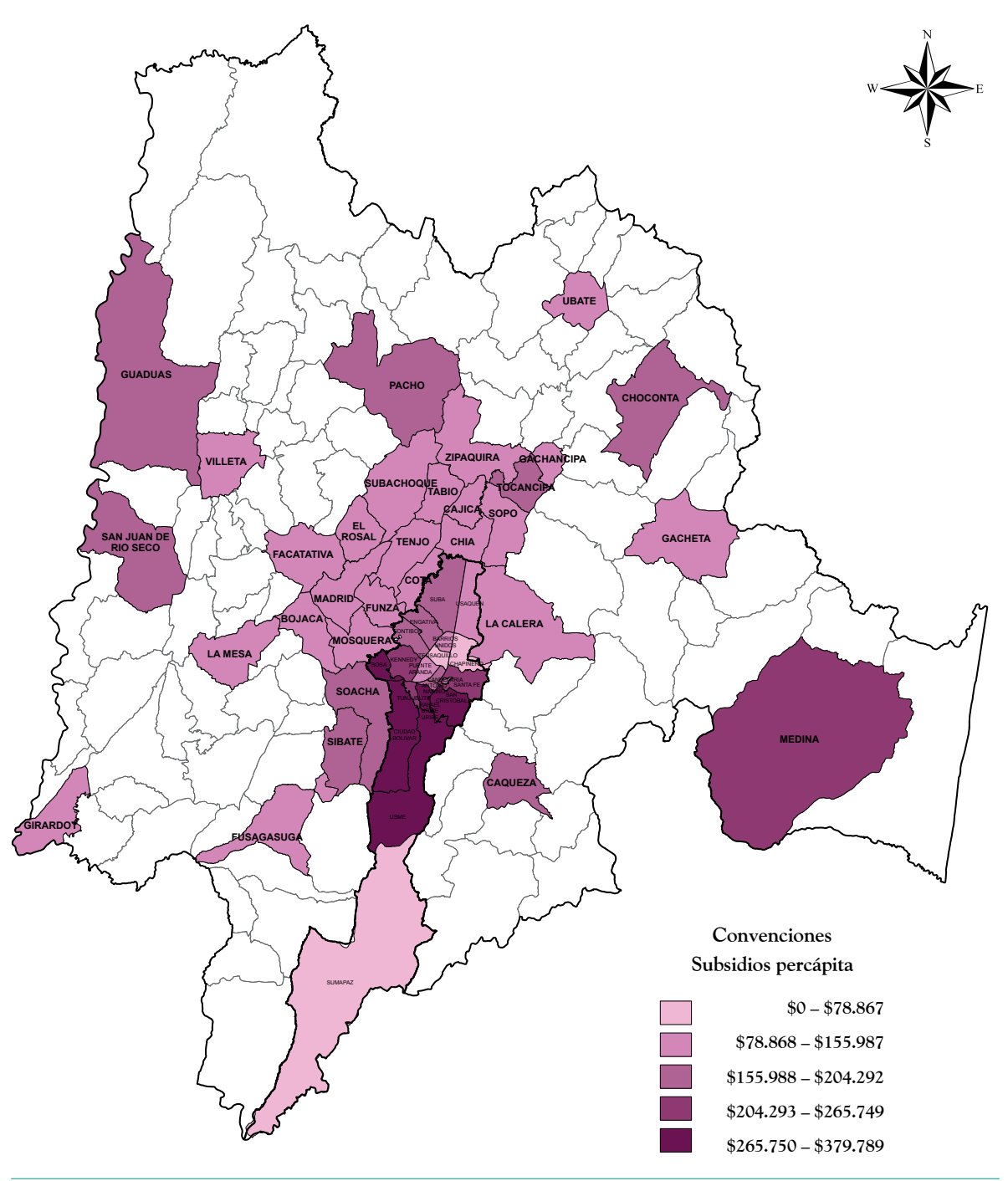

Fuente: EM2014, elaboración propia. 
Componente 3. Impuestos

Distribución impuestos total en Bogotá y Cundinamarca

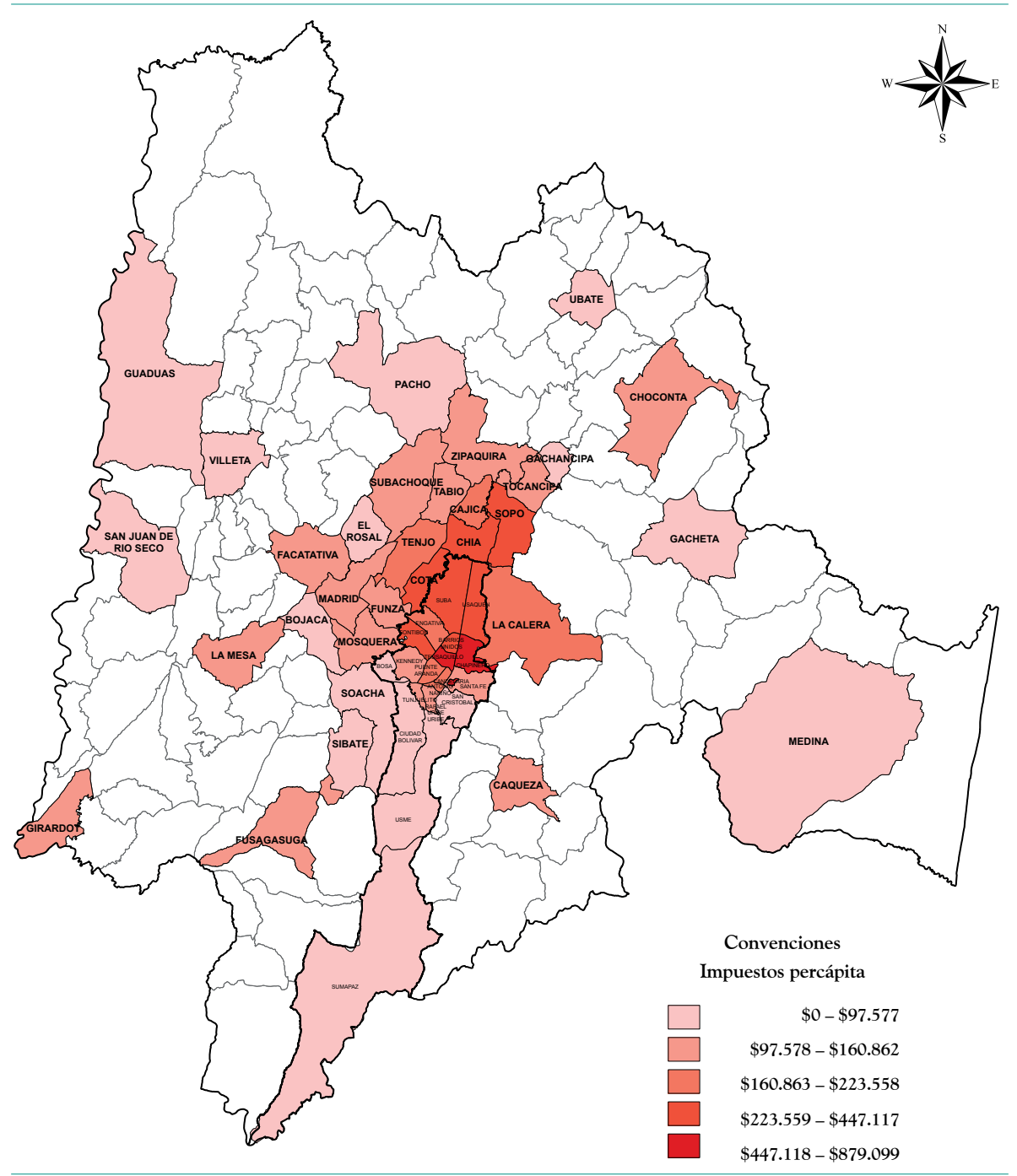

Nota: dada la dispersión geográfica de los municipios, la unidad espacial en el gráfico hace referencia a los límites del municipio total y a las localidades de Bogotá, sin embargo es importante recordar que la EM2014 sólo se aplicó en la zona urbana de los municipios.

Fuente: EM2014, elaboración propia.

Al realizar el mismo análisis con todos los municipios de la EM2014, los mayores ingresos se concentran en las localidades al centro y nororiente de Bogotá y en los municipios del nororiente de la capital; los ingresos medios se encuentran principalmente asociados a los municipios al occidente de 
Bogotá y los municipios más alejados de la capital presentan los niveles más bajos del ingreso total. Frente a los subsidios, los municipios de la zona sur de Bogotá son los que más subsidios reciben, sin embargo llama la atención que los municipios del nororiente de Bogotá y la zona occidental tienen niveles de subsidio similar aun cuando por ingreso se evidencian diferencias en nivel. En términos generales, los municipios más alejados de la capital son los que mayor nivel de subsidio reciben. Finalmente, respecto a los impuestos, los municipios de la zona nororiental de Bogotá son los que muestran mayores niveles de aportes solidarios; los municipios más alejados de la capital tienen niveles bajos de impuestos, mientras que la zona occidental tiene leves diferencias en el nivel de impuestos siendo Cota y Chía los municipios que más impuestos pagan respecto a sus vecinos del occidente.

Una revisión general de los mapas generados da cuenta de una evidente correlación espacial en el caso del análisis Bogotá - Región, donde los municipios cercanos a la ciudad tienden a presentar valores cercanos a los observados en Bogotá, particularmente el sector nororiental. Para el análisis particular de Bogotá, si bien se observan sectores de concentración de cada una de las variables, estas concentraciones se encuentran dispersas en la ciudad, lo que lleva a inferir que las correlaciones espaciales pueden ser más locales que globales. Con esto en mente, se realiza la estimación del Índice de Moran para cada nivel de análisis. Los resultados de estos cálculos se observan en la tabla 6.1.

Tabla 6.1. Índice de Moran del ingreso disponible y sus componentes

\begin{tabular}{lcccc}
\hline Nivel de análisis & Ingreso disponible & Ingreso corriente & Subsidios & Impuestos \\
\hline Bogotá - Región & $0,202 * * *$ & $0,233 * * *$ & $0,239 * * *$ & $0,187 * * *$ \\
\hline Sólo Bogotá D. C. & $0,117 * * *$ & $0,182 * * *$ & $0,245 * * *$ & $0,211 * * *$ \\
\hline \multicolumn{4}{c}{ Significancia al ***1\%, **5\%, $* 10 \%}$. \\
Fuente: EM2014, cálculos de los autores.
\end{tabular}

De la tabla 6.1 se concluye que en todas las variables y realizando la prueba de hipótesis para todos los municipios o sólo Bogotá D. C., se evidencia presencia de auto-correlación espacial de las variables. La mayor auto-correlación se presenta en los subsidios que reciben los bogotanos y el menor nivel se presenta para el ingreso disponible en la ciudad. 


\section{Modelo econométrico de correlación espacial}

Por medio del modelo de econometría espacial se busca establecer si los efectos de los componentes del ingreso disponible tienen un componente espacial estadísticamente significativo. Para determinar esto, se realiza primero la estimación simple del modelo de mínimos cuadrados (sin el componente espacial), en el cual se espera que los parámetros asociados a los componentes sean significativos y además que para el ingreso corriente y los subsidios sean positivos, mientras que para los impuestos (que incluyen aportes solidarios en servicios públicos domiciliarios SDP) sea negativo. La tabla 6.2 presenta los resultados de la estimación del modelo econométrico simple por el MCO.

Tabla 6.2. Estimación del modelo econométrico simple para ingreso disponible por $\mathrm{MCO}$

\begin{tabular}{lcl}
\hline \multicolumn{1}{c}{ Variable } & Bogotá-Región & Sólo Bogotá \\
\hline Intercepto & $139.979 * * *$ & $208.537 * * *$ \\
\hline Ingreso corriente & $0,96525 * * *$ & $0,9478 * * *$ \\
\hline Subsidios & $0,88508 * * *$ & $0,7579 * * *$ \\
\hline Impuestos & $-0,97521 * * *$ & $-0,9871 * * *$ \\
\hline & Significancia al $* * * 1 \%, * 5 \%, * 10 \%$. \\
& Fuente: EM2014, cálculos de los autores.
\end{tabular}

De la tabla anterior se aprecia que los sectores cartográficos que fueron objeto de estudio en la EM2014 en promedio tienen un ingreso disponible inicial, persona mes, alrededor de los $\$ 140$ mil. Puesto que la línea de pobreza a nivel nacional para ese periodo es de $\$ 211.807^{1}$ el faltante sería de unos $\$ 70$ mil. Cuando se estima el modelo con tan sólo los sectores de Bogotá se aprecia que el ingreso disponible inicial para los hogares es similar a la línea de pobreza nacional. En el examen del impacto de los subsidios, al considerar solamente a Bogotá la incidencia es menor que cuando se incluye a los municipios restantes. En el caso de los impuestos sucede al contrario.

1 Boletín Técnico DANE consultado de: https://www.dane.gov.co/files/investigaciones/condiciones_vida/pobreza/bol_pobreza_15_pdf 
El impacto es mayor cuando solamente se considera Bogotá. Es decir, en la región el efecto progresivo de los subsidios es mayor y la incidencia negativa de los impuestos es menor en comparación con la capital.

Estimado el modelo simple y en concordancia con la metodología planteada, se realiza la prueba del Multiplicador de Lagrange para determinar el tipo de modelo espacial a estimar para cada nivel de análisis.

Tabla 6.3. Pruebas de multiplicador de lenguaje para comparar tipos de modelos de correlación espacial

\begin{tabular}{rcc}
\hline Nivel de análisis & SAR & SEM \\
\hline Todos los municipios & 1,2 & $4,31^{* *}$ \\
\hline Sólo Bogotá D. C. & $4,43^{* *}$ & 0,00716 \\
\hline
\end{tabular}

Significancia al ***1\%, **5\%, *10\%.

Fuente: EM2014, cálculos de los autores.

Los resultados muestran la presencia de auto-correlación espacial en los residuos del modelo econométrico estimado inicialmente, por tanto, para el total de municipios al nivel de sectores cartográficos se debe realizar la estimación de un modelo SEM. Caso contrario sucede en el caso de la ciudad de Bogotá D. C., donde existe auto-correlación espacial en la variable dependiente, es decir, el modelo estimado para Bogotá D. C. tiene problemas de endogeneidad y se requiere de una especificación tipo SAR.

Tabla 6.4. Comparación de los modelos de MCO y SEM para el caso del nivel Bogotá-Región

\begin{tabular}{lll}
\multicolumn{1}{c}{ Variable } & \multicolumn{1}{c}{ MCO } & SEM \\
\hline Intercepto & $139.979 * * *$ & $144.386 * * *$ \\
\hline Ingreso corriente & $0,96525 * * *$ & $0,9640682 * * *$ \\
\hline Subsidios & $0,88508 * * *$ & $0,8693819 * * *$ \\
\hline Impuestos & $-0,97521 * * *$ & $-0,9771742 * * *$ \\
\hline
\end{tabular}

Significancia al ***1\%,**5\%, *10\%.

Fuente: EM2014, cálculos de los autores.

La tabla 6.4 resume los dos modelos estimados para el nivel de análisis Bogotá-Región; la estimación del modelo de econometría espacial con 
auto-correlación espacial en los residuos SEM, cambia ligeramente los parámetros encontrados en el modelo sin correlación espacial, el modelo por MCO; para el caso del intercepto aumentó en $\$ 5.000$, que al compararlo con la línea de pobreza está unos $\$ 65.000$ por debajo de la línea de pobreza nacional. Para los hogares de los municipios de la EM2014 significa que su ingreso disponible inicial es inferior a la línea de pobreza en el valor mencionado. El ingreso disponible de los hogares de la región aumenta un $96 \%$ del ingreso corriente, un $86 \%$ del subsidio y se ve disminuido en un $97 \%$ de los impuestos que asume el hogar.

Tabla 6.5. Comparación de los modelos por MCO y SAR solo Bogotá

\begin{tabular}{lcc}
\multicolumn{1}{c}{ Variable } & MCO & SAR \\
\hline Intercepto & 208.537 & 271.048 \\
\hline Ingreso corriente & 0,9478 & 0,9487926 \\
\hline Subsidios & 0,7579 & 0,7319857 \\
\hline Impuestos & $-0,9871$ & -0.9812462
\end{tabular}

Nota: todos los resultados de la tabla son significativos al $1 \%$.

Fuente: EM2014, cálculos de los autores.

Para el caso del modelo sólo para la ciudad de Bogotá D. C. se observa un aumento en el valor del ingreso disponible inicial para los hogares capitalinos. Si se compara con la estimación por MCO el valor aumenta en $\$ 63.000$. Esta cifra es superior a la línea de pobreza nacional. Igualmente, se concluye que a partir del ingreso disponible inicial se aumenta en un $95 \%$ del ingreso corriente de los hogares capitalinos, un $73 \%$ por efecto de los subsidios que destina el Distrito y la Nación a la ciudad de Bogotá, y el impacto en reducción por efecto de cargas impositivas es del $98 \%$ (ver última columna, modelo SAR en Tabla 6.5).

El ingreso disponible de los hogares tal y como se describió en capítulo 3, tiene el efecto esperado por subsidios y contribuciones, es decir, un aumento del mismo por el primero y una reducción por el segundo. Aunque los resultados son consistentes para la estimación de un modelo de regresión por MCO frente a un modelo de regresión que considera auto-correlación espacial, la posibilidad de identificar espacialmente los hogares entrevistados 
presenta estimaciones más robustas para el modelo de correlaciones especiales, de allí la importancia de poder contar con esta información. Cuando se estudió dicho modelo de correlación espacial sólo para el caso de Bogotá D. C., resultó haber endogeneidad espacial del ingreso disponible mientras que para el caso de todos los municipios esta endogeneidad se da en los residuos, es decir, no son espacialmente aleatorios. 



\section{Bibliografía}

Araar, A. (2006). On the decomposition of the Gini coefficient: An exact approach, with an Illustration Using Cameroonian Data. Cahiers de Recherche, 0602, CIRPEE.

Bucheli, M.; Lustig, N.; Rossi M. y Amábile F. (2014). Social spending, taxes, and income redistribution in Uruguay. Public Finance Review, $42(3), 413-433$.

Camelo, H. (2001). Ingresos y gastos de consumo de los hogares en el marco del SCN y en encuestas a hogares. En línea http://repositorio.cepal.org/ bitstream/handle/11362/4718/1/S01010054_es.pdf

Combes, P., Duranton, G. y Overman, H. (2005). Agglomeration and the adjustment of the spatial economys. Papers in regional science: The journal of the Regional Science Association International, 84(3), 311-349.

DANE, Departamento Nacional de Estadísticas. (2017). Pobreza monetaria y multidimensional en Colombia 2016. Bogotá: DANE. En línea: https://www.dane.gov.co/index.php/estadisticas-por-te$\mathrm{ma} /$ pobreza-y-condiciones-de-vida/pobreza-y-desigualdad/ pobreza-monetaria-y-multidimensional-en-colombia-2016

Dovoedo, Y. H. (2011). Contributions to Outlier Detection Methods: Some Theory and Applications.

Duranton, G. (2016). Determinants of city growth in Colombia. Papers in regional science: the journal of the Regional Science Association International, 95(1), 101-131.

Duranton, G. (2008). Viewpoint: From cities to productivity and growth in developing countries: From cities to productivity and growth. Canadian Journal of Economics / Revue canadienne d'économique, 41 (3), 689-736. 
Econometría (2008). Evaluación de la estratificación socioeconómica como instrumento de clasificación de los usuarios y herramienta de asignación de subsidios y contribuciones a los servicios públicos domiciliarios. Informe al DNP. Bogotá.

Gallego Acevedo, J. M., Gutiérrez Ramírez, L. H., Ramírez Gómez, M. y Sepúlveda Rico, C. E. (2015). Subsidios y contribuciones, balance financiero de los hogares bogotanos. Bogotá: Editorial Universidad del Rosario.

Glaeser, E. y Gottlieb, J. (2009). The Wealth of Cities: Agglomeration Economies and Spatial Equilibrium in the United States. Cambridge: National Bureau of Economic Research. En línea http://www.nber.org/papers/ w14806.pdf

Higgins, S. y Pereira, C. (2014). The effects of Brazil's taxation and social spending on the distribution of household income. Public Finance Review, 42(3), 346-367.

Jaramillo, M. (2014). The incidence of social spending and taxes in Peru. Public Finance Review, 42 (3), 391-412.

Joumard y Londoño (2013). Income inequality and poverty in Colombia part 1 . The role of the labor market. OCDE, ECO/WKP 28.

Lambert, P. (1993). The distribution and redistribution of income: A mathematical analysis. Manchester: University Press.

Lustig, N. y Pessino, C. (2014) Social spending and income redistribution in Argentina during the 2000s. The increasing role of noncontributory pensions. Public Finance Review, 42 (3), 304-325.

Lustig, N.; Pessino, C. y Scott, J. (2014). The impact of taxes and social spending on inequality and poverty in Argentina, Bolivia, Brazil, Mexico, Peru, and Uruguay. Public Finance Review, 42 (3), 287-303.

Marshall, D. y Selowsky, M. (1980). Who benefits from government expenditures? A case study of Colombia. Political Science Quarterly, 95(3), 541.

Meléndez, M. (2008). Subsidios al consumo de los servicios públicos: reflexiones a partir del caso Colombiano. CAF Working Paper, 2008-2.

Moran, P. A. (1950). Notes on Continuous Stochastic Phenomena. Biometrika, 37(1-2), 17-23

Núñez, J. (2009). Incidencia del gasto público social en la distribución del ingreso, la pobreza y la indigencia. Archivos de Economía. Bogotá: Departamento Nacional de Planeación. 
Parra, M. (2011). Infraestructura y pobreza: el caso de los servicios públicos en Colombia, Working Paper 56. Bogotá: Fedesarrollo.

Pérez, Á., Castillo, M., González, J. y Rodríguez, M. (2015). Análisis de la distribución de competencias por niveles de gobierno definidas en la Ley 715 de 2001 para el Sector Educativo, y Propuesta de Ajuste y Revisión de la Canasta Educativa por Niño Atendido con el Fin de Aportar Insumos para la Propuesta Integral de Ajuste de la Ley 715 de 2001, Ministerio de Educación, Economía Urbana, Bogotá, mimeo

Pyatt, G. (1976). The interpretation and disaggregation of Gini coefficients. Economic Journal, 86, 243-255.

Ravallion, M. (1998). Does aggregation hide the harmful effects of inequality on growth? Economics letters, 61(1), 73-77.

Rodríguez, C.; Gallego, J.; Gómez, D.; Montoya, T. y Peralta, T. (2016). Examining the Implementation and Labor Outcomes of Targeted Transit Subsidies: SISBEN Subsidy in Bogota, Colombia. Transportation Research Record Journal of the Transportation Research Board, 2581, 9-17. Sánchez F. y Núñez, J. (2000). La geografía y el desarrollo económico en Colombia: una aproximación municipal. Desarrollo y sociedad, 46, 43-108. Sepúlveda Rico, C. E., López Camacho, D. y Gallego Acevedo, J. M. (2014). Los límites de la estratificación: en busca de alternativas. Bogotá: Editorial Universidad del Rosario.

Scott, J. (2014). Redistributive Impact and Efficiency of Mexico's Fiscal System. Public Finance Review, 42 (3), 368-390.

Vélez, C. E. (1996). Gasto social y desigualdad: logros y extravíos: estudio de la incidencia del gasto público social en Colombia. Bogotá: DNP. 



\section{Anexos}

\section{Anexo 1. Capítulos de la EM2014}

\section{Capítulo \\ Descripción}

A. Identificación Se identifica la vivienda, y se dispone del estrato socioeconómico de la vivienda por localidad.

B. Datos de la vivienda y su entorno

Se observa la calidad habitacional, el entorno, el tipo de vivienda, entre otras.

C. Condiciones habitacionales del hogar

Ocupación jurídica de la vivienda, fuentes de financiación, subsidios otorgados, cuotas de amortización, celaduría, entre otras.

D. Servicios Públicos Domiciliarios y de TIC

Se pregunta sobre la tenencia de servicios públicos, para observar la calidad; también hay información acerca del uso de las TIC, el gasto en telefonía, internet y televisión por cable, entre otras temáticas.

E. Composición del hogar y Se identifican las personas que conforman el hogar y el núcleo familiar, al igual demografía que el jefe del hogar.

Se identifican las condiciones de afiliación al sistema de salud de los miembros del hogar, como régimen de afiliación, cobertura de servicios

F. Salud complementarios, el gasto en salud, el pago por la afiliación básica a salud, planes complementarios, gastos en hospitalizaciones, cirugías, medicamentos. De igual manera, la incidencia de enfermedades, entre otros.

G. Atención integral de los niños y niñas menores de 5 años

Este capítulo solo va dirigido a los niños y niñas menores de cinco años que están en el hogar y a identificar la persona o institución que cuida de ellos.

En este se identifica la población en edad escolar que asiste a establecimientos educativos; se determinan los gastos en educación (matrículas, pensiones,

H. Educación uniformes, útiles escolares, entre otros) para los diferentes niveles educativos. Se cuantifica los subsidios y créditos educativos y se indagan por diferentes temáticas, como el alfabetismo, el sitio de permanencia de los niños por fuera de la jornada escolar, las actividades que desarrollan en el tiempo libre.

Continúa 


\section{Capítulo}

Descripción

I. Uso de tecnologías de la información TIC

Está dirigido a los miembros del hogar mayores a diez años, con el fin de analizar el acceso y uso de tecnologías de información y comunicaciones.

En este capítulo, se recoge información estadística que permita una aproximación a la medición del capital social de los habitantes de Bogotá y a

J. Participación en conocer el grado de asociación de los individuos a través de la participación organizaciones y redes sociales en grupos primarios, el funcionamiento de las redes sociales y familiares en la solución de problemas de los hogares, el nivel de identificación que tienen los jóvenes con respecto a grupos culturales y urbanos, conocidos como grupos suburbanos.

Se caracteriza la actividad económica de la población, se identifican las personas ocupadas (asalariados e independientes), los trabajadores sin

K. Fuerza de trabajo remuneración, los desocupados e inactivos, y, además, se indaga por todas las fuentes de ingreso de las personas encuestadas (salarios, ganancia, arriendos, pensiones, entre otras).

Este capítulo busca conocer la percepción del hogar sobre el estado y la

L. Percepción sobre las dinámica de sus propias condiciones de vida y capacidades (pobreza subjetiva, condiciones de vida y el suficiencia de ingresos para cubrir gastos, etc.), así como afectaciones desempeño institucional por aspectos de victimización. Igualmente, indaga sobre las condiciones alimenticias y de equipamientos urbanos.

M.

M-1: Gastos en alimentos y bebidas no alcohólicas de los hogares y otros gastos

Se identifica el gasto de los hogares según diferentes bienes y servicios y pago del hogar de impuestos.

M-2: Otros gastos del hogar

Fuente: EM2014, elaboración de los autores. 


\section{Anexo 2. Lista de siglas y acrónimos}

\begin{tabular}{|c|c|}
\hline AAA & Acueducto, Alcantarillado y Aseo \\
\hline CEPAL & Comisión Económica para América Latina y el Caribe \\
\hline DANE & Departamento Nacional de Estadísticas \\
\hline DNP & Departamento Nacional de Planeación \\
\hline DPS & Departamento para la Prosperidad Social \\
\hline EM2014 & Encuesta Multipropósito 2014 \\
\hline Fonvivienda & Fondo Nacional de Vivienda \\
\hline GPS & Gasto Público Social \\
\hline $\mathrm{ICBF}$ & Instituto Colombiano de Bienestar Familiar \\
\hline Icetex & $\begin{array}{l}\text { Instituto Colombiano de Crédito Educativo y Estudios Técnicos } \\
\text { en el Exterior }\end{array}$ \\
\hline IPC & Índice de Precios al Consumidor \\
\hline IVA & Impuesto al Valor Agregado \\
\hline MERPD & $\begin{array}{l}\text { Misión para el Diseño de una Estrategia para la Reducción de } \\
\text { la Pobreza y la Desigualdad }\end{array}$ \\
\hline PIB & Producto Interno Bruto \\
\hline PIC & Plan Intervenciones Colectivas \\
\hline POS & Plan Obligatorio de Salud \\
\hline SDP & Secretaría Distrital de Planeación \\
\hline SED & Secretaría de Educación del Distrito \\
\hline SENA & Servicio Nacional de Aprendizaje \\
\hline SGSSS & Sistema General de Seguridad Social en Salud \\
\hline SHD & Secretaría de Hacienda Distrital \\
\hline SISBEN & Sistema de Selección de Beneficiarios Para Programas Sociales \\
\hline SITP & Sistema Integrado de Transporte Público \\
\hline SMMLV & Salario Mínimo Mensual Legal Vigente \\
\hline SPD & Servicios Públicos Domiciliarios \\
\hline SSPD & Superintendencia de Servicios Públicos Domiciliarios \\
\hline UPC & Unidad de Pago por Capitación \\
\hline
\end{tabular}


Este libro fue compuesto en caracteres GoudyOlSt BT 11,5 puntos, impreso sobre propal de 70 gramos y encuadernado con método Hot Melt, en septiembre de 2017, Bogotá, D. C., Colombia

Panamericana Formas e Impresos S. A. 
Este libro presenta nueva evidencia del efecto redistributivo de la política fiscal que afecta el balance financiero de los hogares en Bogotá, municipios de la Sabana y el departamento de Cundinamarca. Se presenta una cuidadosa identificación de aquellos subsidios, contribuciones e impuestos que reciben o pagan los miembros de un hogar y de este modo, utilizando la metodología de análisis de incidencia, logra medir el efecto redistributivo en términos de ingreso tanto en Bogotá como en los municipios que conforman la región de influencia de la capital del país.

En esta obra los autores van más allá de calcular el efecto redistributivo y enfocan sus resultados a reconocer la capacidad redistributiva que tienen las grandes urbes para mejorar la distribución del ingreso de sus habitantes. El texto logra explicar y mostrar que ciudades como Bogotá cuentan con diversos instrumentos que mejoran sustancialmente el bienestar de sus residentes y reducen los niveles de desigualdad. Este libro es un aporte sustancial en la generación de evidencia empírica sobre el papel que pueden jugar las ciudades para mejorar el bienestar social de sus residentes. 